
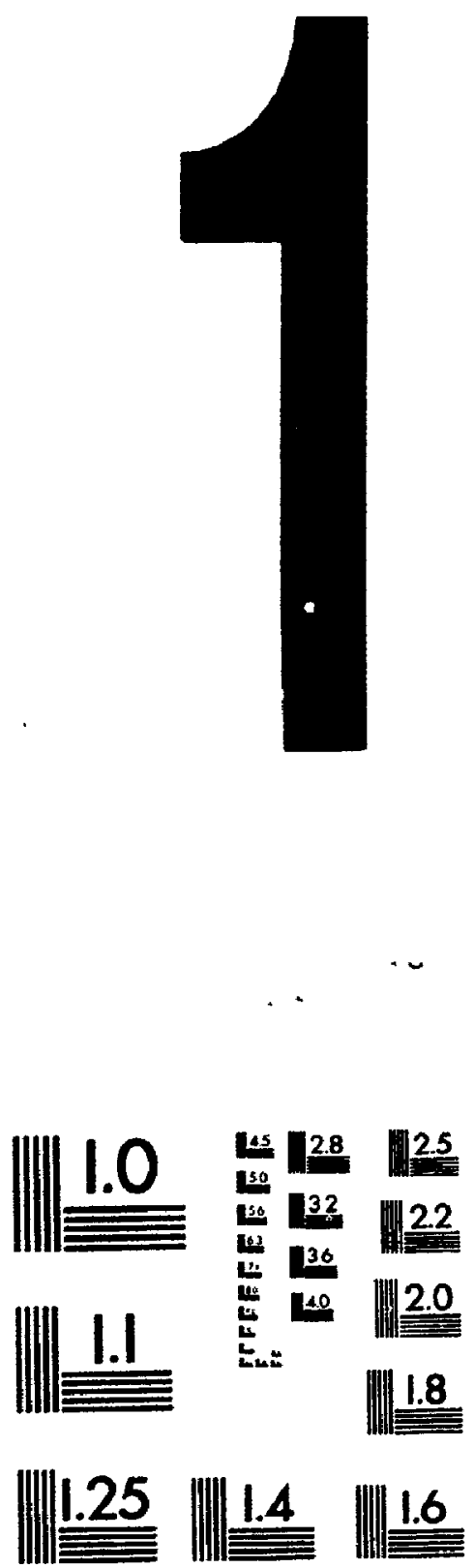

$$
\begin{aligned}
& \text { MICROCOPY RESOLUTION TEST CHART } \\
& \text { NATIONAL BUREAU OF STANDARDS } \\
& \text { STANDARD REFERENCE MATERIAL 1010a }
\end{aligned}
$$
(ANSI and ISO TEST CHART No. 2) 
Ottawa. Canada

KIA ON4

\section{Service des thèses canadiennes}

\section{NOTICE}

The quality of this microform is heavily dependent upon the quality of the original thesis submitted for microfilming. Every effort has been made to ensure the highest quality of reproduction possible.

If pages are missing, contact the university which granted the degree.

Some pages may have indistinct print especially if the original pages were typed with a poor typewriter ribbon or it the university sent us an inferior photocopy.

Reproduction in full or in part of this microform is governed by the Canadian Copyright ACt, R.S.C. 1970, C.C-30, and subsequent amendments.

\begin{abstract}
AVIS
La qualité de cette microforme dépend grandement de la qualité de ta thèse soumise au microfilmage. Nous avons tout fait pour assurer une qualité supérieure de reproduc. tion.

S'il manque des pages, veuillez communiquer avec runiversité qui a conféré le grade.

La qualité d'impression de certaines pages peut laisser à désirer, surtout si les pages originales ont été dactylogra. phiées à l'aide d'un ruban usé ou si l'université nous a tait parvenir une photocopie de qualité inférieure.

La reproduction, mème partielle. de celte microlorme est soumise à la Loi canadienne sur le droit d'auteur, SRC 1970. c. C-30, et ses amendements subséquents.
\end{abstract}




\title{
Studies on Mercury Cold-Vapor Atomic Absorption Spectrometry
}

\author{
by
}

R. Scott Daniels, B.Sc.

A Thesis submitted to

the Faculty of Graduate Studies and Research

in partial fulfillment of the requirements for the degree of

Doctor of Philosophy

Department of Chemistry

Carleton University

Ottawa, Ontario

April, 1991

(C) copyright

R. Scott Daniels. 1991 
Canadian Theses Service Service des thèses canadiennes

The author has granted an irrevocable nonexclusive licence allowing the National Library of Canada to reproduce, loan, distribute or sell copies of his/her thesis by any means and in any form or format, making this thesis available to interested persons.

The author retains ownership of the copyright in his/her thesis. Neither the thesis nor substantial extracts from it may be printed or otherwise reproduced without his/her permission.
L'auteur a accordé une licence irrévocable et non exclusive permettant à la Bibliothéque nationale du Canada de reproduire, preter. distribuer ou vendre des copies de sa thèse de quelque manière et sous quelque forme que ce soit pour mettre des exemplaires de cette thèse à la disposition des personnes intéressées.

L'auteur conserve la propriété du droit d'auteur qui protège sa thèse. Ni la thèse ni des extraits substantiels de celle-ci ne doivent être imprimés ou autrement reproduits sans son autorisation.

ISBN $0-315-68832-7$ 
The undersigned hereby recommend to the Faculty of Graduate Studies and Research acceptance of the thesis

Studies on Mercury Cold-Vapor Atomic Absorption Spectrometry

submitted by

R. Scott Daniels, B.Sc.

in partial fulfillment of the requirements for the degree of Doctor of Philosophy
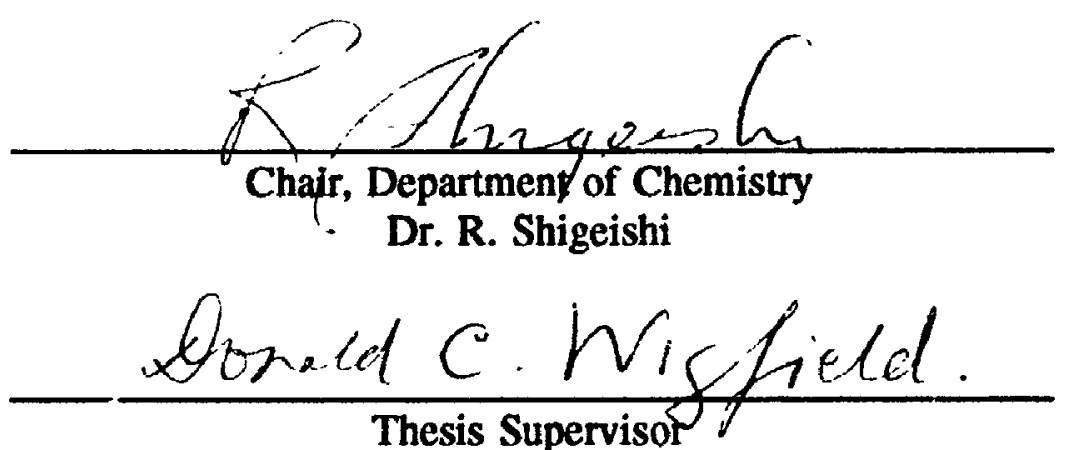

Dr. D. Wigfield

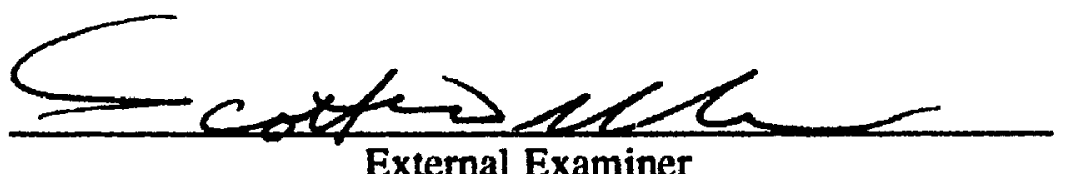

S.N. Willie

Carleton University

April, 1991 


\begin{abstract}
A study of the cold-vapor atomic absorption method, for mercury, was undertaken with special emphasis placed on the absorbance signal, its units, and related studies whose underlying common thread was optimized sensitivity.

Employing the alkaline reduction technique, a reagent volume optimization study revealed that $4.5 \mathrm{~N} \mathrm{H}_{2} \mathrm{SO}_{4}$ and $8.7 \mathrm{~N} \mathrm{NaOH}$ volumes used in the past $(5 \mathrm{~mL}$ each) were far in excess of the 0.1 to $1.0 \mathrm{~mL}$ each that were found adequate. Additionally, it was concluded that the heat of neutralization between the acid and base played no significant role in the method.
\end{abstract}

As a result of the reagent volume optimization study, a decrease in sensitivity was observed for the chemical reduction of mercury when it occurred under acidic reducing conditions. This reduced sensitivity was traced to the reagent cysteine, that complexed with the mercury until alkaline conditions prevailed releasing the mercury for its subsequent reduction to $\mathrm{Hg}^{\circ}$ by divalent tin. By exploiting this difference in sensitivity between alkaline and acidic reduction, a methodology was described for the speciation of sulphydryl-complexed and free-mercury.

The absorbance signal, reported for all types of quantitative atomic absorption spectrometry, was scrutinized for its universality with respect to atom residence times in the analysis volume, and analysis volume cross-sectional area. The normalization for these two values gives an absoroance whose units are $\mathrm{cm}^{2}$. This normalized absorbance was applied to comparing cold-vapor atomic absorption with graphite furnace atomic absorption for mercury. Additionally, this normalized absorbance method of signal 
reporting was extended to the concept of a characteristic mass. A new analytical figure of merit was proposed - the normalized characteristic mass.

Fourteen different types of tubing were evaluated for their characteristic affinities for adsurption of trace elemental mercury vapor from air. A silicone elastomer, Silastic ${ }^{\circ}$, was found to be the least desirable, producing large adsorptional losses of trace mercury vapor, while nickel tubing was found to be the best in minimizing adsorptional losses. Borosilicate glass, quarty, and teflon were found to be suitable replacements for nickel. A mathematical model was developed to investigate the question of an optimized tubing diameter for minimizing trace atom loss during mass transport through delivery tubing. For a fixed standard flow rate and tube length, the model predicted decreased atom loss with decreasing tube diameter. This relationship was confirmed experimentally. 


\section{ACKNOWLEDGEMENTS}

Someone once said, the most creative force in the universe is the helief that someone believes in you. Well, the list of believers is a long one, and I would like to thank Don (Dr. Wigfield), for being invariably able to find a ripe apple in the diven instead of pointing out the eleven rotten ones. Don gave me the freedom to follow any direction I chose in my research, and even though we often found ourselves a long way from toxicology and physical organic chemistry, his unfailing, optimistic attitude was always a sure catalyst for success.

Chak (Dr. Chakrabarti) was another believer. He did not necessarily point out the eleven rotten apples in the dozen, rather, he showed me how to cut out the worms and make apple pie.

Karl Diedrich deserves special mention for being always ready with his golf clubs to teach Peter Buist and me how to enjoy r.search careers on a Friday afternoon. Karl, the father figure, and the friend, will be missed when I leave.

Many friends have shared the lab over the past four years: Susan Eatock, Doug Goltz, Annette Fishpool, Reese Adeney, Judy Douglas and Grant Campbell - all who deserve credit for having helped by being patient listeners at one time or another when I've wanted to hear myself talk.

As a final note, that "PV=nRT stuff," as Don once put it, may have finally found a place in his lab. 


\section{LIST OF PUBLICATIONS AND PRESENTATIONS ARISING FROM THIS RESEARCH}

1. D.C. Wigfield, R.S. Daniels, The observation of unusually large blank values in the cold-vapor atomic absorption analysis for total mercury, J. Anal.Toxicol., 12: 94-97 (1988)

2. D.C. Wigfield, R.S. Daniels, The matrix effect in the cold-vapor atomic ahsorption analysis of mercury in environmental samples, J. Anal. Toxicol., 13: 191-192 (1989)

3. R.S. Daniels, D.C. Wigfield, The effect of experimental parameters on the coldvapor mercury atomic absorption determination and speciation of sulphydryl-hound mercury, J. Anal. Toxicol., 13: 214-217 (1989)

4. R.S. Daniels, D.C. Wigfield, Cold-vapor mercury atomic absorption spectrometry I. Reagent volume optimization, Science of the Total Environment, 89: 319-.323 (1989)

5. R.S. Daniels, D.C. Wigfield, Cold-vapor mercury atomic absorption spectromctry II. Acidic versus alkaline reduction, Science of the Total Environment, 89: 325329 (1989)

6. R.S. Daniels, D.C. Wigfield, Cold-vapor mercury atomic absorption spectrometry III. Signal reporting options, 89: 331-335 (1989)

7. R.S. Daniels, D.C. Wigfield, Cold-vapor atomic absorption spectrometry IV. Increased sensitivity 89: 337-339 (1989)

8. R.S. Daniels, D.C. Wigfield, Gas phase adsorption of $\mathrm{Hg}^{\circ}$ in cold-vapor mercury atomic absorption spectrometry, Analytica Chimica Acta, accepted February, 1991

9. R.S. Daniels, D.C. Wigfield, Hydrogen chloride interference in cold-vapor mercury atomic absorption spectrometry, in progress

10. R.S. Daniels, D.C. Wigfield, The kinetics of mercury reduction and tin determination, in progress

11. R.S. Daniels, D.C. Wigfield, A mathematical model for trace atom loss in delivery tubing, in progress

12. R.S. Daniels, D.C. Wigfield, Using normalized absorbances to compare cold-vapor mercury atomic absorption and graphite fumace atomic absorption, in progress 
Most of the preceding work has been presented at various conferences and workshops including:

$35^{\text {th }}$ Canadian Spectroscopy Conference (CSC, Carleton University, Ottawa, August 7-9. 1988)

$3^{\text {rd }}$ Annual Workshop on Metals in Biological Systems (National Wildlife Research Centre, Hull, Quebec, June 23, 1989)

$73^{\text {rd }}$ Chemical Institute of Canada conference (CIC, Halifax, Nova Scotia, July 15-21, 199())

$36^{\text {th }}$ Canadian Spectroscopy Conference (CSC, Brock University, St. Catharines, Ontario, August 1-3, 1990) 


\section{TABLE OF CONTENTS}

ABSTRACT v v

ACKNOWLEDGEMENTS vii

LIST OF PUBLICATIONS AND PRESENTATIONS ix

LIST OF TABLES XV XV

LIST OF FIGURES $\quad$ xvii

$\begin{array}{ll}\text { LIST OF APPENDICES } & \mathbf{x x}\end{array}$

CHAPTER 1 INTRODUCTION 1

CHAPTER 2 REAGENT VOLUME OPTIMIZATION 5

Introduction $\quad 5$

Experimental Section 6

Results and Discussion 7

Conclusions 11

$\begin{array}{lll}\text { CHAPTER } 3 & \text { ACIDIC VERSUS ALKALINE REDUCTION AND } 13\end{array}$ THE DETERMINATION OF SULPHYDRYL-BOUND MERCURY

Introduction 13

Experimental Section 15

Results and Discussion $\quad 15$

Conclusions 20

CHAPTER $4 \quad$ SIGNAL REPORTING OPTIONS

Introduction $\quad 21$

Experimental Section $\quad 25$

Results and Discussion 25

Conclusions $\quad 33$

CHAPTER 5 EXPERIMENTALLY VERIFIED NORMALIZED 35 ABSCRBANCE

Introduction $\quad 35$

Experimental Section $\quad 37$

Results and Discussion 38

Conclusions 45 
CHAPTER 6 A NORMALIZED CHARACTERISTIC MASS FOR ATOMIC ABSORPTION SPECTROMETRY AND ITS APPLICATION IN ABSOLUTE ANALYSIS

Introduction

Theory

Experimental Section

Results and Discussion

Conclusions

CHAPTER 7 GAS PHASE ADSORPTIONAL LOSSES OF $\mathrm{Hg}^{\circ}$ IN

COLD.VAPOR SPECTROMETRY

Introduction

Experimental Section

Results and Discussion

Conclusions

CHAPTER 8 MATHEMATICAL MODELLING OF ATOM LOSS 69 IN DELIVERY TUBING

Introduction

69

Results and Discussion

Conclusions

CHAPTER 9 HCI INTERFERENCE IN COLD-VAPOR ATOMIC 85 ABSORPTION SPECTROMETRY Introduction

Experimental Section

86

Results and Discussion

86

Conclusions

92

CHAPTER 10 INCREASED SENSITIVITY WITH A NEW 95 DETECTOR POSITION

Introduction

Experimental Section

96

Results and Discussion

96

CHAPTER 11 THE MATRIX EFFECT IN THE COLD-VAPOR 103 ATOMIC ABSORPTION DETERMINATION OF MERCURY

Introduction

Experimental Section

104

Results

105

Discussion 
REFERENCES 
xiv 


\section{LIST OF TABLES}

Table 2.1 Details of apparatus and reagents

Table 2.2 Chronology of experimental parameters and reagents 9

Table 5.1 Mercury adsorption in absorption cells for 10 $\mu \mathrm{L}$ 40 saturated mercury-vapor

Table 5.2 Variation of $\mathbf{Q}_{\mathbf{A}(\tau, \sigma)}$ with flow rate

Table 5.3 Relationship of sensitivity to cuvette cross-sectional area

Table 6.1

Types of absorbance

Table 6.2

Characteristic masses for mercury

Table 6.3

Data for experimental absorbance transients by 57 CVMAA, MVSIAA, and GPFA

Table 7.1

$\mathrm{Hg}^{\circ}$ adsurptional losses in different types of tubing

Table 8.1

Model 1: Incremental atom loss

Table 8.2

Model 2: Incremental atom loss

Table 8.3

Estimation of the latex sticking probability factor, $\rho$, by comparison of experimental and theoretical loss data

Table 10.1

Analytical response to $5.0 \mathrm{ng}$ of mercury for two different detector positions in the optical path

Table 10.2

Attenuation of low-pressure mercury lamp intensity for two optical filters

Table 11.1

Calculations for making determinations and measurements for the degree of matrix effect

Table 11.2 Typical environmental analyses results

Table 11.3 Rideau River mercury determinations and matrix 107 evaluations 
Table 11.4

Typical hair analysis results for a comparison of the matrix effect using phenylmercuric acetate and mercuric chloride internal standard additions 


\section{LIST OF FIGURES}

Figure 1.1 Cold-vapor atomic absorption instrument layout

Figure 2.1 Peak area absorbance of $10.0 \mathrm{ng}$ of mercury as a 10 function of sodium hydroxide $(8.75 \mathrm{~N})$ and sulphuric acid $(4.5 \mathrm{~N})$ volumes

Figure 3.1

Analytical sensitivity of mercury as a function of $8.8 \mathrm{~N}$ 16 $\mathrm{NaOH}$ and $4.5 \mathrm{~N} \mathrm{H}_{2} \mathrm{SO}_{4}$ volumes

Figure 3.2

The effect of cysteine on the sensitivity of mercury 18 under acidic versus alkaline reducing conditions.

Figure 4.1

Schematic diagram illustrating how atoms may: 28 contribute to an integrated absorbance signal more than once, or, how they may be, "counted," more than once

Figure 4.2

Illust:ative model for integrated signals in analysis cells of different optical analysis dimensions

Figure 5.1

Closed CVAAS set-up for leak calibration and detection

Figure 5.2 Absorbance transients for $10 \mu \mathrm{L}$ of mercury vapor at $21^{\circ} \mathrm{C}$

Figure 5.3

Dependence of the Normalized absorbance and the integrated absorbance on flow rate

Figure 6.1

Typical graphite probe furnace atomization transient for mercury, and a plot of $\ln$ (absorbance) versus time transient and a chemically reduced mercury transient

Figure 6.3 Cold-vapor atomic absorption set-up showing injection 58 ports 1 and 2

Figure 7.1 Schematic diagram of setup used for the production, delivery, and measurement of adsorptional losses of trace mercury-vapor in tubing samples 
Figure 7.2 Influence of tube radius and flow rate on trace analyte loss by surface adsorption

Figure 8.1 Variation of atom residence time with tube diameter

71

Figure 8.2 Atom loss model 1. Plot of $\mathrm{N} / \mathrm{N}_{\mathrm{o}}$ versus

$\log$ (tube radius)

Figure 8.3

Atom loss model 2. Plot of $\mathrm{N} / \mathrm{N}_{\mathrm{o}}$ versus

78 $\log$ (tube radius)

Figure 8.4

Atom loss model 3. Plot of $N / N_{0}$ versus

82 $\log$ (tube radius)

Figure 9.1A Typical CVAA transients of mercury at different flow 88 rates

Figure 9.1B

Three typical CVAA transients of mercury followed by 88 an absorbance by some unknown gas

Figure 9.2

Two CVAA traces showing mercury peaks followed by 90 large, anomalous absorbance pulses when the solution was left to aerate following the evolution of the mercury peak

Figure 9.3 Schematic diagram of instrumental arrangement for monitoring of selective adsorption of anomalous gas on gas sampling tube

Figure 9.4 Mass spectrum of blank. Gas sampled from glasswool plug inserted in the flow-stream of a CVAA instrument when no absorbance was occurring at $253.7 \mathrm{~nm}$

Figure 9.5 Mass spectrum of unknown gas - $\mathrm{HCl}$. Gas sampled from glass wool plug that had been inserted in the flowstream of a CVAA instrument when anomalous absorbance at $253.7 \mathrm{~nm}$ was observed

Figure 10.1 Cross-sectional view and top view of absorbance cell holder

97

Figure 10.2 Optical path and possible detector positions for UVD 98 and UVM spectrometers 
Figure 10.3 Energy profile observed by the dual photovoltaic cell detector for the experimental and reference cell as a function of detector distance from the collimating lens 


\section{LIST OF APPENDICES}

Appendix I Glossary of terms used in this work

Appendix II Calibration curve for mass of mercury in $10 \mu \mathrm{L}$ of mercury saturated air versus temperature

Appendix III Calculation for atom residence time, $\tau$, in a graphite

116 furnace

Appendix IV Calculation of the geometry term $1 / 4$, for atom loss

117 model 2 


\section{CHAPTER 1}

\section{INTRODUCTION}

As early as 1939 the $253.7 \mathrm{~nm}$ mercury resonance line was used to monitor the amount of mercury vapor in air [1]. Since then, particularly after incidences of large scale exposures to mercury in Minimata Bay and Iraq in the late $1950^{\circ}$ s, there has been increased concern for the ability to detect smaller and smaller levels of mercury in primarily, biological $[2,3,4,5,6,7,8,9,10,11]$, and more recently some environmental samples $[12,13,14,15,16,17]$. This widespread interest in mercury has lead to new techniques for its determination $[18,19]$, preconcentration [20], and automation of determination $[21,22]$.

Over the course of this work, some changes to the cold-vapor atomic absorption (CVAA) instrument have been made. Although the basic instrument has been thoroughly described in references $[23,24]$ a brief summary of the instrument is presented in Figure 1.1. Modifications that have gone unpublished include: 1) a charcoal filter that removes mercury, and other potential absorbers of $253.7 \mathrm{~nm}$ light, from the ambient air that enters the reaction vessel, 2) air tight, septum sealed, reagent and sample delivery ports, and 3) an optional grass wool filter that removes $\mathrm{HCl}_{(8)}$, a known absorber of $253 \mathrm{~nm}$ light, from the carrier gas.

The cold-vapor atomic absorption technique is not widely understood, and for this reason a very general description of this procedure follows giving reference to Figure 1.1

- Reagents for the chemical reduction of mercury are delivered through port 2. A blank 
or a sample is injected at port 3. Ambient air, continuously entering the system and flowing through the charcoal filter (1), aids the delivery of the solutions down the funnel to the bottom of the acration-reaction vessel (4), where the mercury is chemically reduced (1) $\mathrm{Hg}^{\prime}$. The volatile $\mathrm{Hg}^{\circ}$ is swept away by the air flow through a water vapor condenser (5). The glasswool plug (7) removes any $\mathrm{HCl}$, that has been known to be produced sporadically (Chapter 9), from the carrier gas, and the absorbance at $253.7 \mathrm{~nm}$ is measured by a fixed wavelength, double beam, spectrometer (8). Air leaving the absorbance cell goes through a mass flow meter/controller (9), a charcoal filter (10) to remove mercury from the air, and enters a pump (11) that draws air through the entire system.

This thesis owes much to the organization and thoroughness of two major works in graphite furnace atomic absorption spectrometry $[25,26]$. These two labours have outlined the necessary steps for removing cold-vapor atomic absorption from the grips of an art, and into the present study of the technique as a science. This indebtedness is most evident in Chapters 4 through 6, where signal reporting options for atomic absorption spectrometry are discussed.

\section{ORGANIZATION OF THE THESIS}

Although this thesis is presented in 11 chapters, there are four primary ideas presented herein. First, Chapters 2 and 3 identify a new speciation technique for sulphydryl-bound mercury - a technique that developed fortuitously from a reagent volume optimization study. Second, Chapters 4 through 6 dissect the method used for 


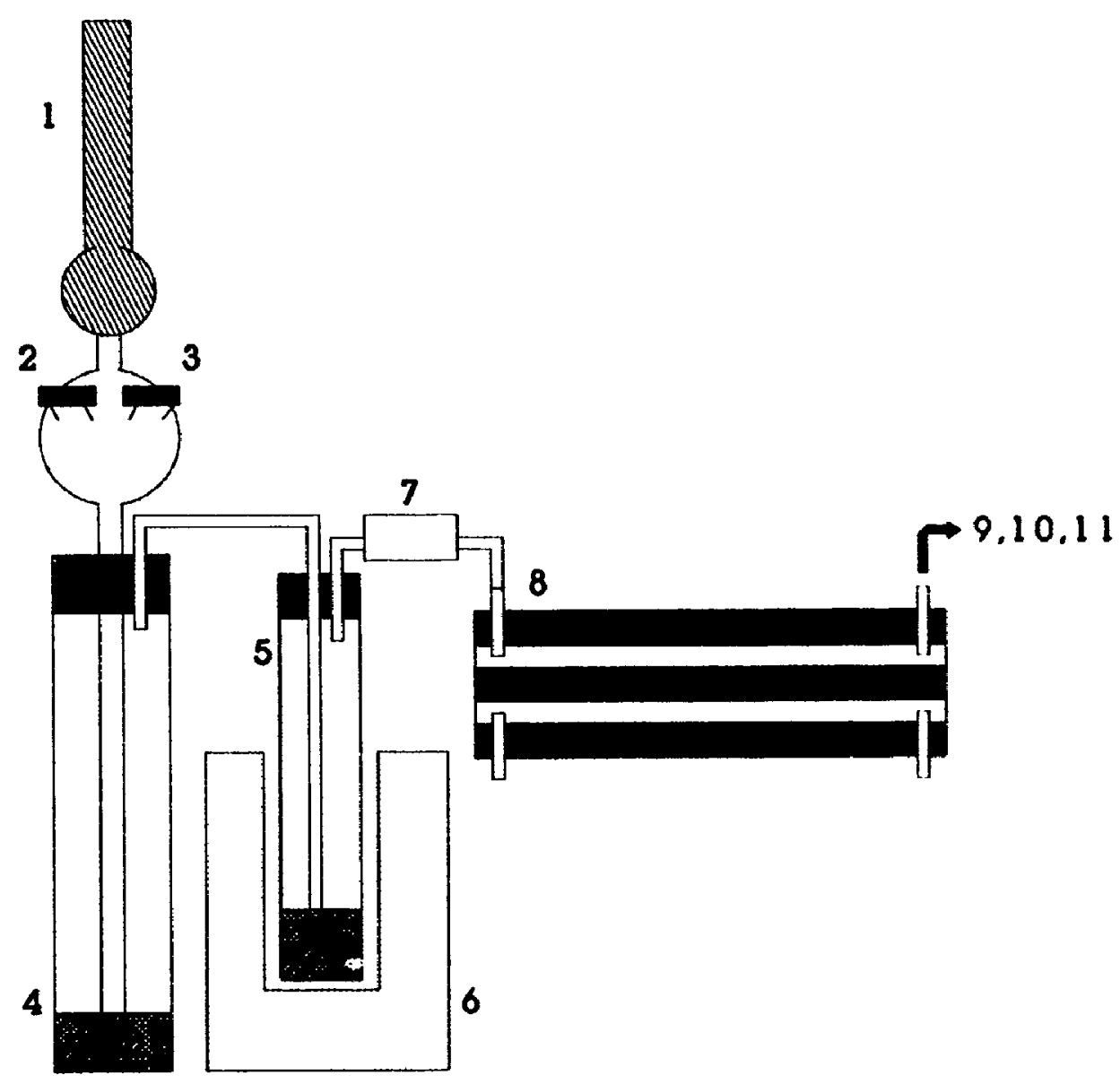

Figure 1.1 Cold-vapor atomic absorption layout: 1, charcoal air filter; 2,3, reagent and sample delivery ports; 4 , aeration-reaction vessel; 5 , water vapor condenser; 6, ice-bath; 7, glasswool filter; $8,253.7 \mathrm{~nm}$ fixed wavelength, double beam, spectrometer; 9, mass flow meter/controller; 10 , charcoal filter; 11 , pump 
4

signal reporting in atomic absorption spectrometry. Third, Chapters 7 and 8 probe a single question: What tubing diameter is best to minimize trace analyte loss when delivering atomic vapor from one site to another? Fourth. Chapters 9 through 11 investigate three problems common to cold-vapor atomic absorption spectrometry: $\mathrm{HCl}$ spectrochemical interference, optical alignment with a dual beam spectrometer, and the matrix effect. 


\section{CHAPTER 2}

\section{REAGENT VOLUME OPTIMIZATION}

\section{INTRODUCTION}

In an attempt to minimize the magnitude of a reagent blank and analysis cost, a reagent volume optimization study has been undertaken. This study reveals some very important aspects concerning the pH-dependence of the sensitivity in cold-vapor mercury atomic absorption spectrometry (CVMAAS). These results also suggest the separate identification of uncomplexed mercury" and sulphydryl-complexed mercury to be discussed in Chapter 3. A study by Hawley and Ingle [27] investigated the effect of optimized instrumental and some experimental parameters, but their work was limited strictly to acidic reduction of divalent mercury and did not optimize individual reagent volumes.

Since the 1969 publication by Magos and Cemik [28], describing an alkaline reduction technique, there has been no critical evaluation of the continually evolving method, yet there have been many subtle changes. The overall direction and purpose of these changes has not been made clear. The objective herein is to present a summary of how the practice of the Magos method has changed over the past nearly 20) years. Also presented are some of our most recent changes to the method. 


\section{EXPERIMENTAL SECTION}

Appuratus. A commercially available Laboratory Data Control/Milton Roy UV Monitor ${ }^{\text {tw }}$ D fixed wavelength detector, equipped with a low pressure mercury lamp operated with a $254 \mathrm{~nm}$ interference filter, and fitted with a $29.0 \mathrm{~cm}$ double beam gas flow cell was used for monitoring absorbance by mercury-vapor. The output signal from the UV monitor was integrated by a Spectra-Physics Model 23000-011 integrator.

Instrumental Settings. The spectrometer was operated with a sensitivity of 0.01 absorbance/10 $\mathrm{mV}$ full scale deflection. The gas flow rate was $2.0 \mathrm{~L} \cdot \mathrm{min}^{-1}$. through the gas cell, whose volume was determined to be $11.1 \mathrm{~mL}$ by filling with water. The integrator analog to digital conversion was determined to be $2.3 \mu \mathrm{V} \cdot \sec ^{-c^{\prime}} \cdot \mathrm{unt}^{-1}$, where the integrator's output was in counts, and its acquisition increment was 0.10 seconds.

Reagents. All reagents were selected for their low mercury content (Table 2.1). A reagent blank signal corresponded to approximately $50 \mathrm{pg}$ of $\mathrm{Hg}$.

Sodium Hydroxide Solution. A $35 \%(\mathrm{~m} / \mathrm{v})$ sodium hydroxide solution was prepared by dissolving $700 \mathrm{~g}$ of sodium hydroxide pellets in DDW and diluting to $2.00 \mathrm{~L}$. The mercury content of the $\mathrm{NaOH}$ was less than $80 \mathrm{pg}^{-1}$.

Reducing Solution For Inorganic Mercury Analysis. A stannous chloride solution was prepared daily by dissolving $2.0 \mathrm{~g}$ of stannous chloride and $0.2 \mathrm{~g}$ of L-cysteine in $100 \mathrm{~mL}$ of sulphuric acid/sodium chloride solution $(20 \mathrm{~g}$ sodium chloride and $250 \mathrm{~mL}$ of concentrated sulphuric acid made up to $2.00 \mathrm{~L}$ with DDW).

Standards. $0.6767 \mathrm{~g}$ of mercuric chloride was dissolved in DDW and diluted to $1.00 \mathrm{~L}$. A $5(K) \mathrm{ng}^{\circ} \mathrm{mL}^{-1}$ stock solution was prepared by adding $1.00 \mathrm{~mL}$ of the first solution, $9.0 \mathrm{~g}$ 
of sodium chloride, and $0.1 \mathrm{~g}$ of L-cysteine to DDW and diluting to $1 .(00) \mathrm{L}$. Working standards of $1.0 \mathrm{ng} \mathrm{mL}^{-1}$ were prepared daily by diluting $1.0 \mathrm{~mL}$ of the stock solution. Procedure. A midget impinger containing $10 \mathrm{~mL}$ of DDW and $1.0 \mathrm{~mL}$ of $9: 1$ ethanol:octanol, immersed in ice was interposed between the reduction aeration column and the gas cell. This removed water vapor from the carrier gas. The spectrometer, integrator and pump were tumed on and allowed to reach a steady-state for approximately 30 minutes before use.

An evaluation of sensitivity began by running blanks. $1.0 \mathrm{~mL}$ of reducing solution, followed by $1.0 \mathrm{~mL}$ of $35 \%(\mathrm{~m} / \mathrm{v})$ sodium hydroxide solution and $4.0 \mathrm{~mL}$ of $\mathrm{DDW}$ were sequentially delivered into the column through a long stem funnel using Brinkmann hottle top dispensettes. The $4.0 \mathrm{~mL}$ of DDW was found to be of crucial importance to ensure complete delivery of the $1.0 \mathrm{~mL}$ of sodium hydroxide. Following the appearance of a signal and return to a stable baseline, the reaction vessel was voided and rinsed. Standards were run in an identical manner by first injecting a $1.0 \mathrm{~mL}$ standard aliquot. Signals were monitored on a voltameter and recorded by the integrator.

\section{RESULTS AND DISCUSSION}

A chronological summary of experimental parameters and reagents is presented for CVMAAS in Table 2.2 for six publications over the past 20 years.

Of particular interest are the decreasing concentrations of $\mathrm{CdCl}_{2}, \mathrm{SnCl}_{2}, \mathrm{~L}$-cysteinc and $\mathrm{NaCl}$ used by successive investigators [28,29,30,23,31,32]. Decreasing quantities reflect more easily procurable sample sizes, cost efficiency, and smaller blank 
signals.

Table 2.1 Details of Apparatus and Reagents

\begin{tabular}{|c|c|}
\hline \multicolumn{2}{|l|}{ Apparutus } \\
\hline Spectrometer & $\begin{array}{l}\text { Mercury UV Monitor" model } 1235 \\
\text { (Laboratory Data Control) }\end{array}$ \\
\hline Integrator & Spectra-Physics Minigrator model 23000-011 \\
\hline l'ump & Neptune Dyna-Pump (vacuum), model 3 \\
\hline ( ias flow control/meter & 0-5 LPM Rotameter, Dwyer Instruments, Inc. \\
\hline \multicolumn{2}{|l|}{ Rexction Vessel ${ }^{+}$} \\
\hline Cilassware & See Introduction Figure 1.1 \\
\hline Solenoid Valves & Skinner No. V52DB2022 \\
\hline & Cole-Parmer No. 1368-50 \\
\hline Solution Dispensettes & $\begin{array}{l}\text { Brinkmann bottle-top dispensers } \\
0.4-2 \mathrm{~mL}, 1-5 \mathrm{~mL}\end{array}$ \\
\hline Pipetter & $1000 \mu \mathrm{L}$ Eppendorf, model 4700 \\
\hline \multicolumn{2}{|l|}{ Regents ${ }^{t}$} \\
\hline $35 \%(\mathrm{~m} / \mathrm{V}) \mathrm{NaOH}$ & Baker Analyzed, 3722-05 \\
\hline $4.5 \mathrm{~N} \mathrm{H}_{2} \mathrm{SO}_{4}$ & AnalR $^{\circ}$, BDH Chemicals, B10276-74 \\
\hline $3 \% 1$-Cysteine & Sigma Chemical Co., C-7755 \\
\hline $8 \%(\mathrm{~m} / \mathrm{V}) \mathrm{NaCl}$ & AnalR ${ }^{\circ}$, BDH Chemicals, B10241 \\
\hline $\operatorname{SnC} \mathrm{I}_{2}$ & AnalR ${ }^{\circ}$, BDH Chemicals, B 10270 \\
\hline $\mathrm{CHCl}_{2}$ & A'fa Products, 87378 \\
\hline $\mathrm{IgCI_{2 }}$ & Anachemia Ltd. AC-5672 \\
\hline Phenylmercuric acetate & Alfa Products, 37125 \\
\hline Water & $\begin{array}{l}\text { Distilled Deionized water, Milli-Q Purification } \\
\text { System,Millipore corporation, } 4891\end{array}$ \\
\hline
\end{tabular}

'details from references[23]

${ }_{\text {reagent solutions prepared using distilled deionized water }}$

Athough the latter does result in decreased absolute and relative detection limits, smaller sample sizes increase the relative detection limit. Clearly it is desirable to maintain as large a sample size as possible while minimizing the amount of reagents necessary.

This study focused on varying the amounts of acid and base with a view to ascertain the minimum amounts of both that could be used. Figure 2.1 shows that as low as 
Table 2.2

\section{Chronology of experimental parameters and reagents}

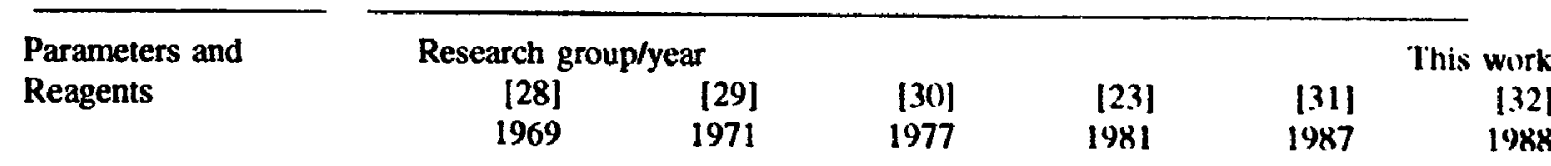

Gas flow

rate/(nL·min $\left.{ }^{-1}\right)$

2.0

2.5

2.5

2.0

2.0

2.1)

Net reaction

volume/(mL)

12.0

52.0

44.0

11.0

6.0

(.)()

Reaction vessel

volume/(mL)

30

200

125

45

45

45

Sample size/(mL)

$1-5.0$

1.0

1.0

1.0

1.0

1.0

Reagent concentrations ${ }^{\dagger}$

$(\% \mathrm{~m} / \mathrm{v})$

$\mathrm{SnCl}_{2}$

$\mathrm{CdCl}_{2}$

L-Cysteine

0.83

N/A

0.19

0.23

0.19

0.29

0.17

0.019

0.023

0.38

0.23

1.0

0.5

0.33

0.00

0.10

0.13

0.083

0.50

0.05

0.033

0.17

Acid/base concentration ${ }^{*}$

(normality)

$\mathrm{H}_{2} \mathrm{SO}_{4}$

$\mathrm{NaOH}$

0.00
1.25

3.2

2.0

4.0

2.3
4.3

1.9

0.75

4.3

4.3

3.6

1.5

$\dagger(\% \mathrm{~m} / \mathrm{v})$ is given as percent mass $/(\mathrm{g})$ of reagent over the net reaction volume/(mL)

\# The normality reported is given as equivalents per liter of the net reaction volume

$0.1 \mathrm{~mL}$ each of $8.8 \mathrm{~N}$ sodium hydroxide and $4.5 \mathrm{~N}$ sulphuric acid could be used without any significant loss in sensitivity provided the sodium hydroxide was completely washed down the long stem glass funnel to ensure complete alkalinization of the net $6.0 \mathrm{~mL}$ reaction solution. If the washing was not complete, incomplete delivery of sodium hydroxide occurred at smaller volumes $(0.1 \mathrm{~mL})$ and the solution remained acidic, resulting in poor sensitivity for mercury. Interestingly, this $\mathrm{pH}$ dependence on the recovery of mercury was exploited for a speciation technique described in the following chapter. 


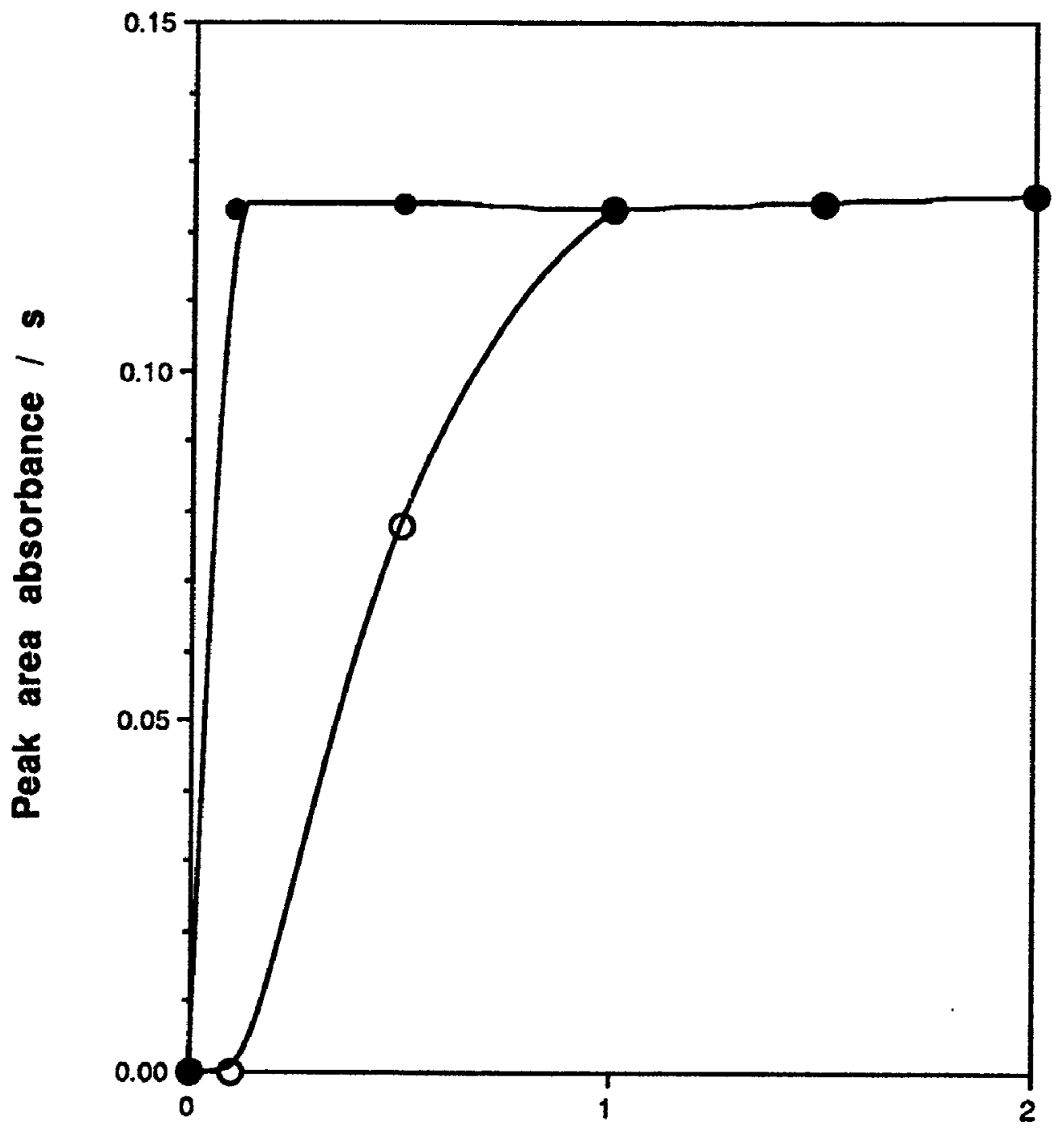

Reagent volume / $\mathrm{mL}$

Figure 2.1 Peak area absorbance of $10.0 \mathrm{ng}$ of mercury as a function of sodium hydroxide $(8.75 \mathrm{~N})$ and sulphuric acid $(4.5 \mathrm{~N})$ volumes with $3.0 \mathrm{~mL}$ of distilled deionized wash $(O)$, and without $(O)$ 


\section{CONCLUSIONS}

Although $0.1 \mathrm{~mL}$ each of $8.8 \mathrm{~N} \mathrm{NaOH}$ and $4.5 \mathrm{~N} \mathrm{H}_{2} \mathrm{SO}_{4}$ were sufficient for standard solutions, $1.0 \mathrm{~mL}$ volumes were used and found adequate for hair, grass, leaves and soil [33]. Even though $1.0 \mathrm{~mL}$ volumes were used, the reagent blank signal was still lower by a factor of five or greater compared with other research groups $\mid 28-31]$ who used volumes greater than or equal to $5.0 \mathrm{~mL}$ each of $\mathrm{NaOH}$ and $\mathrm{H}_{2} \mathrm{SO}_{4}$ either at the ahove concentrations or higher.

Finally, this study put to rest the misconception that the purpose of the $\mathrm{NaOH}$ was to contribute to the volatilization of mercury by the heat of neutralization [34]. Reducing the molar heat of neutralization by a factor of 20 , by reducing the acid and base volume: by the same factor, resulted in only a five percent reduction in sensitivity. 


\section{CHAPTER 3}

\section{ACIDIC VERSUS ALKALINE REDUCTION IN \\ COLD-VAPOR MERCURY ATOMIC \\ ABSORPTION SPECTROMETRY}

\section{INTRODUCTION}

Two schools of thought have dominated the reduction procedure in cold-vapor mercury atomic absorption (CVMAA): acidic reduction [35] and alkaline reduction [28]. This study investigates the effect of cysteine added either to the mercury stock solutions or to the reducing solutions or both in conjunction with the acidic and alkaline reduction procedures. The results show the possibility of speciating mercury in the sulphydryl-complexed and free forms. The superior sensitivity obtained by using the strong reducing power of $\operatorname{tin}^{11}$ chloride in alkaline medium instead of acidic medium has been reported [15], but this increased sensitivity has neither been understood, nor has a comparison been made to acidic reduction.

Along with the growing awareness of more toxic forms of mercury grew the need for its speciation based on the cold-vapor mercury atomic absorption technique. While gas chromatographic techniques $[36,37,38,39,40]$ are necessary for the speciation of organomercurials, the selective reduction of inorganic mercury by $\mathrm{SnCl}_{2}$ and total mercury by $\mathrm{CdCl}_{2}-\mathrm{SnCl}_{2}$ was reported in 1971 by $\mathrm{Magos}$ [29], using the cold-vapor atomic absorption technique. Umezaki and Iwamoto [41], also in 1971, described a similar technique where $\operatorname{copper}^{\mathrm{II}}$ replaces cadmium ${ }^{\mathrm{II}}$ in the total mercury analysis step 
following alkaline reduction conditions. The alternate use of copper instead of cadmium" has been more recently reported, by Toffaletti and Savory [42], using sodium borohydride as the reductant instead of $\operatorname{tin}^{\mathrm{n}}$. Wigfield and Perkins [43] reported a method in 1982 for the separate determination of zero valent and divalent mercury. This idea of mercury valence speciation was extended to divalent diatomic mercury in simultaneous publications by Wigfield et al. [44] and Pinstock et al. [45]. Ahmed, May and Stoeppler [46] recently reported a unique mercury speciation technique that exploited the ultraviolet decomposition of methylmercury.

Cold-vapor atomic absorption has also lead to a new and exciting field of indirect speciation analyses. Christmann et al. [47] and Umland et al. [48] have used Coldvapor mercury-coupled atomic absorption for the ultra-trace determination of $\operatorname{tin}^{\mathrm{I}}$. This technique involves using divalent mercury in excess as the reagent and relies on the near stoichiometric release of $\mathbf{H g}^{\circ}$ from solution by the trace analyte tin'. Although the potential for interference is great, the sensitivity for other-metal, valence-species determination is unequalled. Marshall and Midgley [49] used the following displacement reaction and the subsequent atomic absorption measurement of $\mathrm{Hg}^{\circ}$ as the

$$
\mathrm{Hg}_{2}{ }^{2+}+2 \mathrm{SO}_{3}{ }^{2-} \leftrightarrow \mathrm{Hg}\left(\mathrm{SO}_{3}\right)_{2}{ }^{2-}+\mathrm{Hg}^{\circ} \quad \mathrm{K}=10^{16}
$$

basis of a new analytical method for the determination of picogram amounts of sulfite ion or sulfur dioxide in air.

This Chapter presents some potential errors encountered in the acidic reduction technique, and also indicates the possibility for identifying sulphydryl-complexed mercury" and free mercury" species. 
This new speciation method was developed fortuitously during a reagent volume optimization study [32]. The optimization procedure involved finding the minimum reagent volumes necessary without notably sacrificing sensitivity. At the low reagent volumes employed the signal was found to be pH dependent, because at these small volumes $(0.1 \mathrm{~mL})$, sodium hydroxide, the final reagent, was not being completely delivered down the long stem glass funnel. This caused a loss of sensitivity which was overcome by washing the sodium hydroxide down the funnel with deionized water. Contrary to a popular notion that would have predicted this decrease in sensitivity due (I) a lack of sufficient heat of neutralization, this study shows that the loss of sensitivity is due to incomplete alkalinization of the reaction mixture.

\section{EXPERIMENTAL SECTION}

In difference to the reagent volume optimization of Chapter 2, where the tin(II)-sulphuric acid solution and the sodium hydroxide reagent volumes were decreased, but were always the same volume, the reagent volumes were varied independent of each other in this study. A $5 \times 5$ matrix of data was collected for reagent volumes varying between 0.5 and $2.5 \mathrm{~mL}$ using $0.5 \mathrm{~mL}$ increments.

Other details of the experimental method are presented in Chapter 2.

\section{RESULTS AND DISCUSSION}

Figure 3.1 shows the influence of varying quantities of $\mathrm{H}_{2} \mathrm{SO}_{4}$ and $\mathrm{NaOH}$ on the sensitivity of mercury determination. The non-cubical geometry of the sensitivity surface 


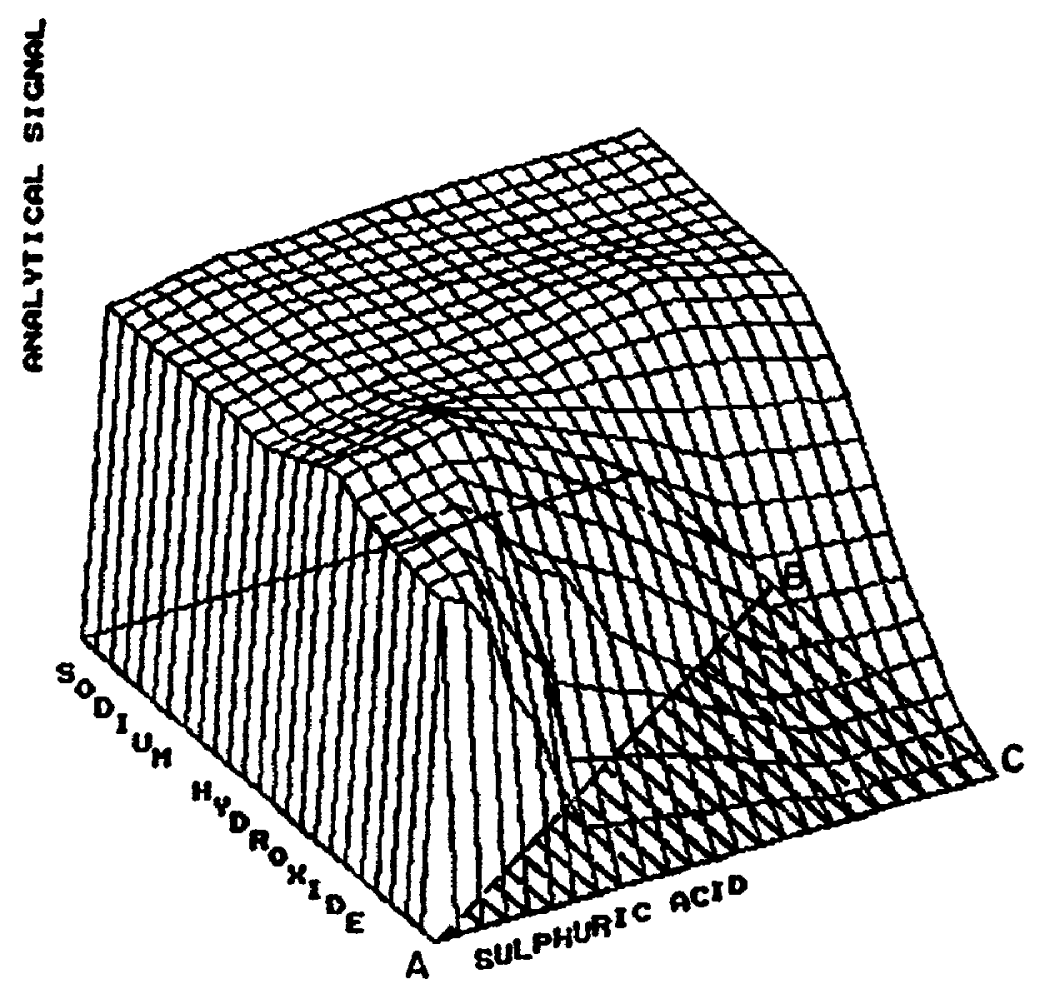

Figure 3.1 Analytical sensitivity of mercury as a function of $8.8 \mathrm{~N} \mathrm{NaOH}$ and $4.5 \mathrm{~N}$ $\mathrm{H}_{2} \mathrm{SO}_{4}$ volumes [front lower comer has coordinates $\mathrm{A}(0,0,0)$, and the volume range is $0-2.5 \mathrm{~mL}$ ] 
shows the influence of $\mathrm{pH}$ on the reduction of mercury. This surface was generaled from a $5 \times 5$ matrix of points (each a mean based on 5 replicates). Polynomial regression was performed to generate more points to fill in the surface. The loss of sensitivity above the acidic hatched $A B C$ region (Figure 3.1) allows the separate determination of sulphydrylcomplexed mercury species.

Cysteine was added to both the reducing and standard solutions to minimize loss of mercury before the reaction was triggered by the addition of excess sodium hydroxide [28]. Mercury" forms a complex with cysteine[50], therehy preventing its reduction by stannous chloride to volatile $\mathrm{Hg}^{\circ}$ until alkaline conditions prevail. It is reasonable to suggest that the "undetectable form" of mercury reported by Ahmed and Stoeppler [51], and Ahmed et.al. [46,52] could in fact be a cysteine or another mercaptan complex.

Figure 3.2 summarizes the effect of cysteine under acidic and alkaline reducing conditions on the sensitivity of mercury determination in CVMAA. The cysteine-tomercury molar ratio was $165: 1$ in the $10.0 \mathrm{ng}^{\circ} \mathrm{mL}^{-1}$ standard solution used. Cysteint, when included in the reducing solution, doubles the cysteine-to-mercury molar ratio to $330: 1$ in the net reaction volume for a $1.0 \mathrm{~mL}$ addition of the reducing solution and a 1.0 $\mathrm{mL}$ standard aliquot. The severe suppressive effect that cysteine had on the mercury signal under acidic reducing conditions is evident from Figure 3.2 (see arrow).

In the case of acidic reduction of cysteine-complexed mercury where cysteine is not present in the reducing solution, partial generation of the signal (46\% compared with alkaline reduction) is most difficult to account for. In contrast to this situation, only 


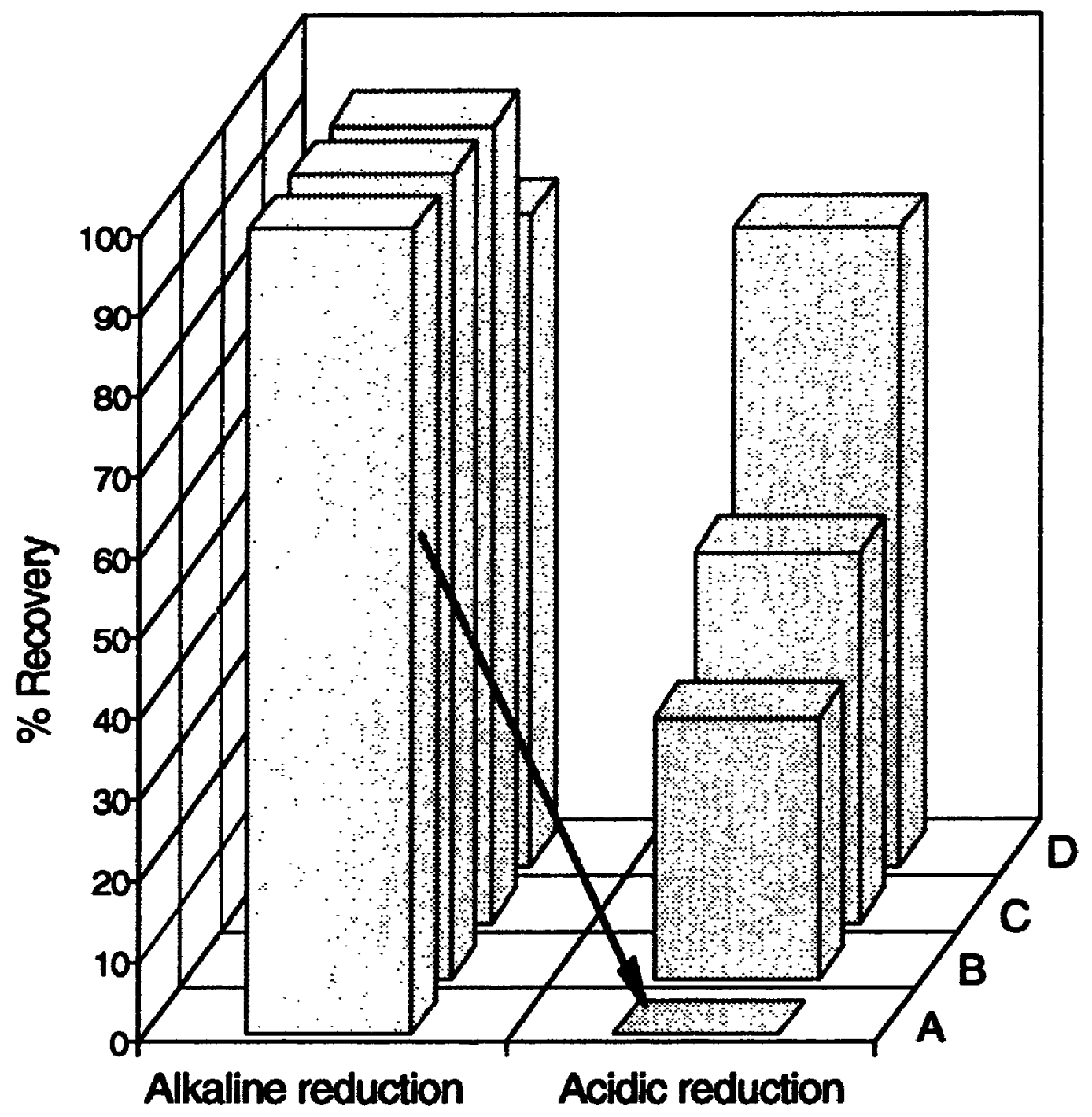

Figure 3.2 The effect of cysteine on the sensitivity of mercury under acidic versus alkaline reducing conditions. (A) cysteine in both the reducing and the standard mercury solution; (B) cysteine in the reducing solution only; (C) cysteine in the standard mercury solution only; (D) cysteina in neither the reducing nor the standard mercury solution 
differing by the addition of cysteine to the reducing solution, no signal is ohserved (seet arrow). The net cysteine-to-mercury molar ratio is believed to be of importance in determining whether a signal will be observed or not. For acidic reduction of free mercury where cysteine is present in the reducing solution, less than $I(1) \%$ signal recovery (based on alkaline reduction) is believed to be attributable to two factors. First. alkaline reduction is a more analytically sensitive technique. Second, two competitive processes are occurring simultaneously: reduction and complexation. One process precludes the other. For purposes of quantitative speciation analysis it is desirahle (I) regard the analyses under the aforementioned conditions as each having characteristic sensitivities towards mercury.

At best only 74 percent of the integrated alkaline signal can be obtained under acidic reducing conditions in the complete absence of cysteine. This point emphasizes the superior sensitivity of mercury reduction under alkaline conditions.

\section{Quantitative determination of sulphydryl-complexed mercury}

For this quantitative speciation analysis, the most important aspects revealed in Figure $\mathbf{3 . 2}$ are the acidic reduction conditions described for zero delectable mercury signal from cysteine-complexed mercury (see arrow), and the alkaline reduction conditions for $100 \%$ signal evolution for the same complexed mercury. By exploiting this difference, it is possible to quantify both total mercury (complexed plus uncomplexed forms) and uncomplexed mercury. The amour. of complexed mercury is taken as the difference between the total and uncomplexed amount. For the described quantitative speciation 
analysis cysteine must be present in all reducing solutions. The calculation takes the following form:

Total Mercury $=\mathrm{Hg}^{\mathrm{II}}+\mathrm{Hg}^{\mathrm{It}}-\mathrm{CYS}$

The tutal mercury present is the product of the alkaline signal sensitivity, $\alpha$, and the alkaline signal, $S_{1}$, while the amount of uncomplexed mercury is the product of the acidic sensitivity, $\beta$, and the acidic signal, $S_{2}$. Therefore, the amount of complexed mercury, $\Psi$. is:

$\psi=(\alpha)\left(S_{1}\right)-(\beta)\left(S_{2}\right)$

\section{CONCLUSIONS}

This study shows that alkaline reduction is superior to acidic reduction in cold-vapor mercury atomic absorption; it also shows that the use of a combination of acidic and alkaline reduction procedures can lead to the separate determination of sulphydryl complexed and free mercury ${ }^{\prime \prime}$ species. 


\section{CHAPTER 4}

\section{SIGNAL REPORTING OPTIONS}

Methodology is presented for the normalization of integrated absorbance signals (in absorbance time units) to time independent absorbance values in analytical flow systems. This measure, in units of $\mathrm{cm}^{2}$ [53] represents the absorbance if all the analyte atoms were simultaneously contained, in atomized form, in a normalized optical analysis volume. The measure, for which the name "normalized absorbance" is suggested, is one which is totally independent of optical analysis cell dimensions and carrier gas flow rates. Application of this method to cold-vapor mercury atomic absorption (CVMAA) is reported.

\section{INTRODUCTION}

Whether to report an analytical signal by peak height or by peak area is a question of long standing in atomic spectroscopy $[54,25]$. Both practices have some problems. In the case of peak height, it should, in principle, be possible to report the signal in absorbance units, but the easy alternative of reporting the maximum peak deflection in millivolts is often used in cold-vapor atomic absorption spectrometry. This practice leaves a reader either hunting for the instrumental sensitivity setting, or completely

\footnotetext{
tnot to be confused with the nomalized absorbance used by Slavin et. al. [66]
} 
ignorant of the experimental sensitivity, in which case the only value of the data is the relation between the signal magnitudes. Perhaps the most serious problem, however, with peak heights is their susceptibility to matrix effects. Thus if a matrix affects the rate of signal production, it will change the shape of the generated signal, which, although not necessarily modifying the peak area, can dramatically change the peak height. In the case of Cold-Vapor Mercury Atomic Absorption (CVMAA), Wigfield et al. [34] have shown that peak areas are far more reliable than peak heights for precisely that reason, and when peak areas were measured in place of peak heights, the so-called matrix interferences were virtually absent.

Peak areas are less susceptible to matrix interferences, but they have a decided disadvantage in the units sometimes used to report them. Currently there is no sufficiently universal peak area unit, from the point of view discussed herein, and many authors (including reports from this laboratory) have, out of ignorance or neglect, reported arbitrary integrator units or "counts." In a flow system, the units of peak area should be absorbance time. In Graphite Furnace Atomic Absorption (GFAA) spectroscopy, this unit seems to be well rooted [55], and in this paper we attempt to bring CVMAA into line with this level of understanding, and practice.

For all types of atomic absorption spectroscopy we suggest that the ideal measure to report should be the absorbance if the entire sample were atomized with 100 percent efficiency while being contained within a normalized analysis volume. We suggest that 
this be referred to as the Normalized absorbance ${ }^{\ddagger}$. This is achievable for CVMAA. Currently, the best option a spectroscopist has available is the integrated absorbance-time signal. This integrated signal does not achieve our current goal because it allows atoms to contribute to the net signal more than once while in transit through the optical path. The integrator must sample the absorbance at a frequency higher than the analysis volume-void frequency. This is necessary to avoid nyquist sampling crrors $[56 \mid$, hut in the conversion to a normalized absorbance this over sainpling, duc to the higher acquisition frequency, must be corrected for. The analysis volume must also be normalized because a given population of atoms will give a different instantaneous absorbance in a cell of different analysis dimensions.

Does one want to report the total (as a function of rime) resonance absorbance that has taken place (i.e. integrated absorbance), or the abuve mentioned "normalized absorbance?" The "normalized absorbance" is an alternative, not a replacement for the already established integrated absorbance (absorbance•time). Both measures are useful. The former indicates purely instrumental sensitivity, while the latter expresses the combined instrumental-experimental sensitivity. Only the normalized measure of fers an absorbance completely independent of the mean length of time spent by atoms in the optical path, and independent of the analysis cell dimensions.

Advantages of reporting normalized absorbances lie in: i) taking CVMAA a step in the direction of standardless analysis, where there exists the possibility of a theoretical

\footnotetext{
FTe "normalized absorbance" is preferable over the "instantaneous absorbance" because: (a) the normalized absorbance in flow systems is a suin of instantancous absorbances, and (b) it nomalizes the analysis cell dimensions.
} 
calibration on the basis of fundamental constants [57], ii) the ability to report analytical sensitivities that are independent of flow atom residence times and analysis cell dimensions, and iii) the determination of absolute values of atomic oscillator strengths, where it is extremely important to have atomic vapors with known populations of atoms.

One difficulty underlying the use of integrated absorbances for the evaluation of characteristic masses, is the manner in which the absorbancetime values are acquired. They do not take into account multiple contributions of atoms to the integrated absorbance. As a result, the "characteristic mass," is then not nearly as characteristic as it could be since it is also dependent on the atom residence time. In the case where an analyst would change an experimental setting (for CVMAA, either the analysis volume, $v$, or the carrier gas flow rate, $f$ ) that would alter the atom residence time, $\tau$, the result

$$
\tau=\frac{v}{f}
$$

would be a changed characteristic mass from the point of view of an integrated absorbanceetime evaluation. This creates an unworkable situation when attempting to compare analytical sensitivities from one atomic absorption technique to another (e.g. CVMAA versus GFAA). There would thus appear to be significant merit in having a characteristic mass that is indeed characteristic of a given apparatus and element regardless of experimental variables.

Herein an alternative method is reported for signal reporting in CVMAA based on a normalized absorbance. This value can be readily obtainable from the integrated peak area provided one knows the atom residence time in the optical path, and the optical 
analysis cell dimensions. The intrinsic value of this method is that it offers the reliability of a peak area measurement coupled with the absolute sensitivity meaningfulness of an instantaneous absorbance. Its use may be relevant to other a omic absorption techniques.

\section{EXPERIMENTAL SECTION}

A Milton Roy UV Monitor Fixed Wavelength Delector was used for making absorbance measurements. The detector was removed from the fluid flow cell and placea at the end of a $30.0 \mathrm{~cm}$ double beam absorbance cell from a Laboratory Data Control UV model 1235 spectrometer. Data acquisition was performed using a Jones Chromatography JCL6000 chromatography data system. Peak-areas were integrated manually by taking the area from the point of departure form the baseline $(3$ times the standard deviation of the baseline noisi, $n \geq 10$ ) to the point of return (determined by the same criterion as for departure). Manual integrations were performed using Quattro ${ }^{\oplus}$ Pro and Lotus 1-2-3 spreadsheets because of concern for exactness of peak areas. The software provided with the JCL6000 package contained an error in the algorithm used to compute peak areas.

Furthe: details of the experimental method are presented in Chapter 2.

\section{PFSURTS AI: D DISCUSSION}

The prop:used method for normalizing integrated cold-vapor mercury atomic absorption signals in: $\tau(\mathrm{sec})$, and the analysis cell cross-sectional area, $\sigma\left(\mathrm{cm}^{2}\right)$. This method presupposes an integrator output in absorbanceotime (peak area). For integrators whose output is in 
arbitrary units, the conversion from arbitrary integrator counts to an integrated absorbance time measure, $Q_{\mathrm{A}}$ is as follows:

$$
Q_{A}=A \cdot B \cdot C
$$

where $\mathrm{A}$ is the integrator response (counts), $\mathrm{B}$ the analog to digital conversion factor $\left(\mathrm{mV} \cdot \mathrm{s}^{\bullet} \mathrm{counn}^{-1}\right)$, and $\mathrm{C}$ is the sensitivity setting (absorbance $\left.\bullet \mathrm{mV}^{-1}\right)$.

\section{Normalization with respect to atom residence time, $\tau$}

For the normalization of the atom residence time in a $0.0111 \mathrm{~L}$ volume analysis cell, the procedure is presented in terms of typical experimental values. At $2.0 \bullet \mathrm{min}^{-1}$, a 1.0 ng mercury atiquot yields an integrated signal of 0.0345 absorbanceseconds. Instead of treating the si $i_{6}$ nal as an area, for purposes of this method it is desirable to interpret the signal as a sum of instantaneous absorbances rather than a sum of the instantaneous absorbances multiplied by the integrator acquisition increment ${ }^{t t}, I_{\Lambda}$. This sum is obtained by dividing $0.0345 \mathrm{~A} \cdot \mathrm{s}$ by the acquisition increment ( 0.10 seconds) to give an absorbance of 0.345 . This absorbance is too large and must be corrected for the number of times that atoms have contributed to the integrated absorbance. This number, $\mathbf{N}_{C}$, is the ratio of the atom residence time ro the acquisition increment. Division of the above absorbance by this factor, 3.3 gives a partially normalized absorbance, $A_{N(z)}=0.10$, which is now independent of the atom residence time.

In summary this calculation takes the following form:

\footnotetext{
$" t$ The acquisition increment $(0.1 \mathrm{~s})$ is the reciprocal of the acquisition frequency $(10 \mathrm{~Hz})$, and is more convenient to use in this context.
} 


$$
\begin{aligned}
N_{C}=\frac{\tau}{I_{A}} & =\frac{\left(\frac{v}{f}\right)}{I_{A}}, \quad \text { where } \tau=\frac{v(\text { analysis volume })}{f(\text { flow rate })} \\
& =\frac{\left(\frac{0.0111 L}{2.0 L / 60 \mathrm{sec}}\right)}{0.1 \mathrm{sec}}=3.3
\end{aligned}
$$

Since the acquisition increment cancels out, it need not be included in the calculation. It is sufficient to divide the integrated absorbance $Q_{\mathrm{A}}$ by the atom residence time in order to obtain this first partially normalized absorbance.

$$
A_{N(\tau)}=\frac{Q_{A}}{\tau}=0.10
$$

An alternative and possibly simpler approach to this normalization, without requiring recourse to the acquisition frequency is as follows. Once again start with an integrated absorbance of 0.0345 absorbancesseconds. If the peak were a rectangle of width 1.0 seconds, its height would be 0.0345 in abst jance. In fact, the peak width is not 1.0 seconds, but in order to achieve the situation in which all atoms contribute only once to the absorbance measure, this width is the atom residence time ( 0.33 secinds). Thus the absorbance is $0.0345 / 0.33=0.10$, as above.

In Figure 4.1 an attempt is made to illustrate how atoms contribute to an integrated signal more than once, or, as it is more loosely referred to as, "atoms being counted more than once." For a hypothetical transient absorbance shown in the bottom of Figure 4.1, and given a carrier gas flow rate of $2.0{\mathrm{~L} \cdot \mathrm{min}^{-1}}^{-1}$ and an optical analysis volume of $0.0111 \mathrm{~L}$, the atom position of a pair of atoms is shown where they would occur every 


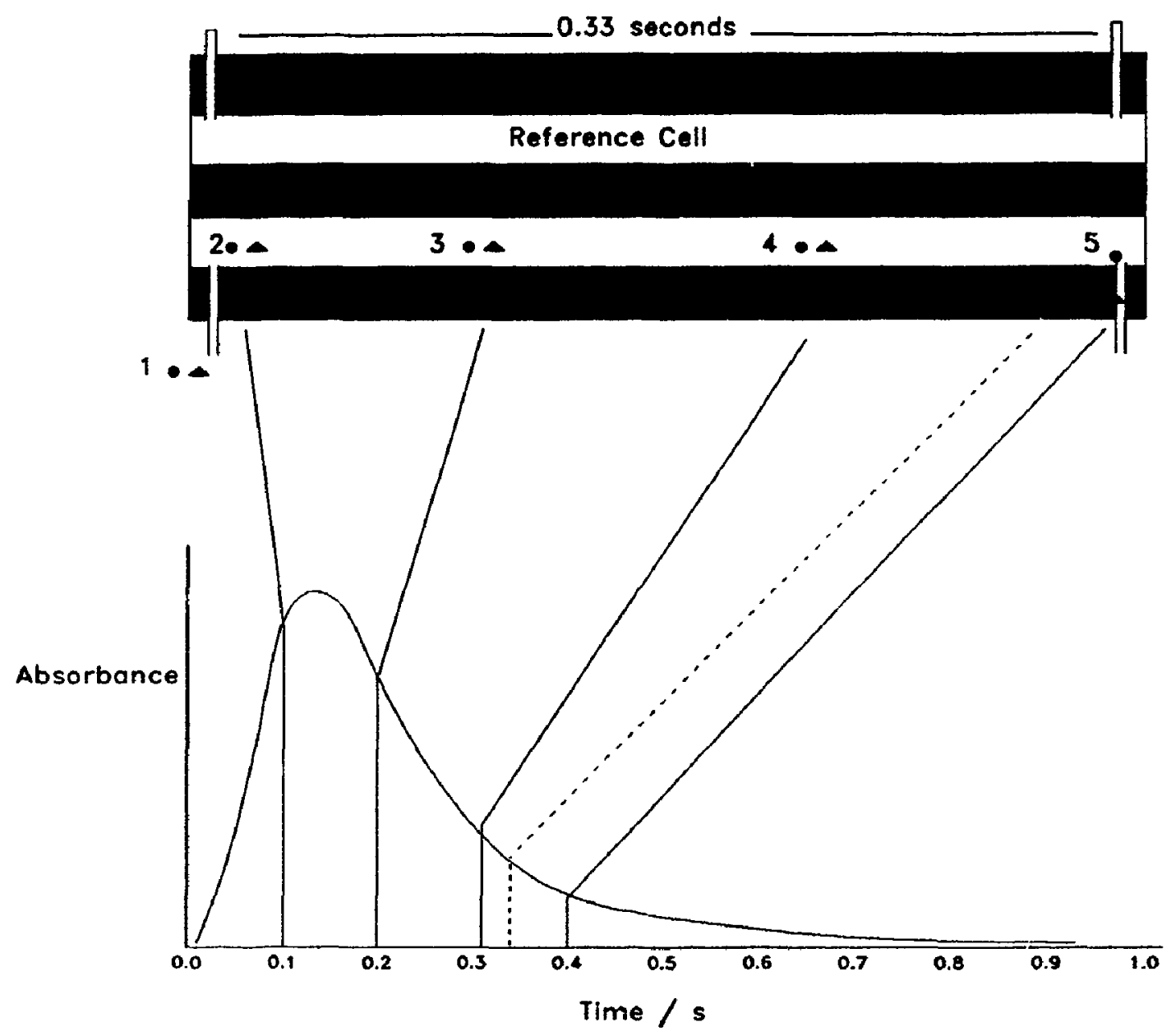

Figure 4.1 Schematic diagram illustrating how atoms may: contribute to an integrated absorbance signal more than once, or, how they may be, "counted," more than once 
0.1 seconds when the integrator would sample the absorbance. At position 1, the pair of atoms have not yet entered the zone of observation, and therefore do not yet contribute to the absorbance. At times $0.1,0.2$ and 0.3 seconds, positions 2,3 , and 4 respectively. the atom pair contributes a total of three times to the integrated absorbance. It could be said that the atoms have been counted three times. At position 5, only the second atom of the pair contributes to the integrated absorbance, therefore, in total, the atom pair have contributed three and a half times to the integrated absorbance. The mean number of times that atoms are counted need not be an integer number. In fact, for the conditions described, atoms are counted 3.3 times (Equation 4.3).

Normalization with respect to the analysis cell cross-sectional area, $\sigma$

The above normalized absorbance, $A_{N(\mathfrak{t})}$ is incomplete. It gives the instantaneous absorbance, $A_{1}$, that would be observed if all the analyte atoms were contained simultaneously, in atomized form, in the optical analysis volume. This quasi-normalized absorbance would be different in any analysis volume having a different cross-sectional area. This dependence upon the cross-sectional area can be revealed in Beer's Law.

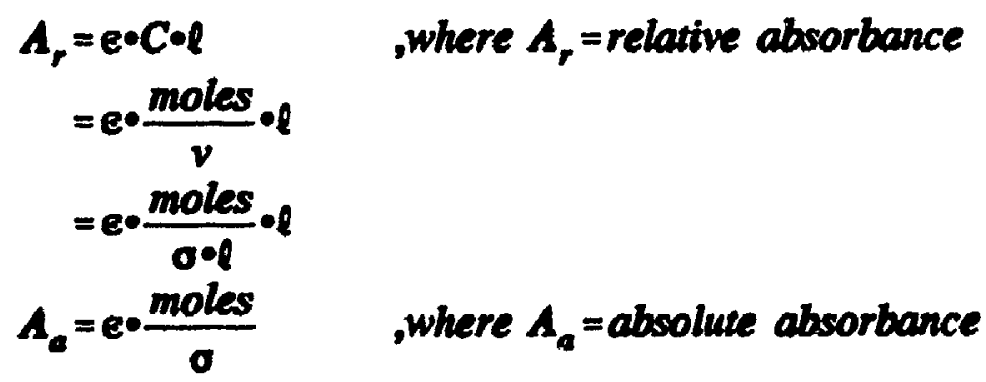

Clearly, an instantaneous absorbance, which Beer's law describes, is directly proportional to the length of the absorption cell in the relative sense of absorbance, $A_{r}$, 
but is inversely proportional to the cross-sectional area of the analysis cell in the absolute sensc of absorbance $A_{a}$. Therefore, to obtain an absorbance measure independent of the absorption cell cross-sectional area, the absorbance above, $A_{N(\tau)}$, normalized for the atom residence time, must be multiplied by the absorption cell cross-sectional area $\left(\sigma=0.38 \mathrm{~cm}^{2}\right)$.

$$
\begin{aligned}
A_{N(r, 0)} & =A_{N(r)} \times 0 \\
& =0.1 \times 0.38 \mathrm{~cm}^{2} \\
& =0.038 \mathrm{~cm}^{2}
\end{aligned}
$$

Figure 4.2 attempts to reconcile two points, concerning the effect of varying absorbance cell dimansions on the absorbance signal, using an illustrative model. The first point is that the integrated absorbance may be different for absorbance cells of different dimensions even though the atom number, $\mathrm{N}$, is the same. The second point is, in the absolute sense, if absorbance is directly proportional to atom number, and Beer's law naively suggests this is true, then a signal should be reportable, even from the integrated case, that would be the same for all four cases cited.

Four absorbance cells are sketched in section A of Figure 4.2 with varied flow rates $(f)$, cross-sectional areas $(\sigma)$, lengths $(\ell)$, and volumes $(v)$ listed in section B. Section C lists the integrated absorbance that would be observed in each cell, for the continuous sampling of some number of atoms, $N$, from an infinitely large reservoir of analyte concentration C. When integration begins it is assumed that the absorbance cell is already filled with analyte at concentration $\mathrm{C}$. Consider that, in case 1 , the integrated absorbance is 1.0 Aes for sampling $\mathrm{N}$ atoms, which, at $2.0 \mathrm{~L} \cdot \mathrm{min}^{-1}$, takes one second to sample. The instantaneous relative absorbance at any time is 1.0 . In case 2 , the time for 
Case 1

Case 2

Casc 3

Case 4

A
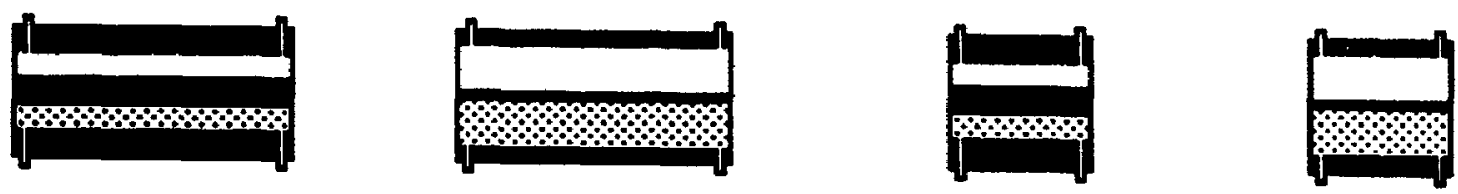

B Carrier gas flow rate / Lomin ${ }^{-1}$

2

2

2

1

Cross-sectional area $(\sigma) / \mathrm{cm}^{2}$

1

2

1

2

Length (0) $/ \mathrm{cm}$

20

20

10

I0

Volume (v) $/ \mathrm{cm}^{3}$

20

40

10

20)

C Integrated Absorbance $\left(Q_{N}\right) / \mathrm{s}$

1.0

1.0

0.5

I.)

D Flow atom residence time ( $\tau$ ). $(\tau=v / f) / s$

0.6

1.2

0.3

1.2

$E$ Absorbance normalized only for $\tau\left(A_{N(\tau)}\right),\left(A_{N(\tau)}=Q_{A} / \tau\right) /$ unitless

1.67

0.83

1.67

0.83

F Absorbance normalized for both $\tau$ and $\sigma\left(A_{N(\tau, \sigma)}\right),\left(A_{N(\tau, \sigma)}=Q_{A} \times \sigma / \tau\right) / \mathrm{cm}^{2}$

1.67

1.67

1.67

1.67

Figure 4.2 Illustrative model for integrated signals in analysis cells of different optical analysis dimensions 
sampling $\mathrm{N}$ atoms is the same, $1.0 \mathrm{~s}$, because the flow rate is the same. The unchanging instantancous relative absorbance over that time is the same because: the cell length is the same, the concentration is the same, and of course the atomic extinction coefficient remains unchanged. Therefore case 2 should give an integrated absorbance of $1.0 \mathrm{~A} \cdot \mathrm{s}$ for $\mathbf{N}$ atoms. In case 3, the time for sampling of $\mathrm{N}$ atoms remains unchanged, but the length of the cell is one half of case 1 and 2. Therefore the instantaneous relative absorbance is one half of that compared to case 1 and 2 , and the integrated absorbance is 0.5 A.s. At $1.0 \mathrm{~L} \cdot \mathrm{min}^{-1 .}$ for case 4, the sampling time for $\mathrm{N}$ atoms would be twice that compared to cases 1,2 and 3 . The instantaneous relative absorbance would be 0.5 , as for case 3, and the integrated absorbance would then be $1.0 \mathrm{~A}$-s.

Once the integrated signals of section $\mathrm{C}$ are normalized for their atom residence times, section D, quasi-normalized absorbance values are reported in section E. Fully normalized absorbances, section $F$, are obtained by multiplying the quasi-normalized absorbance values by their respective analysis cell cross-sectional areas. These normalized integrated absorbances are now all identical and have unts $\mathrm{cm}^{2}$.

In summary, the overall procedure for the normalization of integrated absorbance signals with respect to both the atom residence time and the analysis cell dimensions takes the following form:

$$
A_{N(\tau, 0)}=\frac{Q_{A} \times 0}{\tau}
$$




\section{CONCLUSIONS}

Methodology and some advantages of reporting integrated absorbance•time signals as normalized measures are described. Although applied specifically to CVMAA, other atomic absorption techniques may benefit from this alternative method for signal reporting. 


\section{CHAPTER 5}

\section{EXPERIMENTALLY VERIFIED NORMALIZED ABSORBANCE}

\section{INTRODUCTION}

The idea of a normalized absorbance suggests that there is a measure of light absorption, having units of $\mathrm{cm}^{2}$, which is independent of both the mean atom residence time and the absorption cell cross-sectional area. This measure is only dependent upon the number of atoms and the spectral characteristics of both the light source ant the absorbing atoms. Provided the source emission line is much narrower than the absorption profile and the absorption coefficient $k_{v}$ does not change significantly across the profile of the emission line, then this measure should also be independent of the spectral characteristics of the spectrometer $[25,58]$. This latter condition is not always optimized and very few laboratories are equipped with monochrometers of sufficiently high resolution for evaluating the overlap of the source atomic emission resonance line profile and the analyte atomic absorption resonance line profile. This deficiency will be revealed by using a normalized absorbance. This measure may be obtained from either an instantaneous absorbance or from an integrated absorbance. Signals must be normalized to be able to compare the spectral integrity of different instruments like a cold-vapor atomic absorption spectrometer and a graphite furnace atomic absorption spectrometer. This is done in the following chapter. 
The atom residence time, $\tau$, like in graphite furnace atomic absorption spectrometry, is the mean length of time spent by atoms in the analysis volume. The absorption cell cross-sectional $\operatorname{arc}:, \sigma$, is the area of the cross-section of the absorption cell where light enters the cell, filling that cross-section.

In response to referees* comments ${ }^{*}$ to parts of Chapter 4 of this thesis, experimental work has been performed to confirm their main objection; that, "the residence time is not a simple function of gas flow rate and volume." This is simply not true. The referees were concerned that "there are significant diffusion, condensation and adsorption effects which contribute, and which the authors' model ignores." This chapter shows that these effects are insignificant.

The goal of this chapter is to provide experimental evidence to show that the atom residence time, $\tau$, is a simple function of the flow rate, $f$, and the analysis volume, $v$. The atom residence time is defined, like in GFAAS, as the mean length of time spent by atoms in the optical analysis volume. $\tau=\frac{v}{f}$

The integrated transient absorbance has been known and used since the early works of Livov [25], but its physical meaningfulness appears to have been overlooked. If Equation 5.2 helow, given by L'vov [25], is true, then the absorbance, $A_{o}{ }^{\dagger t}$, should remained unchanged for the quantity $Q_{\wedge} / \tau$, for any value of $\tau$.

\footnotetext{
FThe Analyst. paper number $9 / 03165 \mathrm{~K}$, referee $\mathrm{A}$ and $\mathrm{B}$

${ }^{t+} 1$;vov doxs not define this variable in his text of reference [25], but he clearly means the absorbance that would cccur for all analyte atoms in the sample, $N_{0}$ defined as an absorbance normalized for $\tau, A_{N(\tau)}$ in (hapter 4 of this text.
} 


$$
Q_{A}=A_{0} \cdot \tau
$$

If Equation 5.1 above accurately describes the atom residence time, then a plot of $\mathrm{A}_{w}$ versus $\tau$ should be a horizontal line for a constant number of analyte atoms.

Once a normalized absorbance value is obtained with a high degree of accuracy, then mercury-vapor syringe injection may be used as a highly sensitive technique for measuring gas flow rates in closed systems.

\section{EXPERIMENTAL SECTION}

Mercury vapor syringe injection [59] was used as a source of atomic vapor. Simple ideal gas law calculations ${ }^{\dagger}$ give the mass of mercury in saturated mercury vapor $[6(0)]$. A plot showing the variation of vapor concentration with temperature is shown in Appendix I. The measurement of absorbance cell adsurption was performed by placing the two absorbance cells in series where the second cell served as the measurement sell for the amount of adsorption occurring in the first. The difference between the integrated

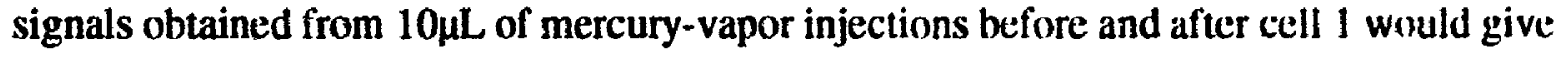
the fraction or percent adsorption on the first cell. Alternating the cell positions would give adsorption data for the second cell.

The careful and exact measurement of the carrier gas flow rate is crucial (I) experimentally verifying that the normalized absorbance does not vary with the flow rate. The digital flow meter used (Matheson 0-2000 standard ${\mathrm{mL} \cdot \mathrm{min}^{-1}}^{-1}$ model $8111-(1423$ ) was

\footnotetext{
4 A Van der Waais gas law calculation is not significantly different when evaluated to 4 significant figures $\left(a=8.093 f^{2} \cdot a t m \cdot m^{-2}, b=0.01696 \mathrm{~mol}^{-1}, \rho_{\mathrm{Hg}^{\mathrm{g}}}(243.15 \mathrm{~K})=0.001201 \mathrm{~mm} \mathrm{Hg}\right)$
} 
calibrated against a $1.2 \mathrm{~L}(5.0 \mathrm{~cm}$ internal diameter) capacity bubble meter. Figure 5.1 shows the closed system that was used to ensure that there were no leaks in the apparatus that would result in erroneous flow rates from the digital flow meter. Any leak into the closed system B resulted in the displacement of water in the inverted graduated cylinder from bubbles leaving the inverted test-tube. The downward displacement of the water was calibrated to measure the leak rate. Alternatively, with the leak calibrator (shown

schematically as \#5) removed from the system, and maintaining a closed system by joining the exhaust from the pump (\#9) directly to the spectrometer (\#6), spraying the connections with mercury vapor, one at a time, and watching for an absorbance deflection on the spectrometer, identified the site of the leak.

Further details of the experimental method are presented in Chapter 2.

\section{RESULTS AND DISCUSSION}

A two-fold argument is necessary for justifying the validity of a normalized measure of absorbance that is independent of $\tau$ and $\sigma$. First, experimental evidence must show that $Q_{A(t, \pi)}$ does not vary with changing flow rates, then it must be demonstrated that $Q_{\text {A(r.o) }}$ d(xss not change with varied analysis volume cross-sectional area.

\section{ATOM RESIDENCE TIME, $\tau$}

The only error that could occur in the calculation of the atom residence time, from Eluation 5.1 above, would be if atoms were lost to the surface of the absorption cell, or if conditions prevailed allowing atoms to contribute to the integrated absorbance a greater 
A)

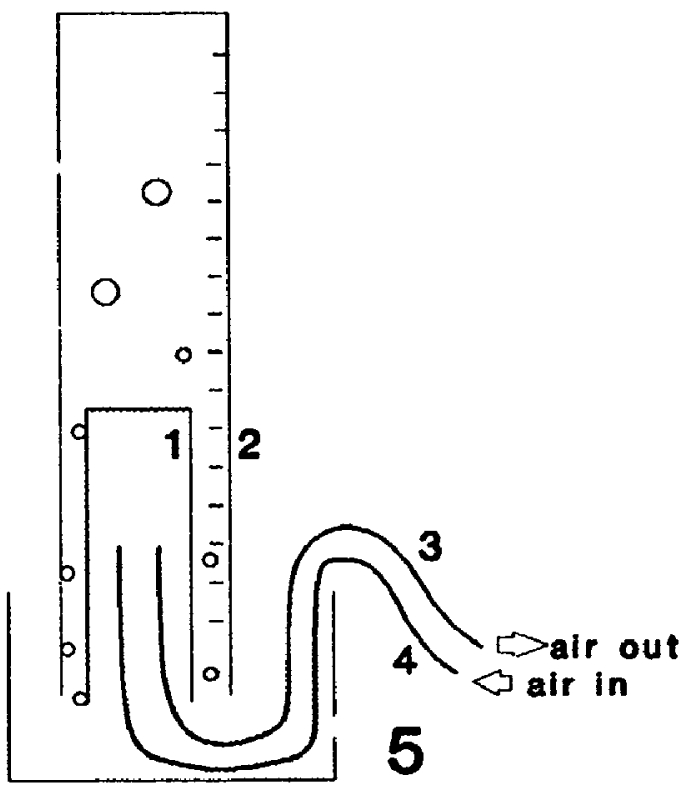

B)

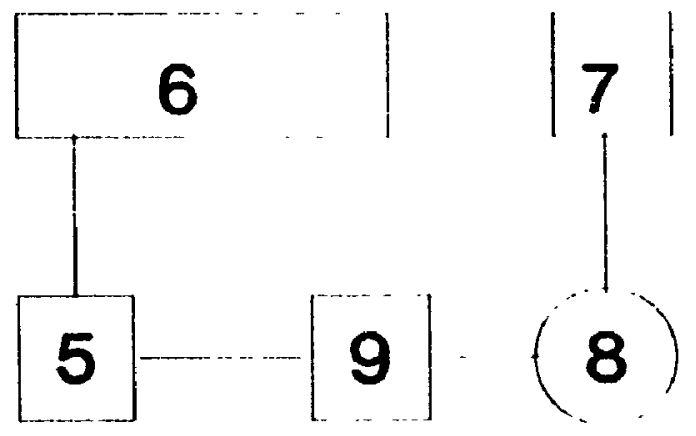

Figure 5.1 Closed system used to calibrate leak rate and find source of leaks. A) leak calibrator; $1,20 \times 200 \mathrm{~mL}$ test-lube; 2 , inverted $500 \mathrm{~mL}$ graduated cylinder; 3, tube connection to spectrometer; 4. tube connection from pump exhaust, B) closed system; 5, leak calibrator; 6, spectrometer; 7, digital flow meter; 8 , rotameter flow controller; 9 , pump inlet 
number of times than determined by the flow rate. Results are presented in Table 5.1 showing the percentage loss due to absorption cell adsorption for two different absorbance cells. Absorption cell 1 , an old cell used for more than 10 years, displayed too large adsorptional losses, at low flow rates, for use in normalized absorbance measurements. Cell 2, less than three years old yielded no appreciable loss at any flow rate, and was adequate for performing normalized absorbance measurements. Assuming isotropic

Table 5.1 Mercury adsorption in absorption cells for $10 \mu \mathrm{L}$ saturated mercuryvapor at $21^{\circ} \mathrm{C},\left(\overline{\mathrm{x}}_{5}, \pm\right.$ S.D. $)$

\begin{tabular}{lll} 
I.low Rate/ & Absorption Cell \#1 & Absorption Cell \#2 \\
(ml $\left.\cdot \mathrm{min}^{-1}\right)$ & Loss/(\%) & Loss/(\%) \\
50 & $40 \pm 6$ & $6 \pm 5$ \\
I(X) & $25 \pm 2$ & $5 \pm 2$ \\
150 & $22 \pm 3$ & $1 \pm 2$ \\
$2(x)$ & $15 \pm 3$ & $4 \pm 3$ \\
$4(X)$ & $5 \pm 3$ & $0 \pm 2$ \\
$6(x)$ & $4 \pm 2$ & $1 \pm 5$ \\
$8(x)$ & $7 \pm 1$ & $0 \pm 3$ \\
\hline
\end{tabular}

diffusion ofvapor, which is a reasonable assumption when there is no measurable adsorptional loss occurring, there should be no radial concentration gradient that would permit diffusion towards the slower moving boundary region nearer the surface of the absorbance cell.

Figure 5.2 shows how transients are broader at lower carrier gas flow rates due to the longer atom residence times. The decreased peak heights, at higher flow rates, are due to the atom residence time approaching the time required for plunging the syringe. The time required for plunging the syringe is not an easily measurable quantity, but is

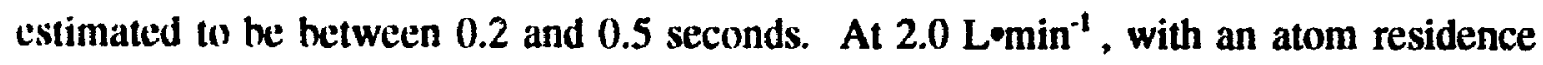




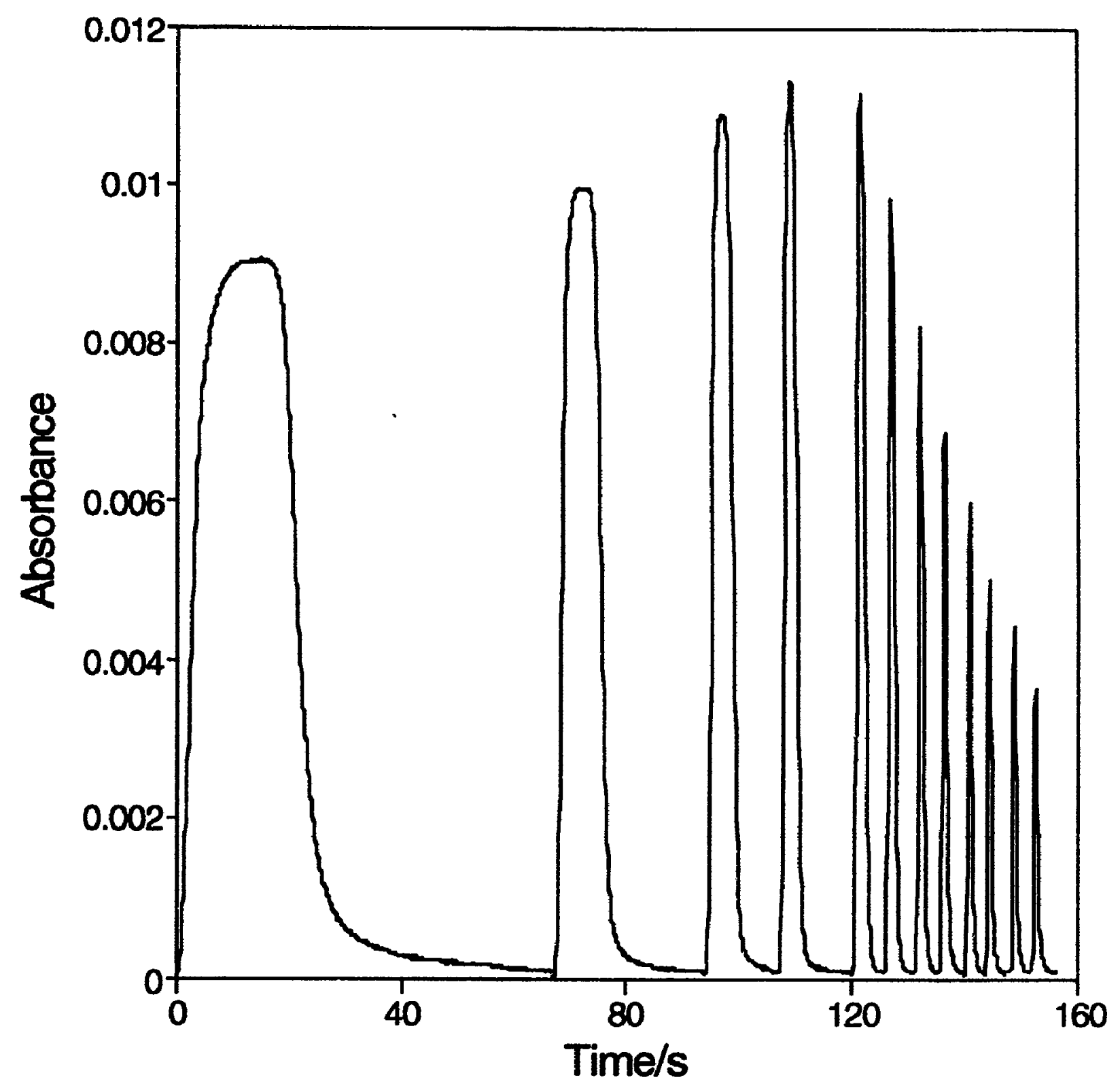

Figure 5.2 Absorbance transients for $10 \mu \mathrm{L}$ of mercury vapor at $21^{\circ} \mathrm{C}$. From left to right, flow rates $\left.\left(\mathrm{mL} \mathrm{min}^{-1}\right): 47,97,167,267,397,607,837,11\right) 67$, 1267,1537 , and 1947 
time of 0.33 seconds in a $0.0111 \mathrm{~L}$ optical analysis volume, a 0.5 second syringe plunge time would mean that the first atoms entering the analysis volume would have left the observation zone before the last atoms from the syringe enter the analysis volume. Consequently the peak height ahcorbance would decrease at higher flow rates as illustrated in Figure 5.2.

Figure 5.3 is a plot of the fully normalized absorbance, $Q_{A(\tau, \sigma) \text {, and the integrated }}$ absorbance, $Q_{A}$, as a function of flow rates. The normalized absorbance for the aliquot of mercury used, approximately $0.162 \mathrm{ng}$, appears to be decreasing slightly with increased flow rates. Data was collected with replicates of 5 starting with the lowest flow rates. This apparent trend may be attributed to repeated injections, from lower to higher flow rates, that:

1) cumulatively degrade the ability of the micro-liter syringe to deliver its full capacity, as small air particulates slowly plug the narrow bore of the needle, and

2) decrease the concentration of mercury-vapor in the small volume of the, "saturated," reservoir [61].

To be certain that this trend was not due to errors in the method used for calculating atom residence times (Equation. 5.1), data was collected with attention to minimizing the number of injections, so as to reduce the effects of points 1 and 2 above. Table 5.2 shows that the same normalized signal can be obtained at 100,200 and $1930 \mathrm{~mL}^{-} \mathrm{min}^{-1}$. Further, this also confirms the validity of this simple method used to calculate atom residence times. 


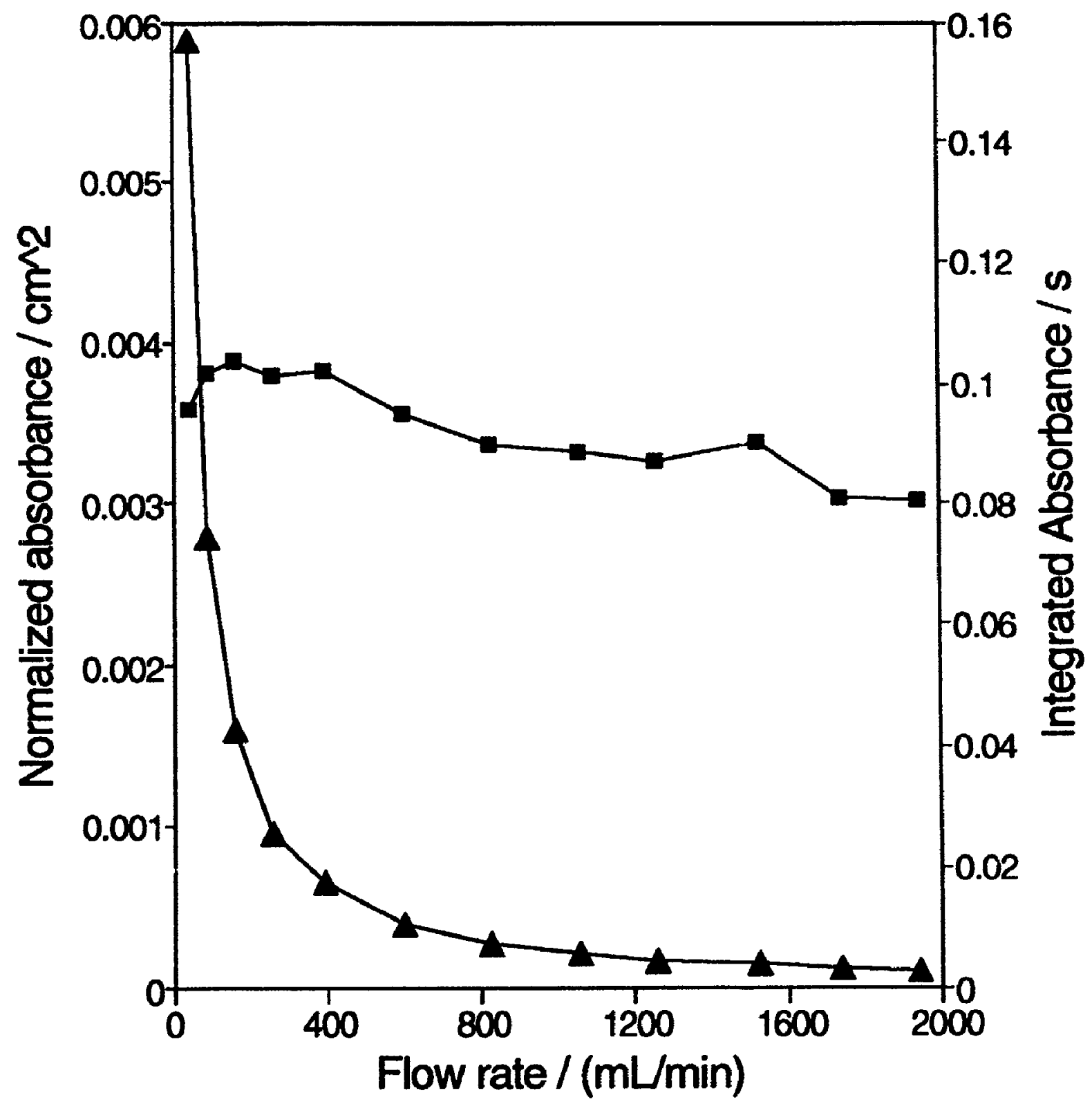

Figure 5.3 Dependence of the Normalized absorbance( $\square$ ) and the integrated absorbance $(\Delta)$ on flow rate, for $0.162 \mathrm{ng}$ of mercury from $10 \mu \mathrm{L}$ of saturated mercury-vapor at $22.5^{\circ} \mathrm{C}$ 
Table 5.2 Variation of $Q_{\text {A(r.o) }},\left(\bar{x}_{5}, \pm S . D.\right)$, with flow rate

\begin{tabular}{|c|c|}
\hline $\begin{array}{l}\text { 1.]ow rate / } \\
\text { ml.omin-1 } \\
\text { I(x) } \\
2(x) \\
1930\end{array}$ & $\begin{array}{l}Q_{\text {Ar(o) }^{\prime}} l \\
\mathrm{~cm}^{2} \\
0.00285 \pm 0.00004 \\
0.00274 \pm 0.00005 \\
0.00298 \pm 0.00012\end{array}$ \\
\hline
\end{tabular}

\section{ANALYSIS VOLUME CROSS-SECTIONAL AREA, $\sigma$}

L'vov has already reported work that investigates the effect of varied analysis cell cross-sectional areas on the absorbance signal in a graphite cuvette [25]. The first three columns of Table 5.3 are form this work in which absorbance values are reported for cadmium, measured at $228.8 \mathrm{~nm}$. L'vov was aware of the apparent variable analytical

Table 5.3 Relationship of sensitivity to cuvette cross-sectional area

\begin{tabular}{llll}
\hline$\sigma /\left(\mathrm{cm}^{2}\right)$ & $10^{10}$ mass $/ \mathrm{g}$ & Absorbance & Absorbance/(cm $\left.{ }^{2} \bullet \mathrm{ng}^{-1}\right)$ \\
0.75 & 5 & 0.73 & 1.10 \\
0.36 & 2.25 & 0.78 & 1.26 \\
0.18 & 1.25 & 0.75 & 1.08 \\
\hline
\end{tabular}

sensitivity upon the cuvette cross-sectional area, but no analytical figure of merit has yet been widely accepted to reflect this variable of instrumental sensitivity. The fourth column of Table 5.3 has been added to demonstrate that absorbance signals may be normalized with respect to cross-sectional areas to provide identical signals, for identical numbers of analyte atoms. Deviations in this column are assumed to be due to measurement error. 


\section{CONCLUSIONS}

It has now been demonstrated that normalized measures of absorhance can he reported. These measures are independent of the flow rate that determines $\tau$ in tlow systems like CVMAAS, and are also independent of the optical analysis cross-iectional area. The next two chapters will first, develop an analytical figure of merit, taking this normalized measure into account, then proceed with an application of this figure of merit by comparing mercury signals from cold-vapor atomic absorption spectrometry and graphite furnace atomic absorption spectrometry. 


\section{CHAPTER 6}

\section{A NORMALIZED CHARACTERISTIC MASS FOR ATOMIC ABSORPTION SPECTROMETRY AND ITS APPLICATION IN ABSOLUTE ANALYSIS}

The current definition of characteristic mass, is a mass, $\left(m_{\mathrm{o}}\right)$, of analyle, which, when atomized, produces an integrated absorbance signal equivalent to 0.(1)44 A-s. In the past, however, the characteristic mass was reported from the peak height mode wherehy it is the mass resulting in a peak height absorbance of 0.0044. Both these definitions are lacking in universality insofar as the atom residence time, the cross-sectional area of the measurement volume, and units are concemed. A more universal definition is herein proposed that is more characteristic of the element and less characteristic of the atomization conditions and measurement system. It is not the aim here to replace the currently well established characteristic mass, but rather this normalized measure is intended to enhance analytical communications. By adopting a normalized characteristic mass, absolute methods are used to compare the spectrometric sensitivities of two different instruments towards mercury: a graphite furnace atomic absorption spectrometer (GFAAS), and a cold-vapor atomic absorption spectrometer (CVAAS).

\section{INTRODUCTION}

Analytical atomic spectroscopy has come a long way since Walsh's first work in this area [62], yet his repeated mention to absolute analysis has been slow in bearing fruit over the past thirty-five years. De Galen defines absolute analysis as the technique of 
determining the amount of an element without previous establishment of a working curve [63]. This is accomplished in emission or absorption mode, although more reproducible in the latter, by prior knowledge of certain characteristic constants of the clement and of the measurement system. Some of the malaise where absolute analysis is concerned may be attributed to past shortsightedness in rigorously evaluating characteristic masses. A characteristic mass would be of greater analytical utility if it could convey not only overall sensitivity towards the analyte, but if it could also reflect scparately, the instrumental and the experimental sensitivity.

Not until a comparison of two different measurement systems is made, GFAAS and CVAAS, are shortcomings underlying the currently well documented and accepted characteristic mass $[25,55,64,65,66,67]$ realized. The expression, characteristic mass, was once synonymous with the term sensitivity: the solution concentration of an element that yields an atomic absorption of $1 \%$ [68]. IUPAC has recommended the. "characturistic," terminology so that the term, "sensitivity," can be reserved for numbers that increase as the sensitivity improves [66]. The terms absolute sensitivity [25], characteristic amount [69], characteristic concentration [64], and characteristic mass $[66 \mid$ have all been created in mind of the same end: absolute analysis.

If the characteristic mass is re-evaluated with greater attention to making the figure of merit more characteristic of the analyte and the mass, and less characteristic of the experimental conditions, then some advantages of such an approach are listed below:

1) hetween instrument and interlaboratory comparison of instrumental and 
experimental sensitivity.

2) the ability to evaluate instrumental sensitivity (optics). independent of the experimental sensitivity, and

3) standardless calibration.

The difference between instrumental and experimental sensitivity lies in the parameters used to define each. Experimental sensitivity is determined hy those variahles that an experimentalist may most easily normalize the absorbance signal; namely, the atom residence time, and the detector size factor [70]. The atom residence time is the mean length of time spent by atoms in the optical path of the spectrometer, and the detector size factor is the cross-sectional area of acceptance of the analysis volume.

\section{THEORY}

\section{ABSORBANCE}

Categorizing different types of absorbance measarements is an essential step in introducing new measures of absorbance. Table 6.1 summarizes five measures of absorbance.

An instantaneous relative absorbance, $A_{r}$, perhaps the most common, is a simple logarithmic measure of light attenuation as a function of the solution concentration and the length of the absorbing solution in the analysis cross-section. The instantaneous absolute absorbance, $A_{a}$, has a subtle difference from $A_{r}$. The former is a function of analyte number in the optical path of any leng ${ }^{t h}$ and cross-section $\sigma$, while the latter is 
Table 6.1 Types of absorbance

\begin{tabular}{|c|c|c|c|}
\hline Type & Symbol & Units & Kelationship \\
\hline I. Instantaiesous' relative & A & none & $A=\varepsilon C$ \\
\hline 2. Instantaneous absislute & $A_{a}$ & none & $A_{2}=\varepsilon N / \sigma$ \\
\hline 3. Integrated & $Q_{\Lambda}$ & $s^{ \pm}$ & $Q_{\Lambda}=\int A d t$ \\
\hline 4. Normadized Instantaneous & $A_{N(\sigma)}$ & $\mathrm{cm}^{2}$ & $A_{N(\sigma)}=A \cdot \sigma$ \\
\hline 5. Nombalized integrated & $A_{N(x, 0)}$ & $\mathrm{cm}^{2}$ & $A_{M(t, \sigma)}=\sigma / \tau \int \mathrm{Adt}$ \\
\hline
\end{tabular}

a function of analyte solution concentration in any cross-section of length $\ell$.

The integrated absorbance, $Q_{A}$, is simply a product of the $A_{2}$ and $\tau$. Longer mean atom residence times: diffusion atom residence times (DART), and flow atomi residence times (FART), result in larger integrated absorbances. This point has been made clear in Chapter 5.

The normalized instantaneous and normalized integrated absorbances have been introduced in preceding chapters. These two absorbance types will be the focus of two new figures of merit.

\section{CHARACTERISTIC MASS}

Before proposing the new figures of merit, normalized characteristic masses, a review of the currently existing characteristic mass would be useful. The literature is replete with disregard for the significant difference between peak height and peak area evaluations of

\footnotetext{
† The term instantaneus is used, over static, because many absorbance measurements are made for mon-static systems.

F (Mten written as $A \cdot s$. hut it is understurd that $A$ is unitless
} 
the characteristic mass $[66,71,72,73,74]$. The peak height characteristic mass, mass $0.0044 \mathrm{~A}$, cannot be directly compared to the peak area characteristic mass. mass/0.0044 A-s, as in references [73] and [74]. This crror also resulted in crroneous statements about incr ased absolute sensitivity of integration methods over peak height methods. These two evaluations must he treated separatcly.

\section{Peak Height Characteristic Mass, $m_{\mathrm{oN}+\mathrm{o}}$}

The current peak height definition of characteristic mass, $m_{c,}$ the mass of analyte necessary to produce an absorbance of 0.0044 (1\% light absurption), is worthy of comment on two points. First, the selection of $1 \%$ absorption was purely arbitrary. The second point is that the mass responsible for this absorbance is not just characteristic of the analyte, which this author believes was the initial intention of those proposing the above definition. Rather, the characteristic mass is also characteristic of the absorbance cell cross-sectional area, $\sigma$.

In response to this dependence of the characteristic mass on $\sigma$, the following normalized-instantaneous, or normalized peak-height characteristic mass is proposed.

The normalized-ilsstantaneous, or nomalized peak-height characteristic mass is the mass, $\mathrm{m}_{\mathrm{oN}(\mathrm{o})}$ required to produce a normalized instantaneous absorbarice. $A_{\mathrm{N}(0)}$ of $0.0044 \mathrm{~cm}^{2}$.

Absorbance signals must be the normalized instantaneous type, $A_{N(\sigma)}$. Therefore, instantaneous absorbances must be multiplied by the cross-sectional area of the light beam, and peak-height characteristic masses vill give an absorbance of $0.0044 \mathrm{~cm}^{2}$. The physical meaning of a peak-height normalized characteristic mass is: the mass of analyte 
52

required to produce $1 \%$ absorption or an instantaneous absorbance of 0.0044 in a cell whose cross-sectional area is $1 \mathrm{~cm}^{2}$.

\section{Peak Arta Characteristic Mass, $m_{o N(\tau, \sigma)}$}

The current definition of the peak area characteristic mass, $m_{0}$, the mass required to produce an absorbance of $0.0044 \mathrm{~s}$, has two serious problems. First, like in the instantaneous, or peak-height case, the absorbance is characteristic of the light path crosssectional area. Second, the absorbance is also characteristic of the atom residence time. The following definition is proposed to provide a characteristic mass that is characteristic of the element and its mass - not dependent upon $\sigma$ and $\tau$.

\footnotetext{
The normalized peak-area, of integrated-normalized, characteristic mass is the mass, $m_{\mathrm{o}(\tau, \sigma)}$ required to produce a normalized integrated absorbance, $A_{\mathrm{N}(\tau, o)}$ of $0 .(x) 44 \mathrm{~cm}^{2}$.
}

The physical meaning of an integrated-normalized characteristic mass is: the mass of analyte required to produce $1 \%$ absorption or an instantaneous absorbance of 0.0044 in a cell whose cross-sectional area is $1.0 \mathrm{~cm}^{2}$.

Table 6.2 summarizes some values for characteristic masses for mercury by various lechniques, according to the non-normalized definitions of characteristic mass. Peak height characteristic masses vary considerably as a consequence of a wide variety of atomization efficiencies for the different techniques. 
Table 6.2 Characteristic Masses for Mercury

\begin{tabular}{|c|c|c|c|}
\hline Technique & $\begin{array}{l}\text { Peak Height } \\
\mathrm{m}_{\mathrm{oP} . \mathrm{H}} /(\mathrm{pg} / 0.0044 \mathrm{~A})\end{array}$ & $\begin{array}{l}\text { Peak Area } \\
\mathrm{m}_{\mathrm{uP}} /(\mathrm{pg} /(0.0(144 \Lambda \cdot \mathrm{s})\end{array}$ & Reference \\
\hline $\mathrm{HGA}^{*}$ wall & 150 & & Perkin Limer, 1981 \\
\hline $\mathbf{Z A A S}^{\mathbf{b}}$ & 210 & & Perkin EImer. 1981 \\
\hline STPF & 150 & & Perkin l:Imer, 1981 \\
\hline STPF & & 52 & 55 \\
\hline STPF & & 69) & 71 \\
\hline GPFA $^{d}$ & & 55 & $i$ \\
\hline CVAA & 917 & & this work \\
\hline MVSIAA & 84 & & this work \\
\hline
\end{tabular}

"Heated Graphite Atomizer, model 500 (HGA" is a registered trademark of the l'erkin limker (orpuratiun) Zeeman Atomic Absorption Spectrometer. model 5000

'Stabilized Temperature Platform Atomization

${ }^{\circ}$ Graphite Probe Furnace Atomization, refers to atomization frum a graphite probe following direct inserttens intu, a heated graphite furnace $(1800 \mathrm{~K})$. under stopped flow conditions.

'calculated at $1000 \mathrm{~mL} \cdot \mathrm{min}^{-2}$

\section{EXPERIMENTAL SECTION}

Three spectrometers were evaluated for their sensitivities lowards mercury: a Laboratory Data Control UV Monitor ${ }^{\text {tw }}$ model 1235, a Milton Roy UV Monitor ${ }^{\text {tw }}$ D fixed wavelength detector modified for CVAAS by insertion of a $30 \mathrm{~cm}$ absorbance cell, and a Perkin Elmer model 5000 graphite furnace atomic absorption spectrometer modified for probe atomization.

\section{RESULTS AND DISCUSSION}

\section{COMPARING CVMAA, MVSIAA AND GPFA}

A typical probe GPFA transient is shown for $1.5 \mathrm{ng}$ of mercury in Figure 6.1. An

The data are quoted with the compliments of Dr. Mahiba Shocib, a pust-dictural fellow from Dr. C.L. Chakrabarti's laboratory, Carleton University, Department of (hemistry, 1\%(). 
overlay plot of $\ln$ (absorbance) versus time is added. The slope of this line, $\tau^{-1}$, gives an estimate of the atom residence time, where atom loss is attributed solely to diffusional processes, i.c., exponential decay (see Appendix II). In contrast, for CVAAS, the flow atum residence time, FART, is calculated by the method presented in Chapter 5. Typical absorbance transients are shown in Figure 6.2 for mercury vapor syringe injection atomic absurption, MVSIAA, atd chemical reduction by CVMAA.

Table 6.3 summarizes the results for absorbance transients collected for the atomic absorption of mercury by CVMAA, MVSIAA(two spectrometers, UVD and UVM), and GPFA. The normalized characteristic mass now makes it possible to compare sensitivities between the cald-vapor and graphite furnace techniques. Direct injection of atomic vapor gives slightly better sensitivity (approximately 15\%) than by chemical reduction because of losses that occur in transport from the reaction vessel to the absorbance cell. The integrated signals obtained from the direct injection of vapor at port 1 (Figure 6.3), compared to injection at port 2 , result in $13 \pm 3 \%\left(\bar{x}_{s}, \pm\right.$ S.D. $)$ which agrees well with the difference in instrumental sensitivity, $\left(\mathrm{m}_{\mathrm{oN}(\tau, \sigma)}\right) 15 \%$, between MVSIAA(UVD) and CVMAA(UVD) reported in Table 6.3. The reason for the significant difference between the MVSIAA(UVM) normalized characteristic mass and the three other characteristic masses lies in the poor optical design of the UVM spectrometer discussed in Chapter 10. 


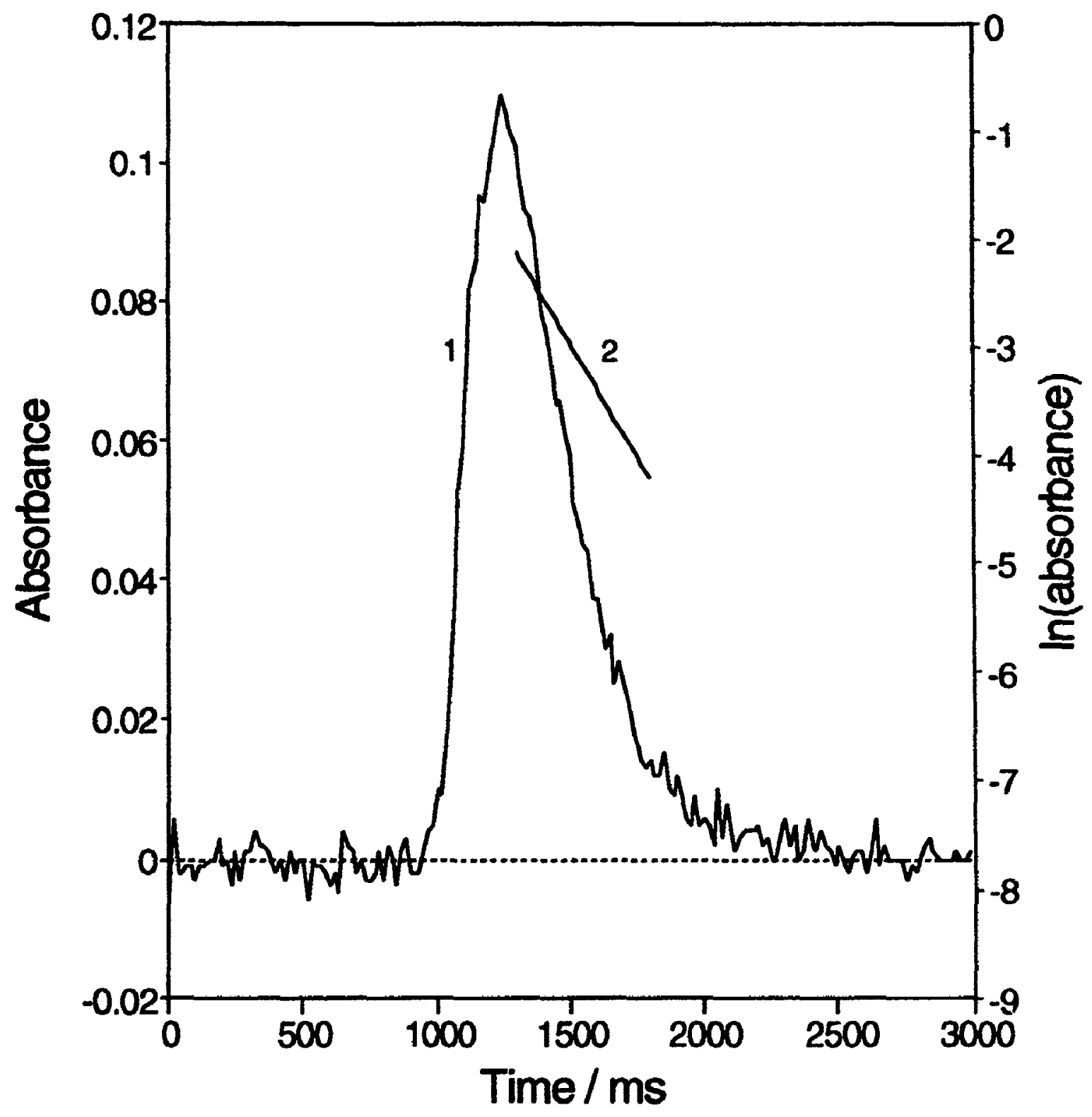

Figure 6.1 Typical graphite probe furnace atomization transient (1) for $1.5 \mathrm{ng}$ of mercury, and a linear least squares plot (2) of In(absorbance) versus time between 1.3 and $1.8 \mathrm{~s}$ 


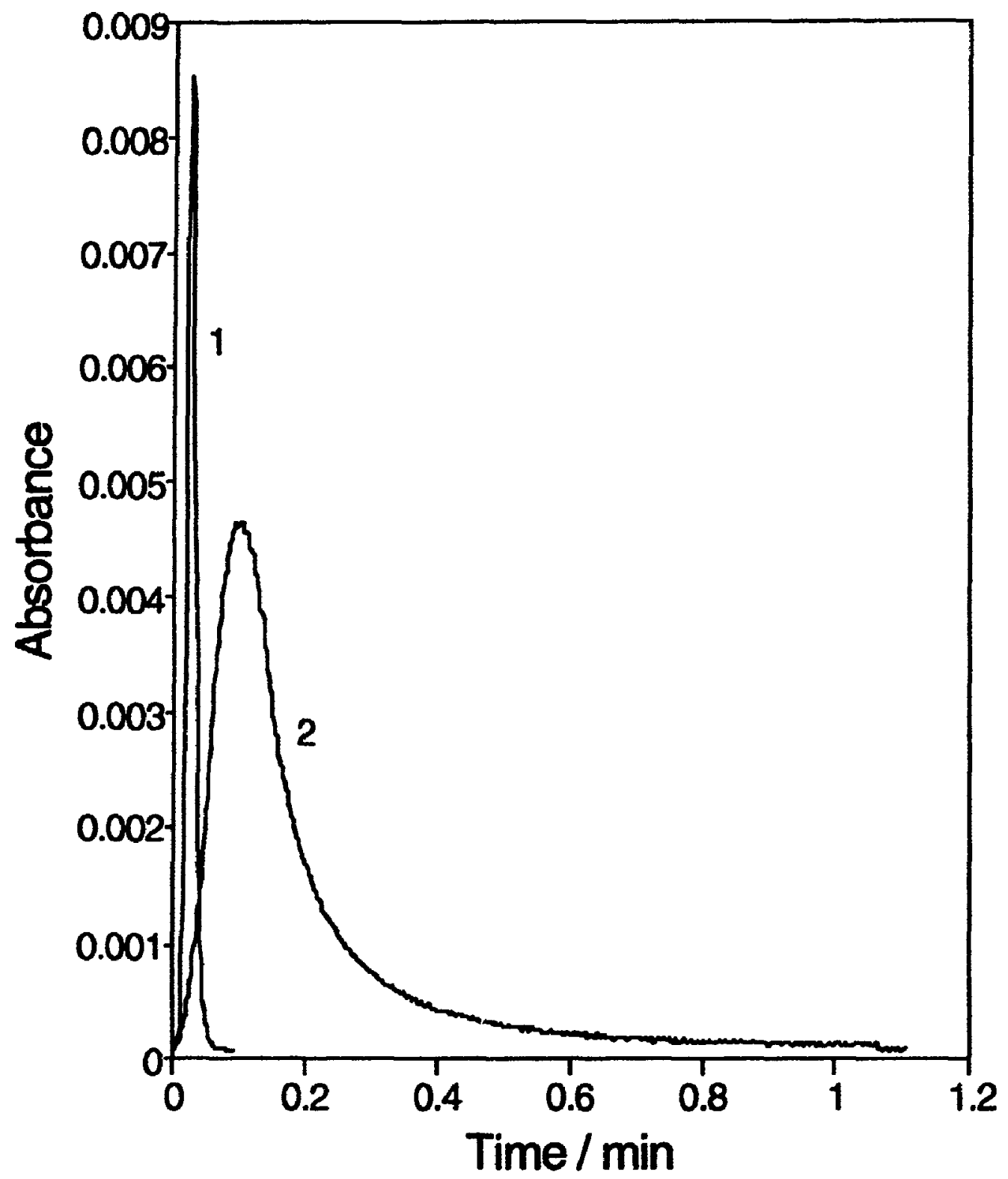

Figure 6.2 Comparison of (1) mercury-vapor syringe injection transient $(10 \mu \mathrm{L}$ at $\left.21.8^{\circ} \mathrm{C} \approx 0.153 \mathrm{ng}\right)$ and $(2)$ a chemically reduced transient $(1.0 \mathrm{ng}$ $\mathrm{Hg}^{2+}$ ), both recorded at $1000 \mathrm{~mL} \cdot \mathrm{min}-1$, detector response time $0.1 \mathrm{~s}$, and $10 \mathrm{~Hz}$ acquisition frequency 
Table 6.3 Data for experimental absorbance transients by CVMAA, MVSIAA. and GPFA

\begin{tabular}{|c|c|c|c|c|}
\hline & CVMAA(UVD) & MVSIAA(IVI])) & MVSIAA(IIVM) & (ilP'A" \\
\hline mass/ng Hg & 1.0 & 0.14 & 0.153 & 1.5 \\
\hline $\begin{array}{l}\text { optical cell } \\
\text { cross-sectional } \\
\text { area, } \sigma / \mathrm{cm}^{2}\end{array}$ & 0.38 & 0.38 & 0.38 & $0.1 \% 6$ \\
\hline $\begin{array}{l}\text { atom residence } \\
\text { time, } \tau / s\end{array}$ & 0.67 & 0.67 & 3.3 & 0.24 \\
\hline $\begin{array}{c}\text { absorbance }(\bar{x}, \pm \text { S.D. }) \\
\text { peak height, A }\end{array}$ & $\begin{array}{l}0.0048 \\
\pm .0001\end{array}$ & $\begin{array}{l}0.0080 \\
\pm .0004\end{array}$ & $\begin{array}{l}0 .(X X) 4) \\
\pm .(X \times(x) 1\end{array}$ & $\begin{array}{l}0.114 \\
\pm .(01.3\end{array}$ \\
\hline peak area, $Q_{\mathrm{A}} / \mathrm{s}$ & $\begin{array}{l}0.050 \\
\pm .001\end{array}$ & $\begin{array}{l}0.0088 \\
\pm .0005\end{array}$ & $\begin{array}{l}0.0167 \\
\pm .0 \times 1 \times 5)\end{array}$ & $\begin{array}{l}0 .(144) 1 \\
\pm .(1) 18\end{array}$ \\
\hline $\begin{array}{l}\text { normalized absorbance } \\
\mathbf{A}_{\mathbb{N}_{(t, 0,0} / \mathrm{cm}^{2}}\end{array}$ & 0.028 & 0.0050 & $0 .(440)$ & 0.1441 \\
\hline $\begin{array}{l}\text { normalized characteris } \\
m_{\mathrm{oN}(\mathrm{t}, \mathrm{S})} /\left(\mathrm{cm}^{2} \circ \mathrm{ng}^{-1}\right)\end{array}$ & 0.028 & 0.033 & 0.013 & $0.0 \div 7$ \\
\hline
\end{tabular}

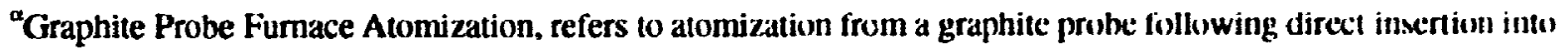
a heated graphite furnace $(1800 \mathrm{~K})$, under stopped flow conditions. 


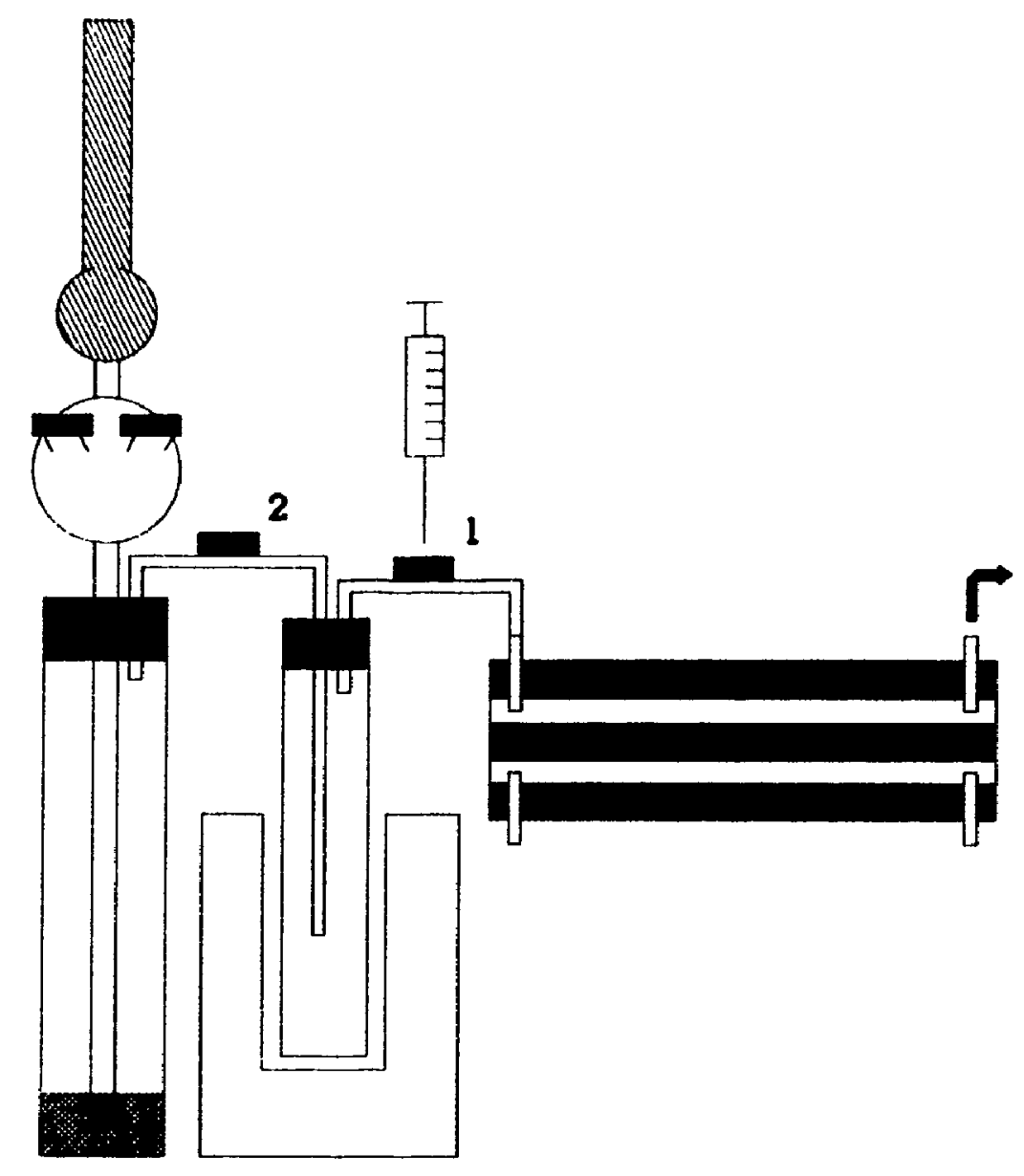

Figure 6.3

Cold-vapor atomic absorption set-up showing injection ports 1 and 2 


\section{CONCLUSIONS}

Before the development of the normalized absorbance, an analytical figure of merit did not permit the evaluation of instrumental-spectrometric sensitivity separately from experimental sensitivity. Only by the evaluation of the former can an analyst compare spectrometric sensitivity between instruments.

An important conclusion of this chapter is the message revealed in the fact that three measurements of normalized characteristic masses, of Table 6.3, are nearly identical. This observation points to the fact that, finally we have a figure of merit that is indeed more characteristic of the element and its mass alone. 


\section{CHAPTER 7}

\section{GAS PHASE ADSORPTIONAL LOSSES OF $\mathrm{Hg}^{\circ}$ IN COLD-VAPOR ATOMIC ABSORPTION SPECTROMETRY}

It is clear that the experimental application of a "normalized absorbance" for the purpose of standardless calibration in cold-vapor atomic ahsorption spectrometry fior mercury would be hindered by adsorptional losses of the trace analyte from the carrier gas. In order to minimize these losses, surface adsorption has been evaluated for 14 types of tubing using syringe injection of mercury-vapor. This chapter reports these tindings

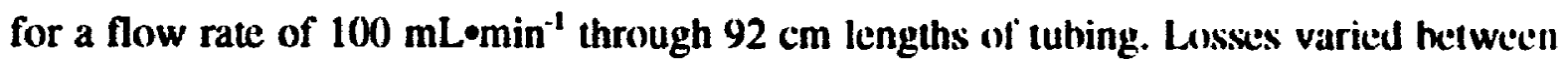
undetectable for nickel tubing and 100 percent for Silastic.

\section{INTRODUCTION}

The cold-vapor atomic absorption method for the determination of mercury, introduced by Poluektov and Vitkun [75], exploited by Hatch and (Ot) [35], and relined by Magos [29], has gained wide popularity owing to its high sensitivity, casce of automation. and inexpense in both design and use. Mercury-vapor syringe injection calibration, first introduced by Dumarey et al. [59], has recently been automated [76]. This calibration technique facilitates adsorption studies by allowing the introduction of trace atomic mercury-vapor at any point along a carrier gas flow syster. The literature is replete with research concerning solution phase adsorption of various forms of ionic mercury. In contrast, no work appears to have been reported on the gas phase adsorption of elemental 
mercury towards various tubing types. From the site of production of el.mental mercury (1) the measurement point, it is desirable (1) minimize the amount of mercury lost by adsorption on the delivery tubing. Further, from the point of view of absolute determination and standardless calibration, the amount of analyte lost must he nondetectable or known.

The amount of mercury lost in a segment of tubing is a function of its length, internal diameter, the gas flow rate, and its inherent sticking probability. The sticking probability incorporates the porosity of the tuhing.

\section{EXPERIMENTAL SECTION}

Detuils of the tubing used are listed in Table 7.1. The study evaluating the atom loss dependence on tubing type used $92 \mathrm{~cm}$ lengths of tubing while the later study investigating the effect of tubing diameter on atom loss used $3.7 \mathrm{~m}$ lengths of latex tuhing. Other details may be found in Chapter 2.

\section{APPARATUS}

A Laboratory Data Control/Milton Roy UVD $253.7 \mathrm{~nm}$ spectrometer was used for measuring the integrated absorbance signals. The fluid flow cell from the UVD monitor was removed and the detector was fixed to the end of a $30 \mathrm{~cm}$ double beam gas flow cell. Data accuisition was performed using a Jones Chromatography 6000 data system.

The experimental selup is illustrated in Figure 7.1. Using a $10 \mu \mathrm{L}$ gas-tight syringe (Hamilton, 1801RN-3), $10 \mu \mathrm{L} \mathrm{Hg}^{\circ}$ vapor (21-23 ${ }^{\circ} \mathrm{C}$, approx. $0.14 \mathrm{ng}$ ) injections were 
Table 7.1 $\mathbf{H g}^{\circ}$ adsorptional losses in different types of tubing

\begin{tabular}{|c|c|c|c|c|}
\hline TUBING & l.d.(mm) & SUPPLIER & Cat. No. & $\operatorname{Loss}(\%)^{\prime}$ \\
\hline Silastic & 6.4 & Canadawide Scientific & $9416-31)$ & $I(x)$ \\
\hline Neoprenet & 9.5 & Canadawide Scientific & $9417-12$ & $14+3$ \\
\hline Nalgene $^{c}$ & 6.4 & Canadawide Scientific & $0448-1 K_{1}$ & 29) \pm 4 \\
\hline Tygon(Plastic) & 4.8 & Canadawide Scientific & $9436 \cdot 14$ & $2(1 \pm 2$ \\
\hline \multirow[t]{4}{*}{ Latex ${ }^{d}$} & 3.2 & Fisher & $14-1512-5 \Lambda$ & \\
\hline & 4.8 & Fisher & $|4-151-5|$ & \\
\hline & 6.4 & Fisher & $14-178-50^{\circ}$ & $42 \pm 1$ \\
\hline & 7.9 & Fisher & $14-15(1-51)$ & \\
\hline Teflon(PTFE) & 6.4 & Chemplast Inc.. N.J. & & $3 \pm 3$ \\
\hline Polypropylene & 4.8 & Chemplast Inc. & & $9_{ \pm 5}$ \\
\hline PVC & 6.4 & Chemplast Inc. & & $20 \pm 2$ \\
\hline Low Density & 4.8 & Chemplast Inc. & & $2(1) \pm 1$ \\
\hline \multicolumn{5}{|c|}{ Polyethylene (LDPE) } \\
\hline Nylon(black) & 4.8 & Chemplast Inc. & & $8 \pm 2$ \\
\hline Quartz & 6.4 & Corning & 221944 & $3 \pm 4$ \\
\hline Pyrex & 6.4 & Coming & 234900 & $1 \pm 2$ \\
\hline Nickel & 5.4 & Chromatugraphic Specialties & $(49340)$ & $(1) \pm 2$ \\
\hline Stainless Steel & 6.4 & Chromatographic Specialties & $(49) 325$ & $64 \pm 2$ \\
\hline
\end{tabular}

Dow Coming. silicone elastomer

synthetic rubber

polyurethane, no plasticizer

natural. amber. sulphur and taic free

(mean \pm S.D. $n=3$ )

made by alternately injecting between port 1 and port 2 in triplicate. The mercury-vapor was housed in a septum-sealed $25 \mathrm{~mL}$ volumetric flask containing $5 \mathrm{~mL}$ of elemental mercury. To minimize the temperature-sensitive fluctuations of the vapor pressure 1, i mercury, the volumetric flask was partially immersed in water contained in a double insulated $200 \mathrm{~mL}$ beaker. 

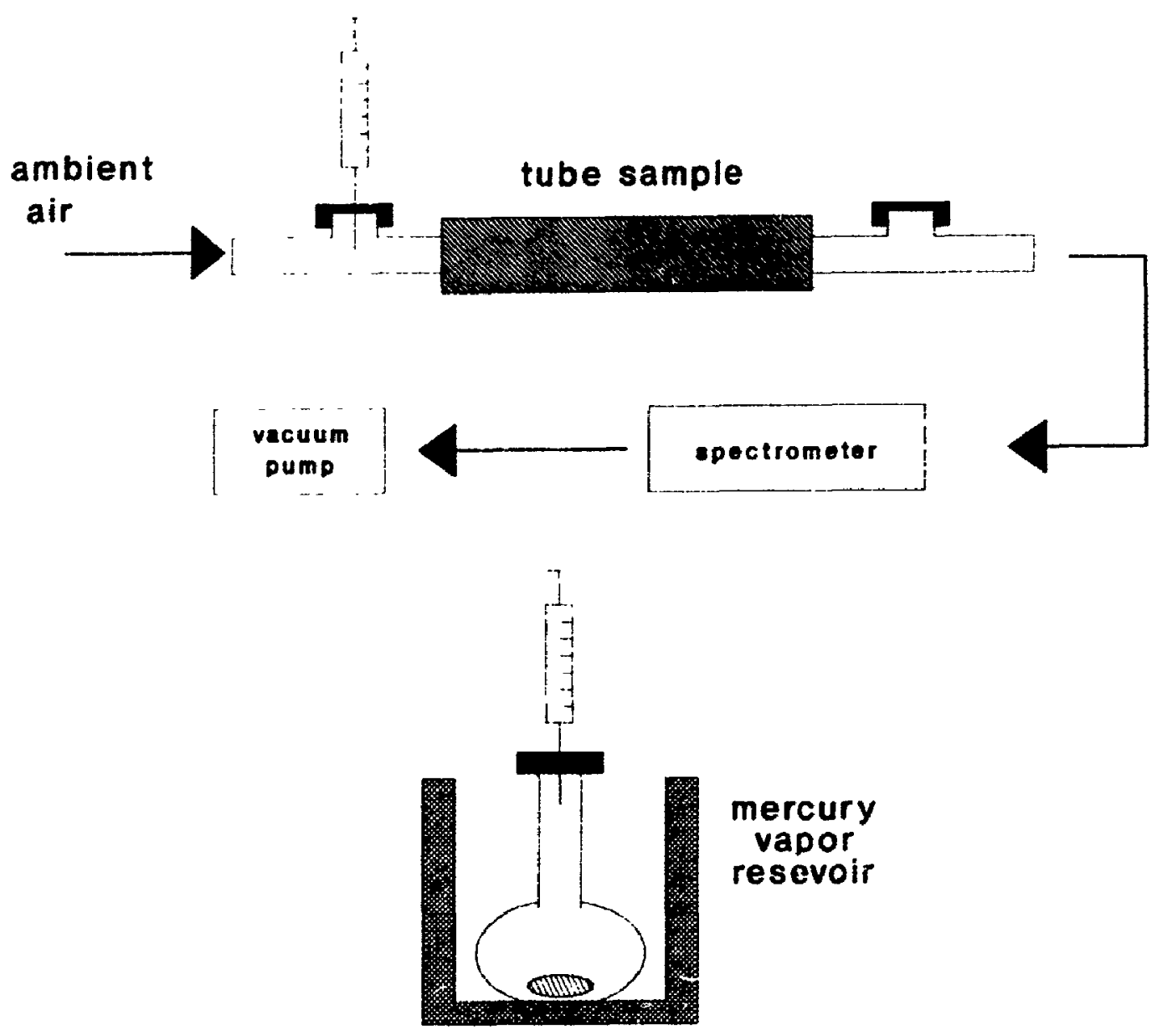

Figure 7.1 Schematic diagram of setup used for the production, delivery, and measurement of adsorptional losses of trace mercury-vapor in tubing samples 


\section{RESULTS AND DISCUSSION}

For $100 \mathrm{~mL}^{\circ} \mathrm{min}^{-1}$ flow rates and $92 \mathrm{~cm}$ lengths of tuhing, the tuhe adsorptional losse's of elemental mercury for 14 types of tubing are given in Table 7.1. Clearly nickel tuhing is the best, but pyrex, teflon(PTFE), and quartz are close rivals. None of these materials possesses the necessary physical properties for forming airtight seals necessary in cold. vapor atomic absorption spectrometry (CVAAS). Latex tubing forms the hest airtight sial and is very flexible. Although a strong adsorhent, latex used at junctions to bridge piecess of nickel, pyrex, teflon, or quartz tubing is effective in minimizing loss of analyle.

Verv surprising was the observation of total analyte loss for silastic tubing. This Dow Corning, silicone elastomer tubing, is advertised as being a non-adherent offering excellent flow characteristics due to resistance to sticking. Insofar as flow of atomic mercury-vapor is concerned, this claim was not substantiated by the data presented herein.

\section{TUBE DIMENSIONS}

In addition to the type of tubing, other factors that affect atom loss include: i)tuhe length( $(\ell)$, ii)flow rate(f), and iii)tube diameter(d). For purposes of minimising losse: during atom transport, clearly a short length and a high flow rate are desirable. Experimental flow rates were all in the laminar flow domain. Once experimental conditions have dictated a certain flow rate and tubing length, the selection of a tubing diameter is not so clear. The tube diameter affects two factors that influence the probability of a surface interaction; the tube surface to volume ratio $(\mathrm{s} / \mathrm{v})$ and the atom residence time $(\tau)$. A small surface to volume ratio and a short atom residence time are desirable to minimize atom loss. Atom loss to the tubing surface is some function $J(\tau)$, 
and $\tau$ varies with the square of the diameter (Equation 7.1 ), while in the case of the surface to volume ratio the loss is some function $J^{\prime}\left(d^{-1}\right)$ (Equation 7.2). Thus, as the tube diameter is increased, $\tau$ becomes detrimental, whereas the $s / v$ factor becomes beneficial,

$$
\begin{aligned}
& \text { lass }=J(\tau)=J\left(\frac{\pi l}{4 f} d^{2}\right) \\
& \text { loss }=J^{\prime}\left(\frac{s}{v}\right)=J^{\prime}\left(\frac{4}{d}\right)
\end{aligned}
$$

and vice versa. The question must therefore be asked: which is more important in contribution to atom loss: a)the atom residence time, or b)the surface to volume ratio? Figure 7.2 supports the former since increased loss of atoms occurs experimentally by increasing the tube diameter. This figure also reveals increasing sensitivity to atom loss as a function of diameter with decreasing flow rates.

\section{CONCLUSIONS}

The careful selection of mass transport conditions are necessary to ensure maximized throughput of trace analyte in a carrier gas. Analyte loss will be kept to a minimum if the smallest tube diameter the shortest length, and the highest flow rate possible are used. The following chapter will present a mathematical model that will add greater justification (1) these suggestions for minimizing analyte loss. This finding shouid prove useful to chemists in the selection of tubing diameters joining tandem instruments(eg. GC-AAS), or merely bridging stages of a single instrument like in MCVAAS. 


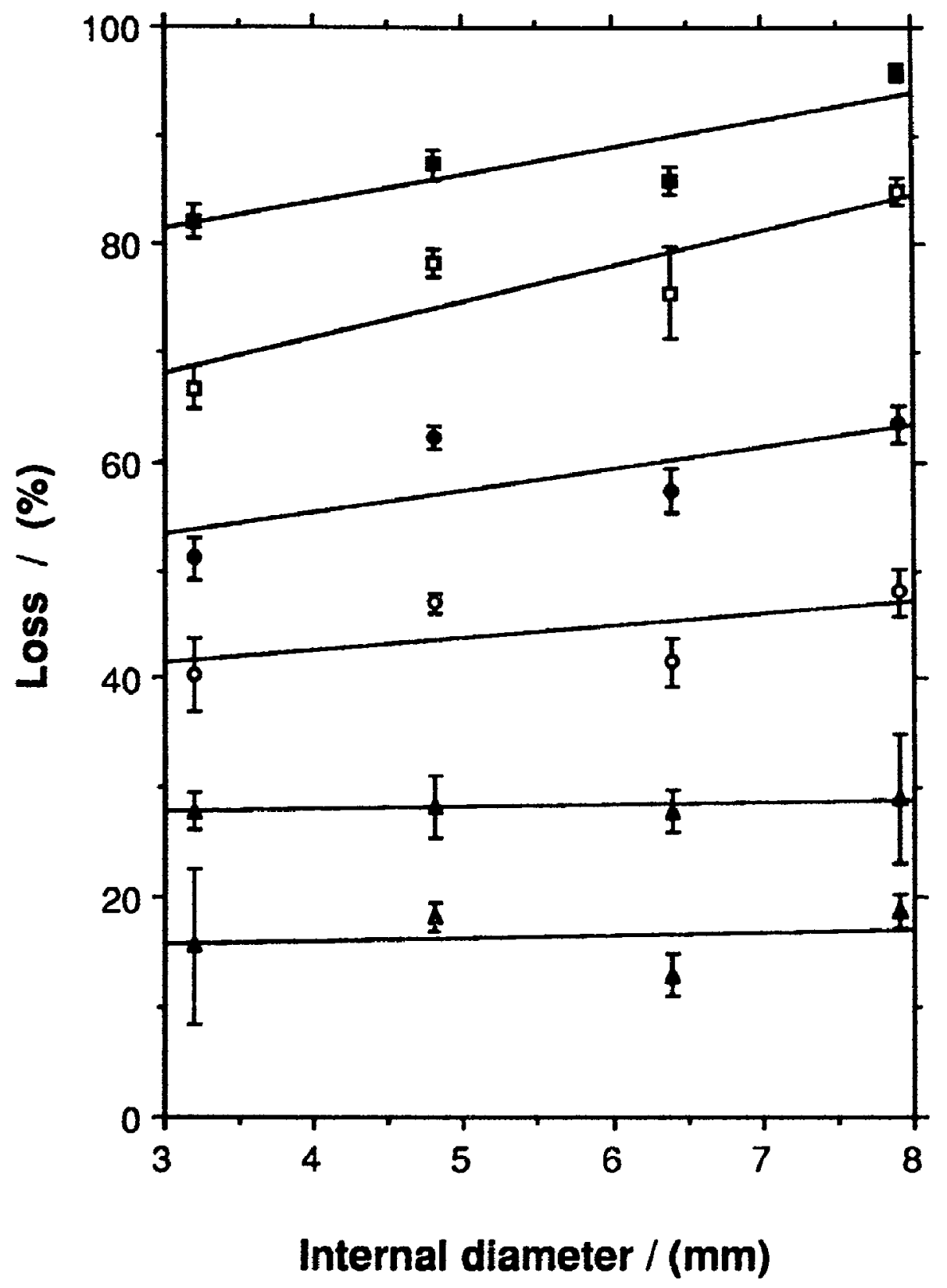

Figure 7.2

Influence of tube radius on trace analyte loss by surface adsorption. Flow rate (mLemin $\left.\left.\left.{ }^{-1}\right): \square 50, \square 100,0200\right), 05(0), \Delta 100(0), \Delta 150\right)$ 


\section{CHAPTER 8}

\section{MATHEMATICAL MODELLING OF ATOM LOSS IN DELIVERY TUBING}

\section{INTRODUCTION}

The substance of this chapter !es in a single question; that is, for a given standard flow rate of a carrier gas containing a trace analyte, which is the hest for minimizing analyte loss to the surface of the delivery tubing: a small diameter tuhe, a large diameler tube, or is there an optimum diameter? ${ }^{\ddagger}$

Cold-vapor atomic absorption spectrometry, electrothermal vaporization-atomic emission, and gas chromatography-graphite furnace atomic ahsorption share onc thing in common: the transport of trace molecular or atomic vapor through delivery tubing. To ensure optimum analytical sensitivity, it is necessary to provide conditions (o minimize analyte loss due to surface interactions along the walls of the delivery tubing. Chapter 7 addressed the question of tubing type and optimum tubing diameter from an experimental standpoint. Due to a limited number of available tubing diameters for testing in the previous chapter, it was felt that a mathematical model of atom loss in tubing, particularly as a function of tubing diameter and tlow rate, would add further justification to the trends observed for the diameters tested. In addition, this model wo'sld permit predictions

\footnotetext{
F There is an analogous question, and an apparent lack of a scientific answer for this question pertaitming to minimizing the heat loss during the transport of a warm gas through optimum piping diameters.
} 
heyond the scope of readily available tubing diameters.

Presentation of the model will take on two parts: a simple intuitive approach will be given, part 1; then followed by a more detailed model of atom loss, part II.

\section{RESULTS AND DISCUSSION}

\section{Part I: A SIMPLIFIED PERSPECTIVE OF ATOM LOSS}

Consider a segment of tubing of length $\ell(\mathrm{cm})$, diameter $\mathrm{d}(\mathrm{cm})$, standard flow rate $f^{\prime}\left(\mathrm{mL} \cdot \mathrm{min}^{-1}\right)$, volume $v\left(\mathrm{~cm}^{3}\right)$, and internal surface area, $\mathrm{s}\left(\mathrm{cm}^{2}\right)$. As a plug of vapor traverses the length of the tube there there is some function $\mathrm{h}$, describing atom loss, that depends on the atom residence time $\tau(\mathrm{sec})$, and the tube surface to volume ratio $\mathrm{s} / \mathrm{v}$,

$$
\text { lass }=h(\tau, s / v)
$$

(Equation 8.1). It is not immediately clear how these two values will be a function of atom loss. but it is tempting to reason that an increased atom residence time, and or an increased surface to volume ratio, would result in increased atom loss. A longer atom residence time would give a higher probability of a surface adsorption, and the greater the amount of surface, the higher would be the probability of a surface interaction. A doubleY plot (Figure 8.1) shows how $\tau$ and $s / v$ vary with the tube diameter at a constant flow rate. If the loss function is an algebraic sum of the contributions from $\tau$ and $s / v$ (curve 3. a simplistic view, yet mathematically incorrect) then there would be a local minimum in the loss function versus tube radius. This will be shown to be incorrect. 


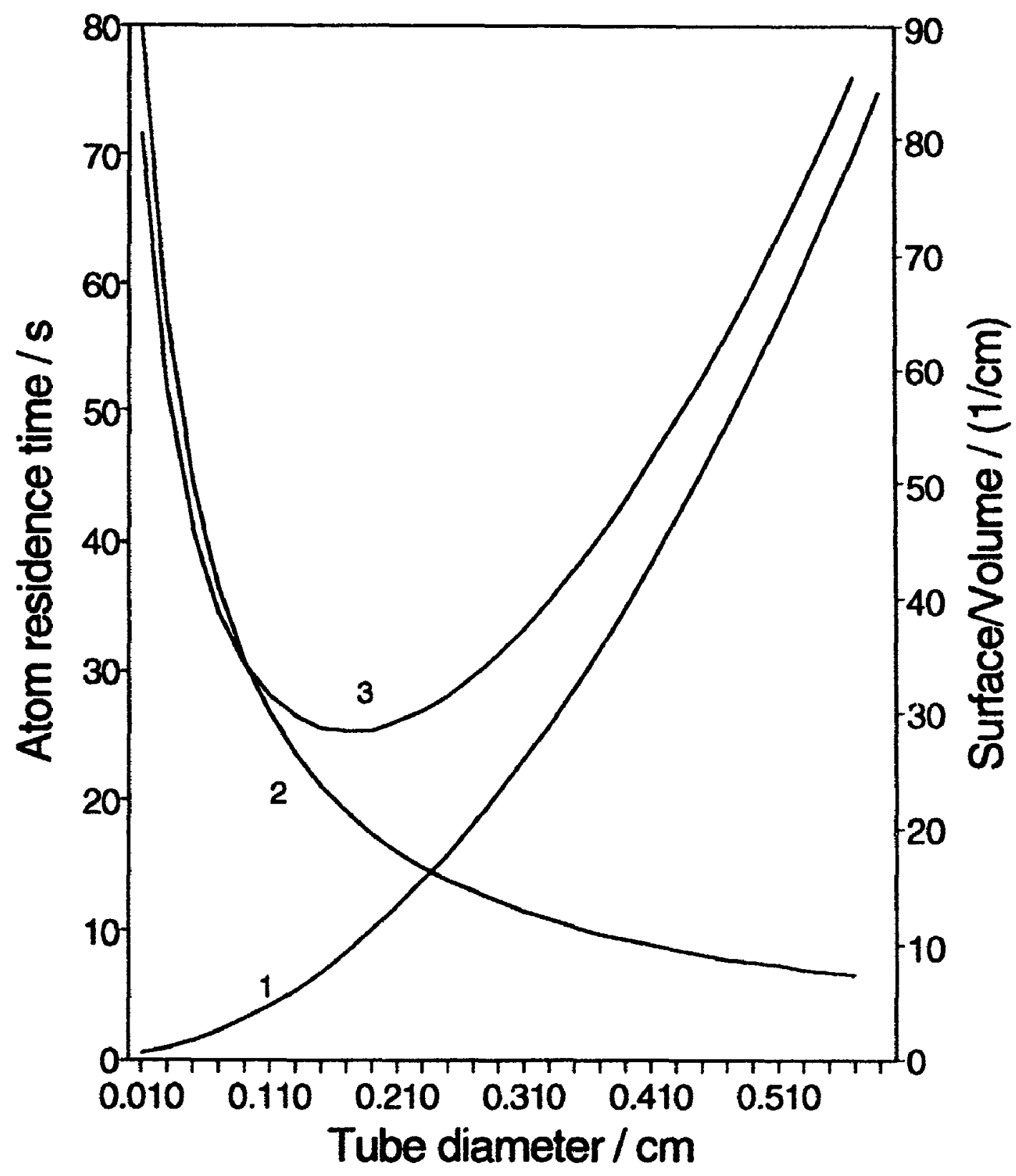

Figure 8.1

Variation of atom residence time, 1; surface (o volume ratio, 2; and their $\mathrm{sum}^{\dagger \dagger}, 3$, with tube diameter at 10() $\mathrm{mL}^{\circ} \mathrm{min}^{-1}$

${ }^{\dagger \dagger}$ arithmetically incorrect, but presented for illustrative purposes 


\section{Part II: A DETAILED MODEL OF ATOM LOSS}

The development of this detailed atom loss model entails a number of assumptions

listed helow:

1. $N_{0}$ mercury atoms are instantaneously injected into a flow of ambient nitrogen carrier gas such that the mercury atoms are evenly distributed across a plug volume of radius $r$ and length $x$.

2. In the time increment $1 / Z$, all atoms a distance $\lambda$ or less from the tube surface are lost to the tube wall. $Z$ is the collision frequency and $\lambda$ is the mean free path of mercury atoms with nitrogen molecules under ambient conditions. This assumption disregards the sticking probability $\rho$, and the kinetic geometry term, g. See Appendix IV.

3. No pressure drop occurs along the tube length, for all tube radii and flow rates omilting the Poisseuille pressure drop.

4. Following each $1 / Z$ increment, the remaining atoms instantaneously re-distribute themselves across the plug volume $v$.

5. No axial diffusional broadening of the plug occurs as it moves along the length of the tuhe.

6. There will exist a uniform non-parabolic velocity distribution along the tube crosssection.

7. The tube wall surface is ideal: no edaies.

x. Syringe injection produces a homogeneous disk distribution of mercury vapor in nitrogen.

9. Nitrogen, $\mathrm{N}_{2(\mathrm{~g})}$, and mercury, $\mathrm{Hg}_{(\mathrm{g})}^{\mathrm{o}}$, behave as ideal gases.

11. Flow is generated by draw from the atmosphere, through the tubing, to a vacuum pump.

11. The tuhe radius will not he less thas. the mean free path $\lambda$.

12. The tuhe wall is flat, not curved. See Appendix IV.

The philosophy adopted for developing this model has been to obtain a mathematical solution for the simplest case: making all the assumptions above, for model 1 , then, 
removing the assumptions sequentially until it is felt that there is sufficient agreement with experimental data. This outlook has resulted in three models presented in the order of making: 1)all the assumptions above, 2)assumptions 3-8 above, and 3)assumptions 4-8 above.

\section{MODEL 1}

The goal of model 1 is to obtain a mathematical expression for the ratio of the number of atoms lost at the tube surface to the number of atoms before any loss, N/N $\mathrm{N}_{w}$. The following notation will be used:

\begin{tabular}{|c|c|c|}
\hline Term & Symbol & Units \\
\hline carrier gas & $\mathbf{N}_{2}$ & \\
\hline viscosity & $\mu$ & $\mathrm{kg} \cdot \mathrm{m}^{-1} \cdot \mathrm{s}^{-1}$ \\
\hline flow rate & $f$ & $m^{3} \cdot s^{1}$ \\
\hline tube length & $e$ & $\mathrm{~m}$ \\
\hline tube radius & $r$ & $\mathbf{m}$ \\
\hline plug length & $x$ & $\mathrm{~m}$ \\
\hline plug volume & $v$ & $\mathrm{~m}^{3}$ \\
\hline $\begin{array}{l}\text { plug, atom residence time } \\
\text { mean free path of }\end{array}$ & $\tau$ & $s$ \\
\hline $\begin{array}{l}\mathrm{Hg}_{(\mathrm{g})}^{\circ} \text { in } \mathrm{N}_{2(\mathrm{~g})} \\
\text { collision frequency, }\end{array}$ & $\lambda$ & $\mathbf{m}$ \\
\hline $\mathrm{Hg}_{(\mathrm{g})}^{\circ}$ with $\mathrm{N}_{2(\mathrm{~g})}$ & $\mathbf{Z}$ & $\mathbf{s}$ \\
\hline
\end{tabular}

The total number of atoms lost is the sum of the number of atoms lost in each of $\eta$ time increments of $1 / Z$, where $\eta$ is the floor of the product of the collision frequency $Z$ and the plug residence time $\tau$. Table 8.1 lists the number of atoms lost to the tube wall, and

\footnotetext{
${ }^{\dagger}$ The floor operator $(\lfloor x\rfloor)$ takes the integer portion of its argument; for example, $\lfloor 3.7\rfloor=3$
} 
the number of atoms remaining, for each of the first four of $\eta, 1 / Z$ increments of time. The number of atoms lost in the first time increment of $1 / Z$ is the number of atoms contained in the rim of the disk whose thickness is $\lambda$, the mean free path of a mercury atom in nitrogen (approximately $45.7 \mathrm{~nm}$, for $20^{\circ} \mathrm{C}$ ), and whose length is $x$. This number is the product of the rim volume and the atom density.

Similarly, the number of atoms lost at the time $2 / Z$ is the product of the new atom density $\left(N_{0}, N_{0} K\right) / v$ and the rim volume. As shown in Table 8.1, this number is merely the product of the remaining number of atoms in the plug volume $\left(N_{0}-N_{0} K\right)$ and $K$, where $K$ is the ratio of the rim volume to the plug volume.

Table 8.1 Model 1: Incremental atom loss

Time Number of atoms lost, $\mathrm{N}$

0

\section{0}

$1 / 2 \quad$ atom density $\times$ rim volume

$$
\begin{aligned}
& \frac{N_{0}}{v}\left[x \pi\left(r^{2}-(r-\lambda)^{2}\right\}\right] \\
= & N_{0} K, \\
\text { where }\left[\frac{x \pi\left(r^{2}-(r-\lambda)^{2}\right]}{v}\right]= & K \\
= & \frac{\text { rim volume }}{\text { plug volume }}
\end{aligned}
$$

$2 / 2$

$$
N_{0} K(1-K)
$$

$3 / 2$

$$
N_{0} K(1-K)^{2}
$$

$4 / 2$

$$
N_{\sigma} K(1-K)^{3}
$$

Number of atoms remaining

$N_{0}$

$$
N_{0}(1-K)
$$

$$
\begin{aligned}
& N_{0}(1-K)^{2} \\
& N_{0}(1-K)^{3} \\
& N_{0}(1-K)^{4}
\end{aligned}
$$


The total number $\mathbf{N}$ of atoms lost is

$$
N_{0} K \sum_{n=0}^{n=n}(1-K)^{n}
$$

where

$$
\begin{aligned}
\eta & =\lfloor Z \times \tau\rfloor \\
& =\left\lfloor\frac{Z \pi r^{2}}{f}\right\rfloor .
\end{aligned}
$$

Summing the geometric series gives

$$
\begin{aligned}
\frac{N}{N_{0}} & =1-[1-K]^{n+1} \\
& =1-\left[1-\frac{x \pi\left\{r^{2}-(r-\lambda)^{2\}}\right.}{v}\right]^{n+1} \\
& =1-\left[1-\frac{\left(2 r \lambda-\lambda^{2}\right)}{r^{2}}\right]^{\left.\left(\frac{z \times\left(r^{2}\right.}{f}\right)+1\right),} \text { where } v=x \pi r^{2} .
\end{aligned}
$$

Figure 8.2 is a plot of the adsorptional loss, $N / N_{0}$, versus the log of the tube radius. This model, like the simplified view of Figure 8.1 , also predicts a local minimum in the loss function versus tube radius. In model 1 , increased tube length has two effects: a shift in optimum diameter to larger radii, and greater losses at all radii. 


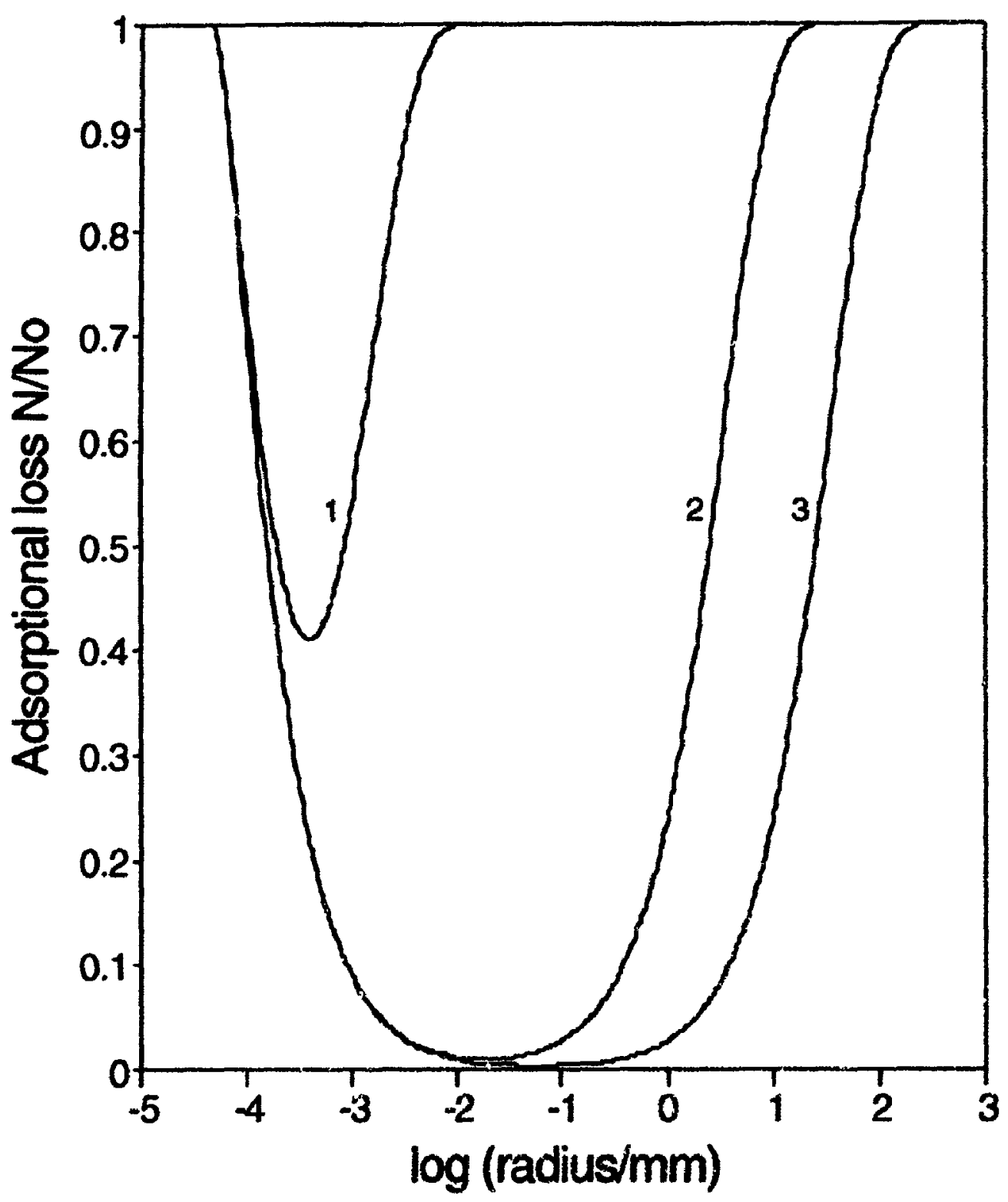

Figure 8.2 Atom loss model 1. Plot of $N / N_{0}$ versus $\log (t u b e$ radius) for 100 $\mathrm{mL}^{-m i n}{ }^{-1}$ and tube lengths/nm : $1,10^{-6} ; 2,400 ; 3,40$ 


\section{MODEL 2}

Model 2 corrects for the certainty that not every atton striking tube surface is lost. It aiso corrects for the fact, that not all atoms, at a distance $\lambda$ or less from the tub: wall. will have trajectories in the direction of the wall. The correction terms will be $\rho$ and g respectively. In fact, only $1 / 4$ of the atons within the distance $\lambda$ from the wall will strike the wall $(g=1 / 4$, Appendix IV). Table 8.2 is an update of Table 8.1 , taking inwo accoum the sticking probability $p$, and the geometry facior, g.

Table 8.2 Model 2: Incremental atom loss

Time Number of atoms lost, $\mathbf{N}$

$1 / 2 \quad g \rho \times$ atom density $\times$ rim wolume

$$
\operatorname{sp}_{=\rho N_{0} K}\left[x \pi\left(r^{2}-(r-\lambda)^{2}\right\}\right], \quad \text { where }\left[\frac{x \pi\left(r^{2}-(r-\lambda)^{2}\right\}}{v}\right]=K
$$

$2 / Z \quad g \rho N_{\phi} K(1-g \rho K)$

$3 / 2 \quad 8 p N_{\sigma} K(1-8 \rho K)^{2}$

$4 / Z \quad g \rho N_{0} K(1-8 \rho K)^{3}$

Summing the geometric series at in model 1 , and substitution of $1 / 4$ for g, gives

$$
\frac{N}{N_{0}}=1-\left[1-\frac{\rho\left(2 r i \cdot-\lambda^{2}\right)}{4 r^{2}}\right]^{\left(2 x t^{2}+1\right)}
$$

Figure 8.3 is a plot of the adsorptional loss, $N_{2} N_{0}$, versus the leg of the tube radius, fir $p$ values of $10^{-4}, 0^{2}$, and 1 . Like the previous model, this model also predicts the: existence of a local minimum in the loss functions of Figure 8.3 at radii of $7.6 \lambda$. 

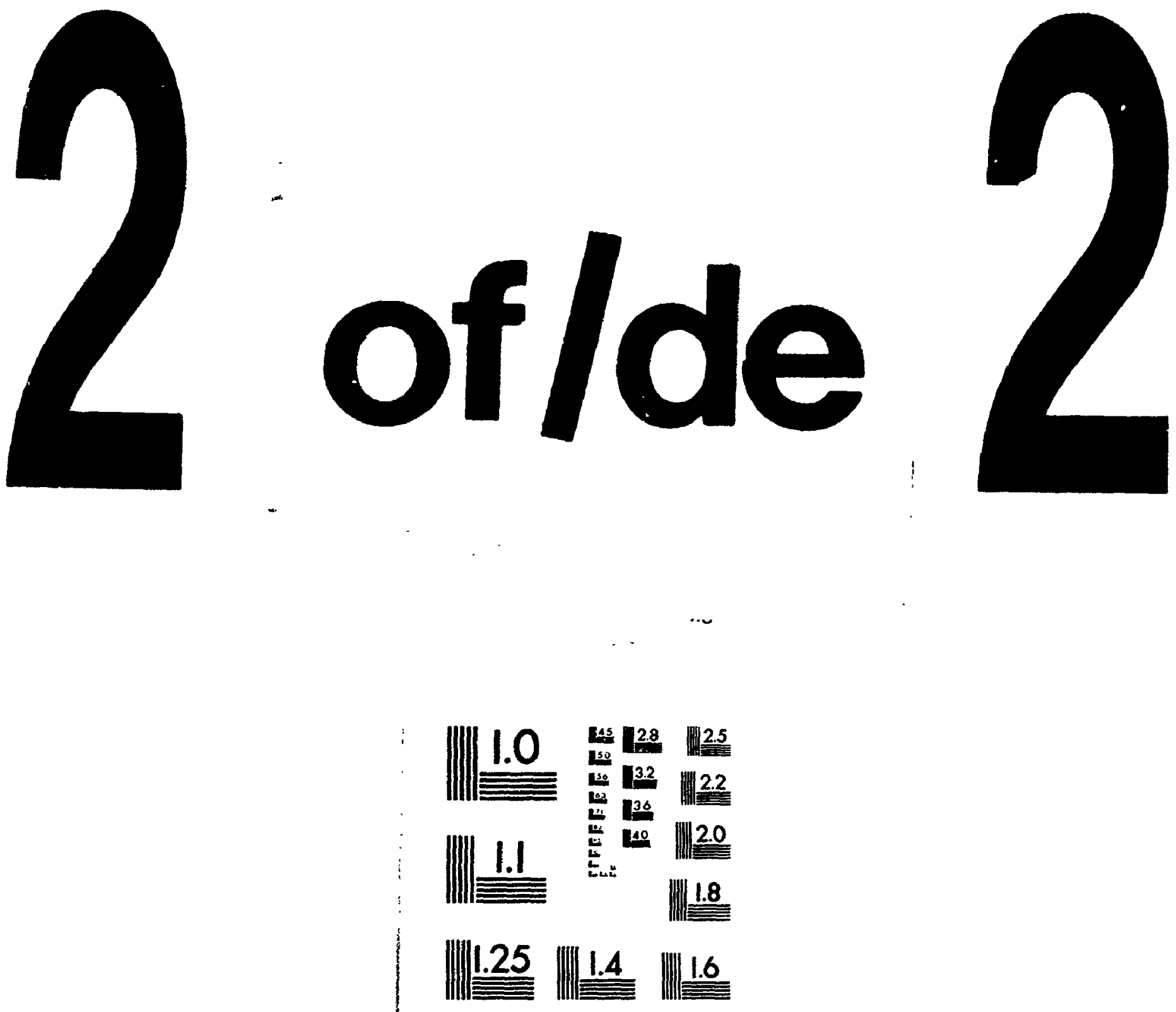

MICROCOPY RESOLUTION TEST CHART

NATIONAL BUREAU OF STANDARDS

STANDARD REFERENCE MATERIAL. 1010a

(ANSI and ISO TEST CHART NO 2) 


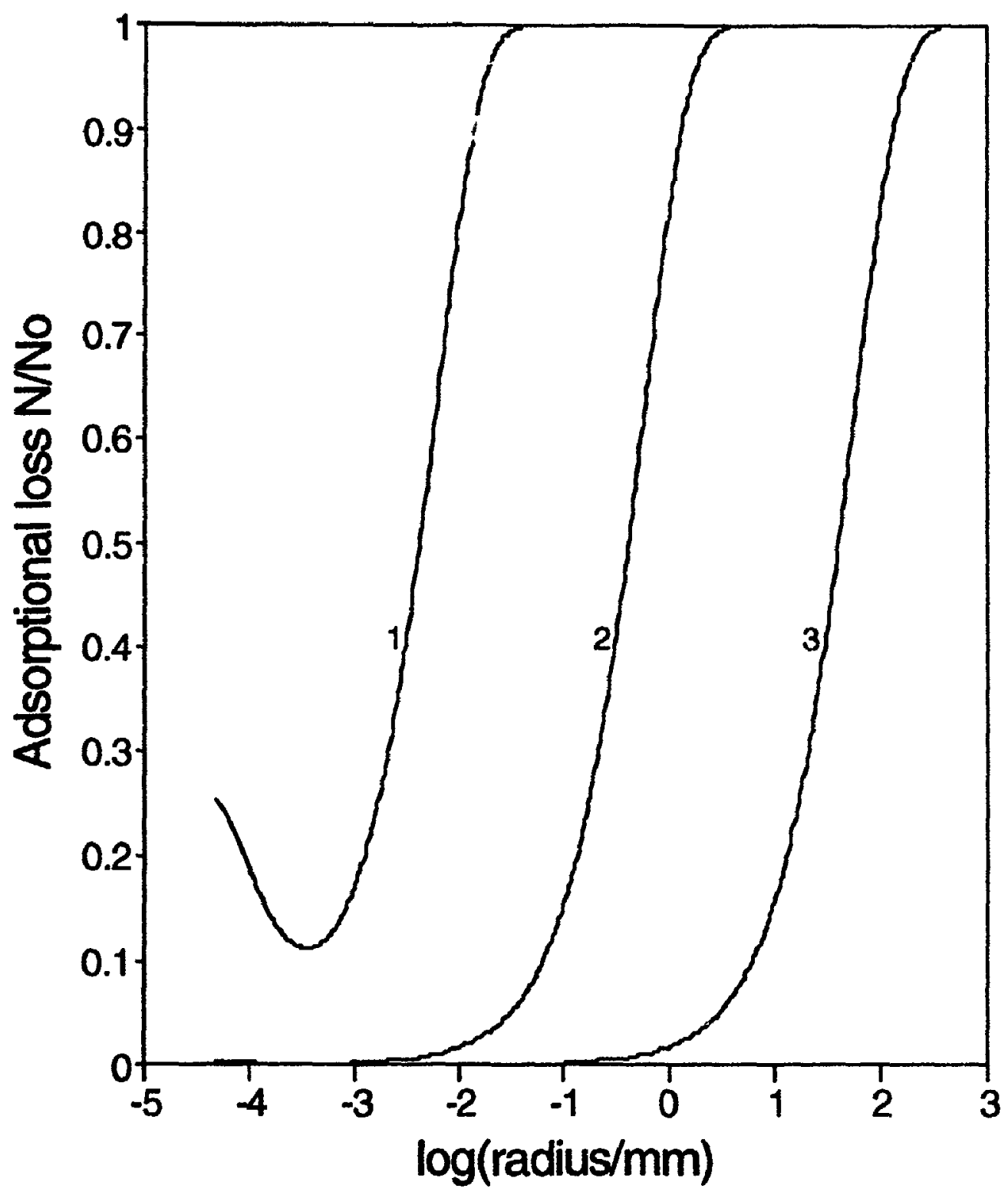

Figure 8.3

Atom loss model 2. Plot of $N / N_{o}$ versus $\log$ (tube radius) for: $f=100$ ) mLomin ${ }^{-1}, t=1.0 \mathrm{~mm}$, and sticking probability, $\rho: 1,1 ; 2,10^{-2}$; $3,10^{4}$ 
According to this intermediate and still very naive model, the limiting tube radii would be $\lambda$, when, in this limit, the loss, N/No, would approach a value of $\rho^{\bullet} \mathrm{g}$. Very small diameters lead to the ludicrous situation of linear atomic trajectories surpassing the speed of light: in fact, $3 \mathrm{c}$, for a flow rate of $100 \mathrm{~mL}^{-\mathrm{min}^{-1}}$ and a tube radius of $\lambda / 2$ ! The real limiting diameter would be the diameter, calculable from the Poisseuille equation, for: a given standard flow rate through a defined length of tubing, and the condition of a pressure drop of one atmosphere along the length of the tube. This limiting diameter is hest illustrated in Modei 3.

MODEL 3

This, the third and final model, takes into account the pressure drop at some distance $y$ along the tube length $\ell$. As the pressure drops in the direction of the vacuum pump, from ambient pressure $P_{1}$ at the open end of the tube to some lower pressure $P_{2}$ at the pump end of the tube, the kinetic properties $Z$, the flow rate $f$, and $\lambda$ change. $P_{2}$ is a function of $y$. To correct for this, the mean values of $Z, f$ and $\lambda$ are calculated and used in place of the fixed values in model 2. The variables $Z^{\prime}, f^{\prime}$, and $\lambda^{\prime}$, are the values of $Z$, $f$, and $\lambda$ respectively under ambient conditions, and are defined as follows:

$$
\begin{aligned}
& \bar{Z}=\frac{1}{l} \int_{y=0}^{y=\ell} Z^{\prime} \frac{P_{2}}{P_{1}} d y, \\
& \text { where } Z=Z^{\prime} \times\left(\frac{P_{2}}{P_{1}}\right) \\
& F=\frac{1}{l} \int_{y=0}^{y=l} f^{\prime} \frac{P_{1}}{P_{2}} d y, \\
& f=f^{\prime} \times\left(\frac{P_{1}}{P_{2}}\right) \\
& \bar{\lambda}=\frac{1}{\ell} \int_{y=0}^{y=1} \lambda^{\prime} \frac{P_{1}}{P_{2}} d y, \\
& \lambda=\lambda^{\prime} \times\left(\frac{P_{1}}{P_{2}}\right),
\end{aligned}
$$

and dy is some infinitestimal of the tube length $\ell$. 
Solving the Poisseuille equation :

$$
f^{\prime}=\frac{\left(P_{1}^{2}-P_{2}^{2}\right) \pi r^{4}}{16 y \mu P_{1}}
$$

for $P_{2}$, and substitution into the previous integral equations gives:

$$
\begin{aligned}
& \bar{Z}=\frac{Z^{\prime}}{P_{1} \ell} \int_{y=0}^{y=l} \sqrt{P_{1}^{2}-\frac{16 \mu P_{1} f^{\prime} y}{\pi r^{4}}} d y \\
& \bar{f}=\frac{f^{\prime} P_{1}}{\ell} \int_{y=0}^{y=\ell} \frac{1}{\sqrt{P_{1}^{2}-\frac{16 \mu P_{1} f^{\prime} y}{\pi r^{4}}}} d y \\
& \bar{\lambda}=\frac{\lambda^{\prime} P_{1}}{\ell} \int_{y=0}^{y=\frac{1}{\sqrt{P_{1}^{2}-\frac{16 \mu P_{1} f^{\prime} y}{\pi r^{4}}}}} d y .
\end{aligned}
$$

The solution for these integral equations is given below:

$$
\begin{aligned}
& \bar{Z}=\frac{Z^{\prime} \pi r^{4}}{24 P_{1}^{2} \ell \mu f^{\prime}}\left[P_{1}^{3}-\left(P_{1}^{2}-\frac{16 \mu P_{1} f^{\prime} \ell}{\pi r^{4}}\right)^{\frac{3}{2}}\right] \\
& \bar{f}=\frac{\pi r^{4}}{8 \ell \mu}\left[P_{1}-\sqrt{P_{1}^{2}-\frac{16 \mu P_{1} f^{\prime} \ell}{\pi r^{4}}}\right] \\
& \bar{\lambda}=\frac{\lambda^{\prime} \pi r^{4}}{8 \mu \ell f^{\prime}}\left[P_{1}-\sqrt{P_{1}^{2}-\frac{16 \mu P_{1} f^{\prime} \ell}{\pi r^{4}}}\right]
\end{aligned}
$$

Substitution of these average values of $Z, f$, and $\lambda$ into the general solution from model 2 gives the general solution for model 3. 
General solution:

$$
\frac{N}{N_{0}}=1-\left[1-\frac{\rho a r^{4}\left[P_{1}-\sqrt{P_{1}^{2}-\frac{b}{r^{4}}}\right]\left[2 r-a r^{4}\left(P_{1}-\sqrt{P_{1}^{2}-\frac{b}{r^{4}}}\right)\right]}{4 r^{2}}\right]\left(16 r^{2}\left[2 P_{1}^{2}+P_{1} \sqrt{P_{1}^{2}-\frac{b}{r^{2}}}-\frac{b}{r^{2}}\right] 1+1\right)
$$

where,

$$
\begin{aligned}
& a=\frac{\lambda^{\prime} \pi}{8 \mu \ell f^{\prime}} \\
& b=\frac{16 \mu P_{1} f^{\prime} \ell}{\pi} \\
& c=\frac{Z^{\prime} \pi \ell}{3 P_{1}^{2} f^{\prime}}
\end{aligned}
$$

A plot of this equation using $\ell=1.0 \mathrm{~m}, \rho=10^{-6}$, and $\mu=1.76 \times 10-5 \mathrm{~kg}^{\circ} \mathrm{m}^{-1} \cdot \mathrm{s}^{-1}$ is given in Figure 8.4 for $f^{\prime}=10,100$, and $1000 \mathrm{~mL} \cdot \mathrm{min}^{-1}$. The model three functions are truncated at radii predicted by the Poisseuille equation. These limiting radii get smaller as the flow rate decreases. Just as predicted by the experimental data of Chapter 7 , the ideal conditions to minimize analyte loss to tubing surfaces are: 1) use the smallest tube diameter possible, and 2) use the highest flow rate possible.

\section{ESTIMATING A VALUE OF $\rho$, THE STICKING PROBABILITY FOR LATEX}

Using the general solution of model 3 above, combined with experimental data for $N / N_{o}$, an estimate of the real value of $\rho$ may finally be made. Variables are used in the model 3 solution of Table 8.3 according to the conditions that prevailed while data was collected. An estimate of $\rho=1.6 \times 10^{-6}$ gives model 3 solutions for $N / N_{o}$ that agree 


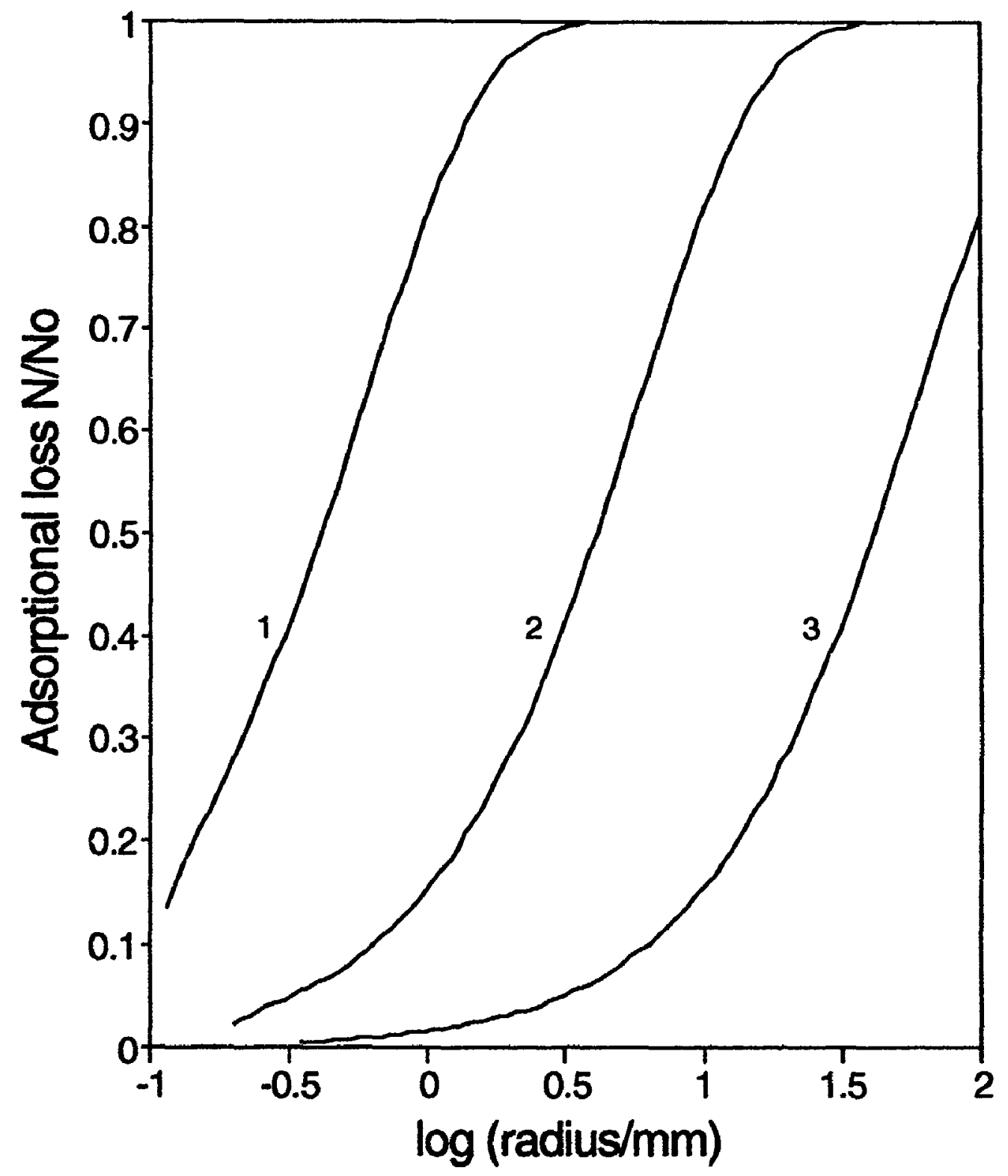

Figure 8.4 Atom loss model 3. Plot of $N / N_{0}$ versus $\log$ (tube radius) for: $\ell=1.0 \mathrm{~m}$, $p=10^{-6}$, and $f /\left(\mathrm{mL}^{\circ} \mathrm{min}^{-1}\right): 1,10 ; 2,100 ; 3,1000$ 
satisfactorily with experimental values, shown in Table 8.3. The mathematical model is more sensitive to a change in loss, with changing tube radii, than is observed

Table 8.3 Estimation of the latex sticking probability, $\rho$, by comparison of experimental and theoretical loss data

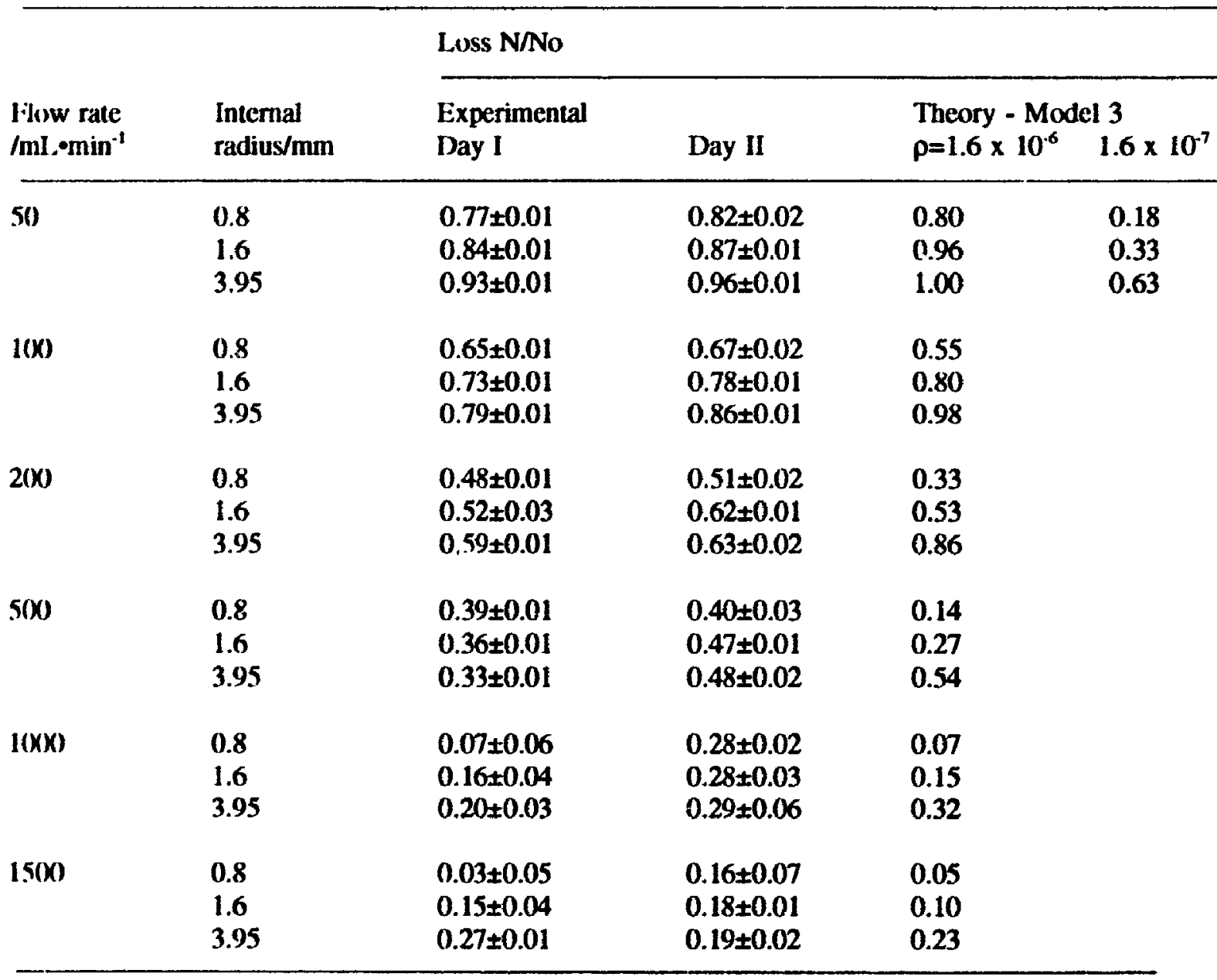

experimentally. At higher flow rates, there is a larger uncertainty and poor reproducibility between days, in experimental values of $\mathrm{N} / \mathrm{N}_{\mathrm{o}}$. This model, in addition to predicting trends, was expected to give values of $\rho$, at best, to within an order of magnitude of its real value. Calculated values are listed in Table 8.3 showing the model 3 estimates for 
$\mathrm{N} / \mathrm{N}_{\mathrm{o}}$ at $50 \mathrm{~mL} \cdot \mathrm{min}^{-1}$ and for three radii, when a value of $\rho, 1.6 \times 10^{-7}$ varies by an order of magnitude from the best estimate of $\rho$.

\section{CONCLUSIONS}

The atom loss model has been developed to the point where it predicts loss trends as a function of varied radii for all possible flow rates, and tube lengths. The primary trend: that is, trace analyte loss increases with increasing tube diameter, was confirmed with this model. Further to this, in conjunction with experimental data, the model allowed the estimation of a sticking probability. For latex tubing it was found that only one mercury atom in 0.83 million $\left(\rho=1.2 \times 10^{-6}\right)$ that strike the tube wall surface, actually remain adsorbed for a sufficient length of time so as to be termed, "lost."

\section{ACKNOWLEDGEMENT}

Dr. Kenneth S. Williams, Department of Mathematics and Statistics, Carleton University, is gratefuliy acknowledged for extensive discussions and contributions to this Chapter. 


\section{CHAPTER 9}

\section{HCI INTERFERENCE IN COLD-VAPOR ATOMIC ABSORPTION SPECTROMETRY}

\section{INTRODUCTION}

Double-peak behaviour has too often been a problem in Cold-Vapor Mercury Atomic Ahsorption Spectrometry, CVMAAS. Although the occurrence of double-peaks has been observed in GFAAS [26] and is attributed to a delayed volatilization of some fraction of the analyte, this has not been reported in the past for CVMAAS.

The fact that this second peak has neither been reported nor identified in CVMAAS is not surprising. In routine analysis, the reaction vessel is always voided immediately following the evolution of the $\mathrm{Hg}^{\circ}$ transient, followed by the addition of reagents for the acration-reduction of the next sample. If the reaction vessel is not voided, and aeration of the sample or standard solution and reagents is allowed to continue, a second peak may occur. The source of this second absorbance is not known. Not included in this Chapter are numerous controlled experiments that were directed towards identifying the source of the second peak, and which were unsuccessful. Attention was subsequently directed towards characterizing this anomalous signal, and to determine which experimental variables promote the sporadic occurrence of a second peak.

The formation of an anomalous second peak poses two problems. First, if the absorbance by the second peak is due to a delayed release of some fraction of the mercury, then evaluation of the first peak only, does not represent an accurate 
determination of the total mercury present, and both peaks must he summed from a peak height or peak area evaluation. Second, is the problem where the second peak appears to be due to an absorbance of some species other than mercury, and where the appearance of the second peak overlaps with the first mercury absorbance peak. Evidence presented herein suggests it is the latter problem that prevans.

\section{EXPERIMENTAL SECTION}

All observations of the anomalous signal were made using both the Laboratory Data Control UV Monitor ${ }^{\text {ru }}$ and the Milton Roy UVD fixed wavelength detector. Reagents used were as described in Chapter 2. Following many failed attempts to find an adsorbing material that was selective to the second peak and inert to the first peak, glasswool, contained in capillary tubes was found to be suitable. The anomalous transient absorbance was observed by letting the reaction vessel continue to aerate the reaction solution for up to 10 minutes following the appearance of a mercury absorbance transient.

\section{RESULTS AND DISCUSSION}

\section{CHARACTERIZATION OF THE SECOND PEAK}

The anomalous peak generally occurs with unpredictable frequency, unpredictable magnitude, and always with unknown origin. However, the fact that it has been:

1) observed in different laboratories [77], 2) observed by different analysts in our laboratory, 3) observed on entirely different CVAA spectrometers and reaction vessels in our laboratory, is overwhelming evidence that the second peak is not a mere artifact, but 
some phenomenon of CVAA that needs attention.

Cumulatively, over a month was spent, by two analysts, trying to identify the source of the second peak. Attempts were made to determine whether its occurrence depended upon: 1) inorganic analyses $\left(\mathrm{SnCl}_{2} / \mathrm{H}_{2} \mathrm{SO}_{4} / \mathrm{NaOH}\right)$, 2) total analyses $\left(\mathrm{CdCl}_{2} / \mathrm{SnCl}_{2} /\right.$ $\mathrm{H}_{2} \mathrm{SO} / \mathrm{NaOH}$, 3) pre-treatment of the reaction vessel with a $\mathrm{H}_{2} \mathrm{SO}_{4}$ clcaning before running a sample or blank, 4) repeated sample or blank analyses run in such a manner that the reaction vessel was voided immediately following the appearance of the first absorbance pulse, and 5) volumes of reagents used. Although the occurrence of the anomalous signal could not be unambiguously attributed to any one experimental variable, a few generalizations were ohserved that may help future work in this area:

1. The repeated analysis of many blanks (10-20) in quick succession, with immediate voiding of the reaction vessel following the first peak, was a procedure often used to induce the appearance of a second peak.

2. Cleaning the reaction vessel with a $5.0-\mathrm{mL}$ aliquot of $4.5 \mathrm{~N} \mathrm{H}_{2} \mathrm{SO}_{4}$ was often but not always sufficient for producing a second peak in a blank or standard solution that immediately followed this cleaning.

3. On days when the second peak was occurring with near predictable regularity, it would continue to be observed for the remainder of that day.

Figure 9.1A shows 10 well-behaved absorbance transients run in quick succession with immediate flushing of the reaction vessel following the appearance of a mercury absorbance. The first three peaks of Figure 9.1B are also well-behaved, but the fourth 

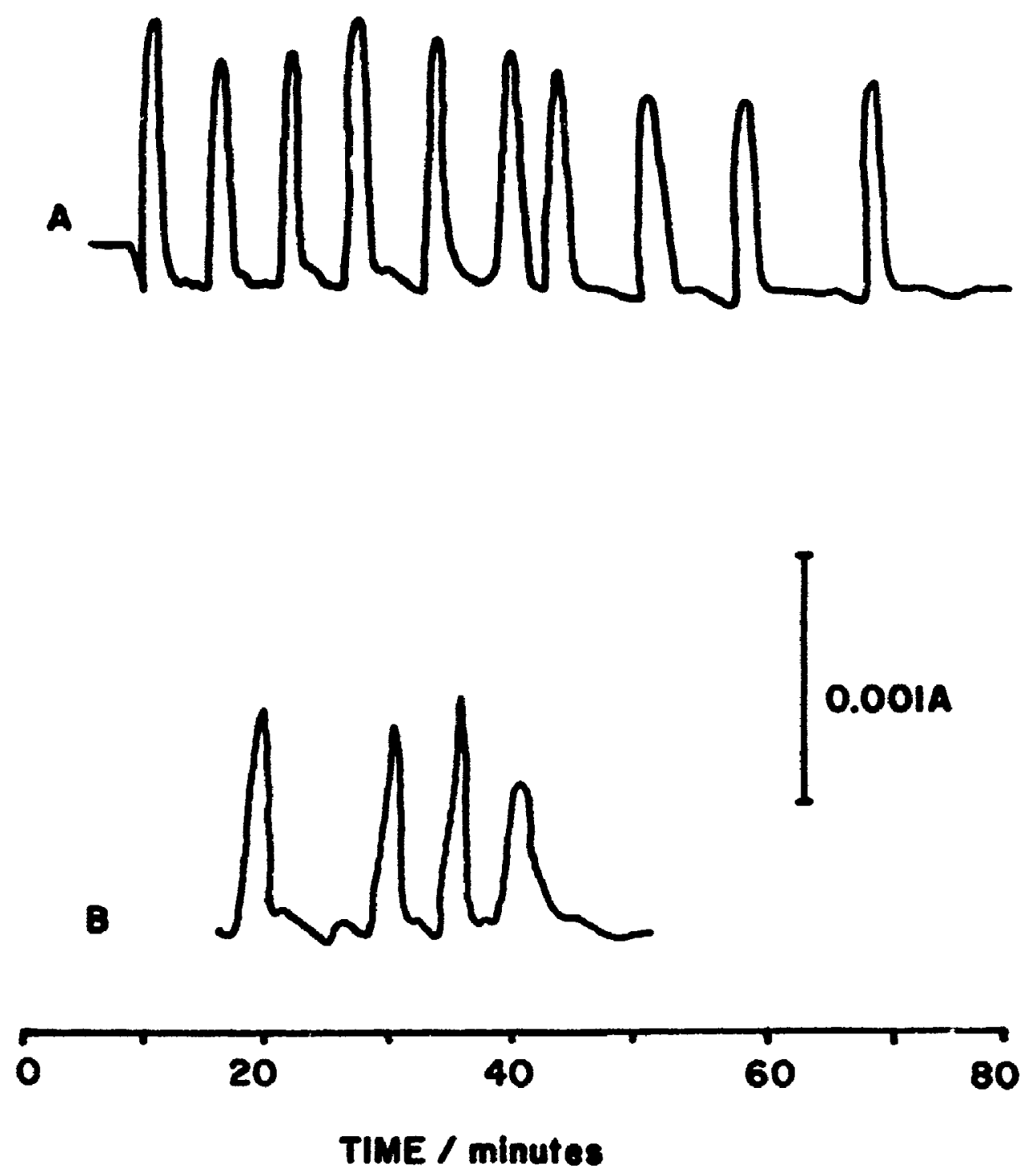

Figure 9.1A Typical CVAA transients of mercury. Recorded at $253.7 \mathrm{~nm}$ with an interference filter, a flow rate of $1000 \mathrm{~mL}^{\circ} \mathrm{min}^{-1}$, and $1.0-\mathrm{mL}$ of $8.5 \mathrm{~N}$ $\mathrm{NaOH}$ and $1.0-\mathrm{mL}$ of $0.2 \%(\mathrm{~m} / \mathrm{v}) \mathrm{SnCl}_{2}$ in $4.5 \mathrm{~N} \mathrm{H}_{2} \mathrm{SO}_{4}$

Figure 9.1B Three typical CVAA transients of mercury followed by an absorbance by some unknown gas 
peak, where the reaction vessel was not voided and flushed following the third peak, is due to absorbance of $253.7 \mathrm{~nm}$ radiation by some unknown gas.

The magnitude of the anomalous peak varied between absorbances smaller than blanks, shown in Figures 9.1A and 9.1B, to absorbances as large as 0.023 . When the second peak had an absorbance greater than 0.01 , which took the absorbance trace offscale, there was usually considerable detail in the second peak as illustrated in the two traces of Figure 9.2. It is most perplexing that after all the reagents are added to the acrated reaction vessel, there is a delay-time between the appearance of the mercury signal and onset of the second peak. This delay time could be as long as 5 minutes and as shon as 3() seconds. In the latter case the second peak usually occurred as a rider peak on the mercury absorbance pulse.

\section{DETERMINATION OF THE SECOND PEAK}

Glasswool, used as an adsorbent, was found to selectively remove the second ahsorbance pulse when it was known to have occurred. Two spectrometers were placed in series with each other in the flow stream from the reaction vessel (Figure 9.3). A $1.5 \mathrm{~cm}$ length of $1.0 \mathrm{~mm}$ i.d. capillary tubing containing approximately $7.5 \mathrm{mg}$ of glasswool was placed in the air flow-stream between the two spectrometers. Three samples were collected on the gas sampling tubes when the second peak was observed to produce absorbances greater than 0.01 . Confirmation that the sample was deposited on the glasswool was established by the absence of a second peak absorbance on spectrometer 2 , that monitored the air as it left the gas sampling tube. Three blanks were 


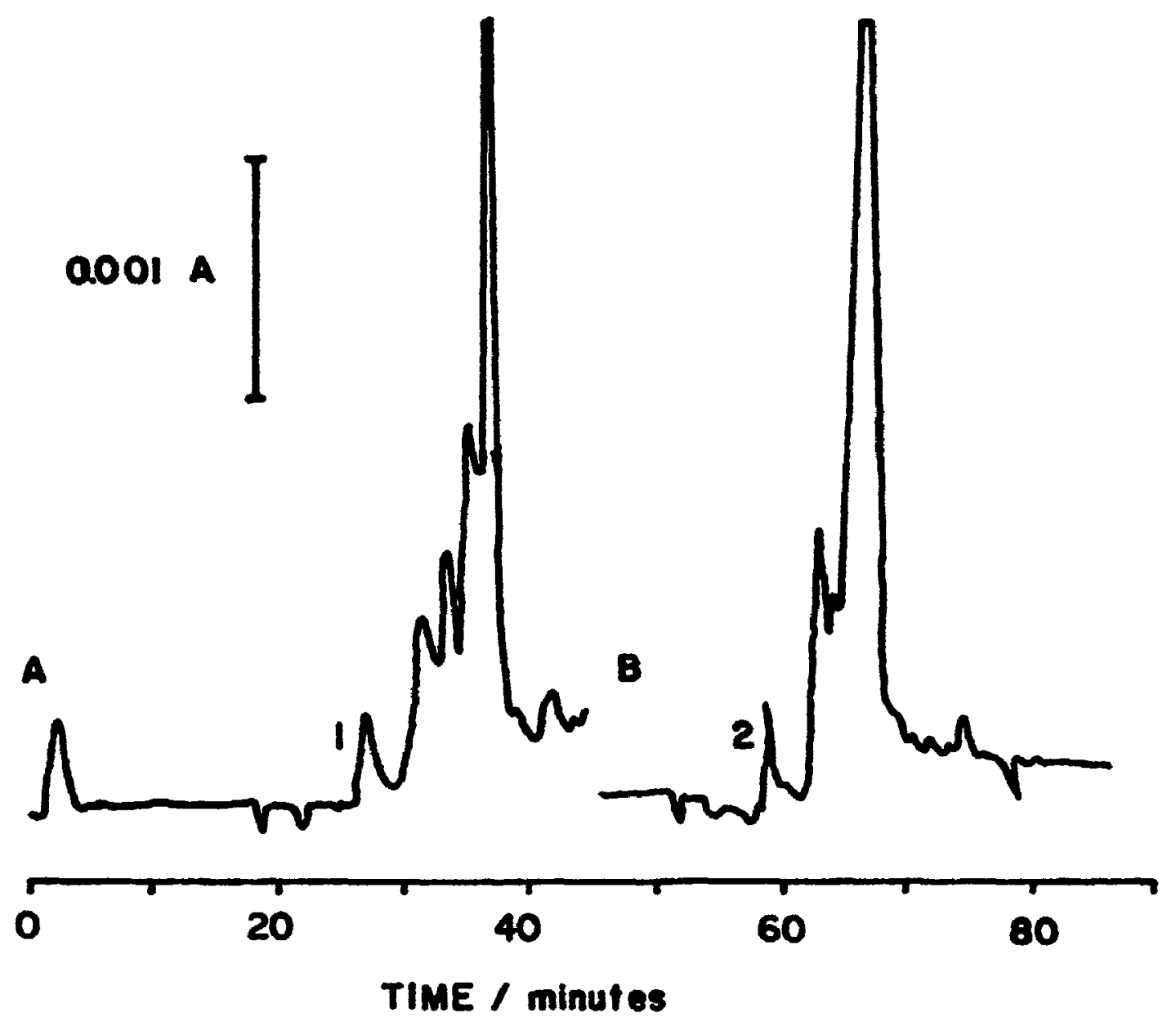

Figure 9.2 Two CVAA traces showing mercury peaks at 1 and 2 followed by large absorbance pulses when the solution was left to aerate following the evolution of the mercury peak 


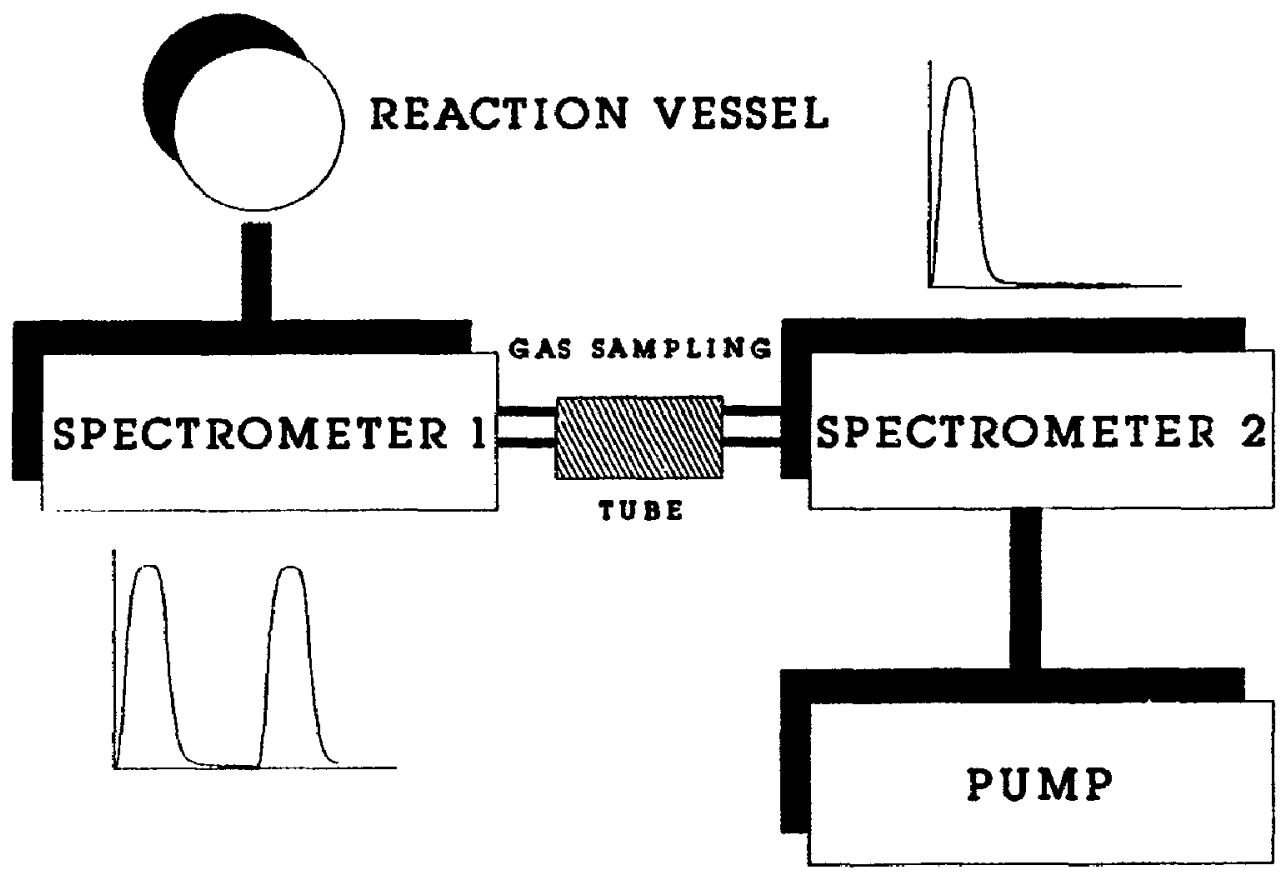

Figure 9.3 Schematic diagram of instrumental arrangement for monitoring of selective adsorption of anomalous gas on gas sampling tube 
also collected by sampling the air flow stream, for the same length of time as sampling occurred, while the reagents remained aerating in the reaction vessel and there was no observable absorbance occurring.

Not later than two hours following collection, temperature programmed thermal desorption mass-spectrometry was performed on the gas sampling tubes. Figure 9.4 shows the mass spectrum of a blank as it occurred 15 seconds into the temperature gradient thermal desorption program. The high abundance of peaks at 43 and $149 \mathrm{amu}$ are characteristic plasticiser fragment peaks. The presence of plasticiser is not surprising in light of the plastic delivery tubing used. These molecular ions were also visible in the mass spectra of the samples containing the anomalous gas (Figure 9.5), but the peaks at 36 and 38 amu dominated at 15 seconds into the programmed thermal desorption. At longer desorption times the background of plasticiser decreased and the peaks at 36 and 38 persisted.

That the peaks at 36 and 38 amu occur in the natural isotopic abundance ratio of $3: 1$ for chlorine is reasonably conclusive evidence that the anomalous gas is $\mathrm{HCl}$. Further (1) this, the molecular spectra of $\mathrm{HCl}_{(\mathrm{g})}$ shows an absorbance maxima near $257 \mathrm{~nm}$ [78], which is sufficiently close enough to the analytical line $253.7 \mathrm{~nm}$, to produce ineasurable absorbance.

\section{CONCLUSIONS}

Although the source of $\mathrm{HCl}$ has not been found, the use of a glasswool plag, inserted between the aeration cell and the absorbance cell, is effective in eliminating the problem of the second peak, while not interfering with CVAAS. 


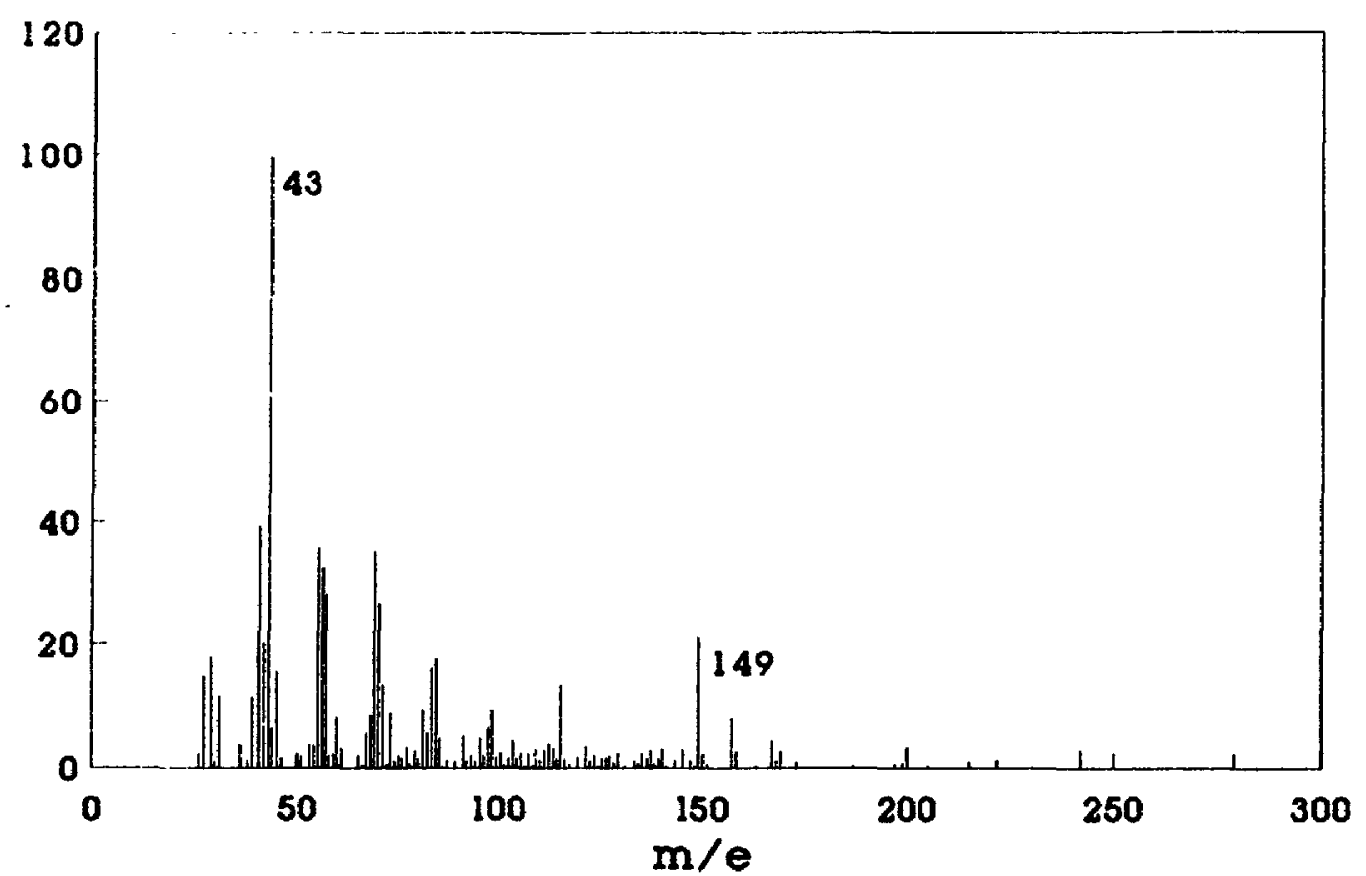

Figure 9.4 Mass spectrum of blank. Gas sampled from glasswool $n^{-1} u g$ inserted in the flow-stream of a CVAA instrument when no absci, bance was occurring at $253.7 \mathrm{~nm}$ 
94

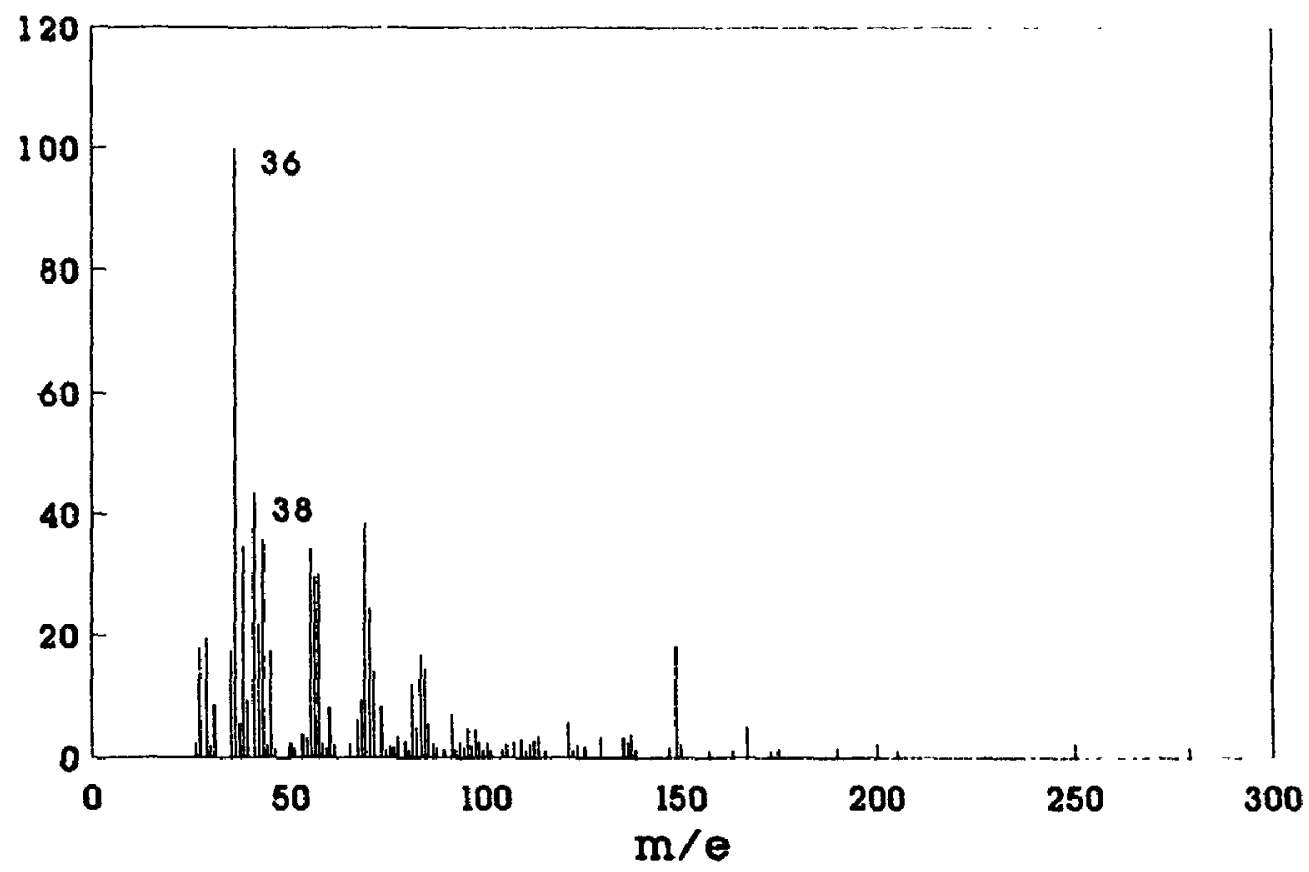

Figure 9.5 Mass spectrum of unknown gas - $\mathrm{HCl}$. Gas sampled from glass wool plug that had been inserted in the flow-stream of a CVAA instrument when anomalous absorbance at $253.7 \mathrm{~nm}$ was observed 


\section{CHAPTER 10 \\ INCREASED SENSITIVITY WITH A \\ NEW DETECTOR POSITION}

\section{INTRODUCTION}

A double beam instrument has been used extensively in cold-vapor mercury atomic absorption (CVMAA) for nearly the last two decades. This instrument has been able to rival many other techniques for mercury analysis, and, as a consequence, the original optical design has gone unquestioned until now. Evidence herein demonstrates a threefold increase in instrumental sensitivity when a new detector position is selected in the optical path.

Traditionally, atomic absorption spectroscopists have improved the experimental sensitivity towards a given analyte by maximizing its atom population in the optical analysis volume during atomization. This has been done by pre-analysis concentration of the analyte. Preconcentration has found its way into volatile metal hydride $[79,80]$, and carbonyl $[81,82,83]$ atomic absorption techniques, graphite furnace atomic absorption spectrometry [84], and into CVMAA where gold-coated sand has been shown to be a preferred adsorbent [61]. An increase in the number of analyte atoms in the analysis volume at a given instant increases only the peak height but not the peak area sensitivity. Under the assumption of $100 \%$ atomization efficiency, one can only hope to improve the integrated sensitivity, or rather seem to, by increasing the atom residence time in the optical analysis cell. This can be done quite easily by decreasing 
the carrier gas flow rate or by changing the analysis cell dimensions [85]. Does providing conditions for atoms to contribute to the net integrated signal more than once really constitute an increase in the sensitivity? Probably not. Then, is it ever possible to increase the integrated sensitivity if $100 \%$ atomization has been obtained? The answer seems to be yes, but only by improving the optical quality of the spectrometer being used.

Two aspects of optical quality that will be considered herein are improved optical alignment, and increased monochromaticity of the light source.

\section{EXPERIMENTAL SECTION}

Details of the experimental method are presented in Chapter 2. The spectrometer used was the Milton Roy UVD fixed wavelength detector. Ultra-violet power readings were measured using a Photodyne model 66XLA optical power encrgy meter. Figure 10.1 shows a diagram of the cell holder designed and built to change the detector position.

\section{RESULTS AND DISCUSSION}

The optical design of the spectrometer used is illustrated in Figure 10.2. The mercury lamp is located at the focal point of the collimating lens L1. Two parallel space-filling beams of collimated light traverse the length of the reference and experimental cell. At the second lens, L2, the two beams are focused as cones of light that first cross at the focal length of L2, and then intercept the dual silicon photovoltaic photocells at position A, where the light intensities are electronically compared to give an absorbance reading. The instrument is supplied by the manufacturer with the detector at this position. 


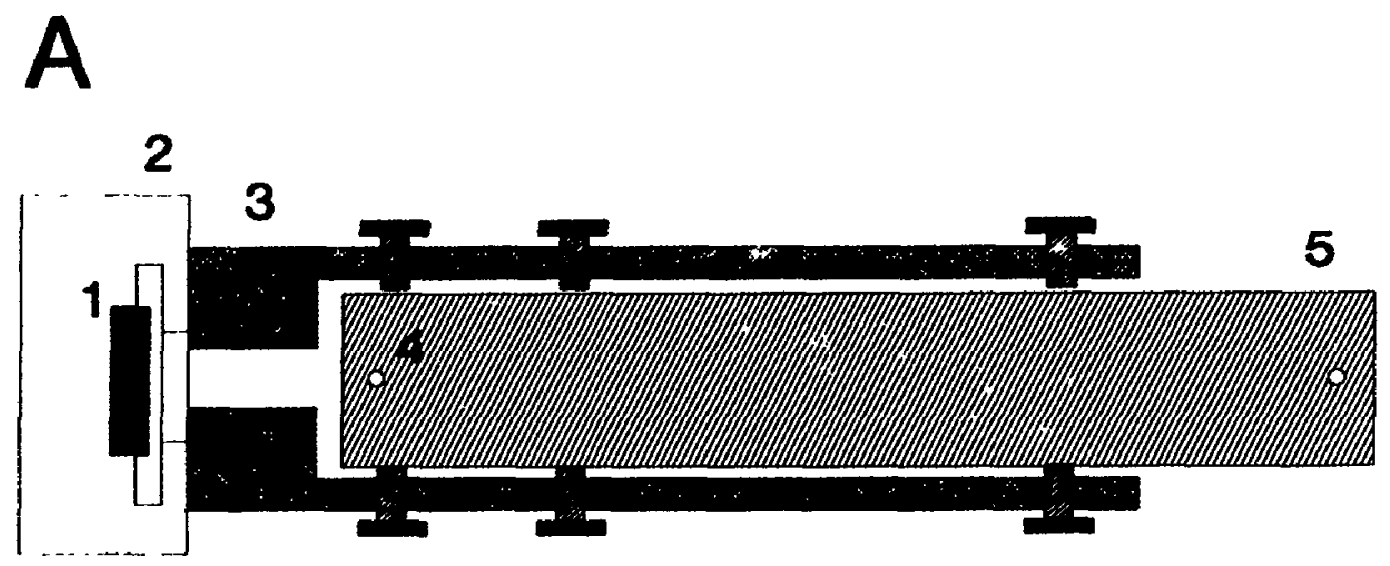

B

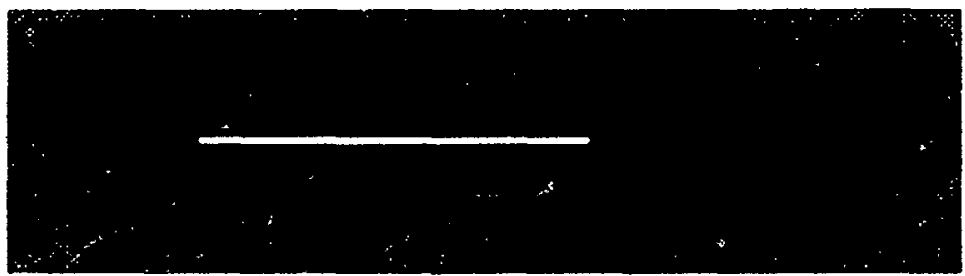

Figure 10.1 Cross-sectional view (A) and top view (B) of absorbance cell holder with: 1, silicon dual photovoltaic cell; 2 , detector housing; 3 , cell holder; 4, air inlet stud; 5 , double beam absorbance cell; 6 , slot in cell holder to permit movement of absorbance cell air inlet stud 


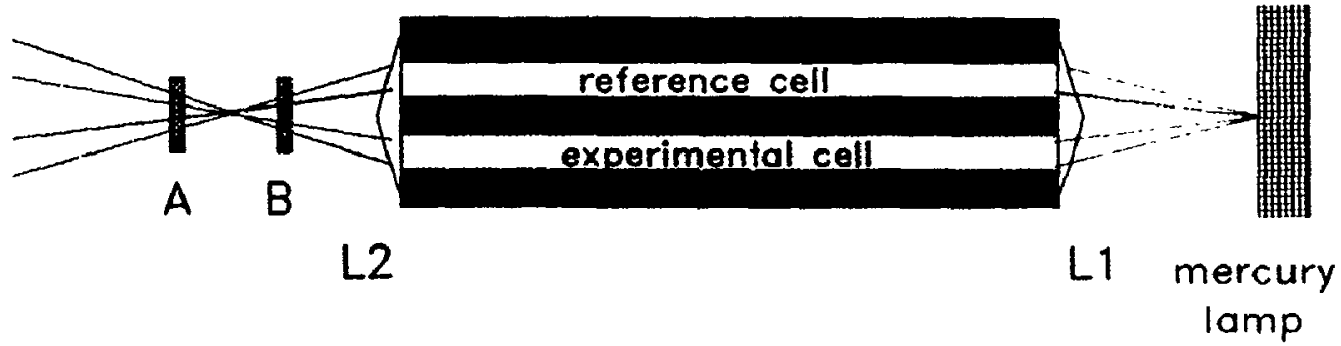

Figure 10.2 Optical path and possible detector positions (A and B). L1 and L2 are collimating lenses 
Inspection of Figure 10.2 reveals that the instrument has a second possible position for Jocating the detector in the optical path - at position B. A new cell holder was designed and built that allowed movement of the detector along the axis of the optical path (Figure 10.i). Figure 11.3 is a plot of the energy intercepted at the dual photovoltaic cell as : function of detector position from the lens L2, for both the reference cell and the sample cell. Advantages of detector position B are: better energy throughput and better coincidence of the peak maxima. At the detector position B, a $270 \%$ increase in peak area sensitivity and a $330 \%$ increase in peak height sensitivity was observed (Table 10.1). It would appear that either detector position should work equally well, but detector position B offers the advantage of a reduced light source to detector distance. This reduced distance minimizes detector alignment errors. Increasing the monochromaticity of a light source for atomic absorption generally increases the sensitivity, provided there is no excessive attenuation of the source. For the low-pressure mercury lamp used in our laboratory, it is the usual case, as indicated by the instrument manufacturer, not to increase the monochromaticity because most of the radiation is at the $253.7 \mathrm{~nm}$ resonance frequency. In spite of this, we observed about a $20 \%$ increase in sensitivity for both peak height and area when a $254 \mathrm{~nm}$ interference filter was used.

This increase in sensitivity was achieved despite the substantial attenuation of the lamp intensity to only $6.5 \%$ transmittance, as shown in Table 10.2 . A broad band-pass filter $(230-400 \mathrm{~nm})$ gave a much smaller increase in sensitivity. 


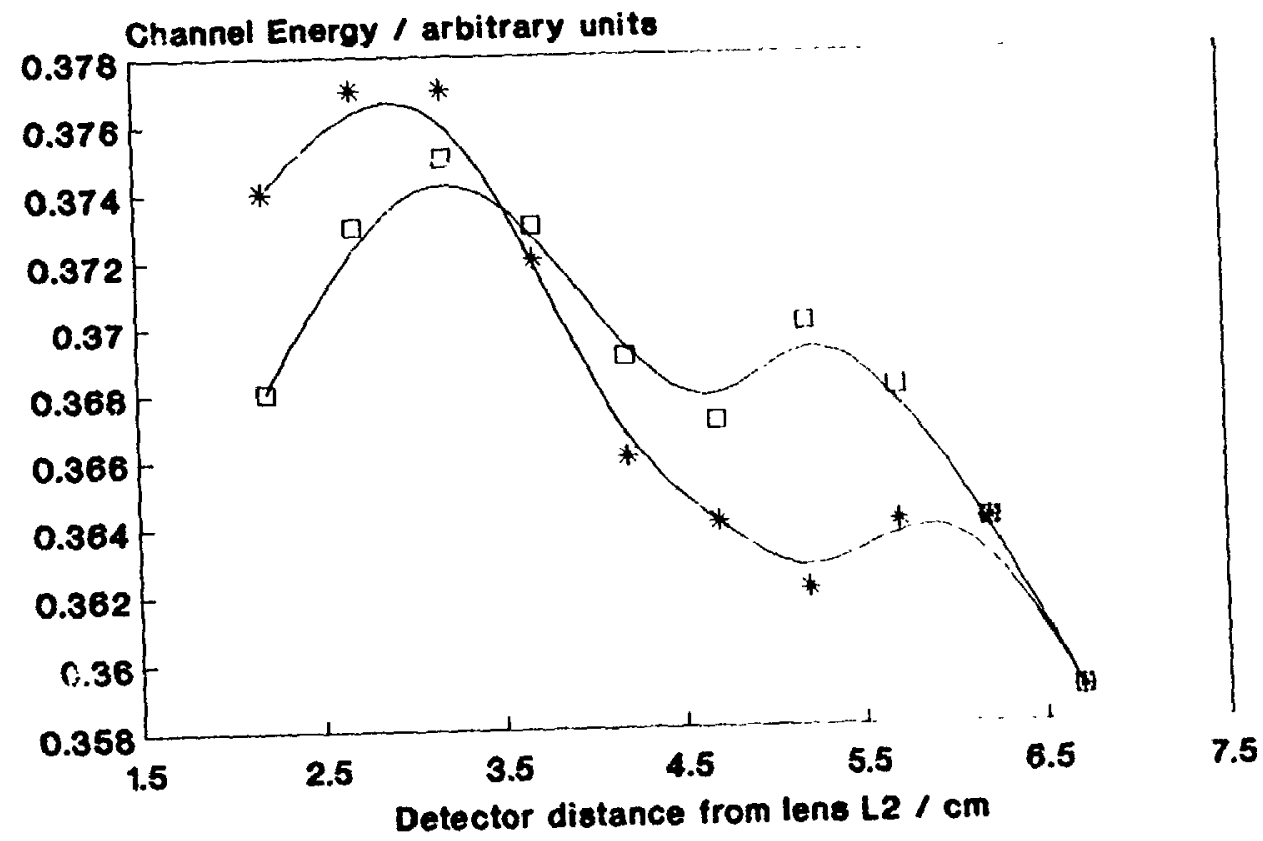

Figure 10.3 Energy profile observed by the dual photovoltaic cell detector for the experimental ( $\square$ ) and reference $(*)$ cell as a function of detector distance from the collimating lens L2 of Figure $\mathbf{1 0 . 2}$ 
Table 10.1 Analytical response to $5.0 \mathrm{ng}$ of mercury for detector positions $A$ and $B$

\begin{tabular}{lll}
\hline Signal & \multicolumn{1}{l}{ Detector placement } \\
\cline { 2 - 3 } & $\mathrm{A}$ & $\mathrm{B}$ \\
\hline $\begin{array}{c}\text { Peak area } \\
\text { /(Aes) } \\
\begin{array}{c}\text { Peak height } \\
\text { IA }\end{array}\end{array}$ & $0.196 \pm 0.003^{+}$ & $0.545 \pm 0.006$ \\
\hline
\end{tabular}

$\pm \bar{x}_{s}, \pm$ S.D.

Table 10.2 Attenuation of low-pressure mercury lamp intensity for two optical filters

\begin{tabular}{lll}
\hline Filter & $10^{6}$ unfocused power / watts & $\begin{array}{l}\text { Percent } \\
\text { transmittance }\end{array}$ \\
\hline None & 37 & 100 \\
$230-400 \mathrm{~nm}$ & 13 & 35 \\
$254 \mathrm{~nm}$ & 2 & 6.5 \\
\hline
\end{tabular}




\section{CHAPTER 11}

\section{THE MATRIX EFFECT IN THE COLD-VAPOR ATOMIC ABSORPTION DETERMINATION OF MERCURY}

\section{INTRODUCTION}

The signal derived from, say $10 \mathrm{ppb}$, in a hair digest solution or a blood sample, is often considerably smaller than that from the same concentration in a clean aqueous solution. This discrepancy is the effect referred to as the matrix effect [34]. This effect has alerted analysts to potential errors in routine determinations from one sample matrix (1) another. In contrast to analyses of biological samples [31], and vegetable samples [86], the cold-vapor atomic absorption determination of mercury in some environmental samples exhibits essentially no matrix effect towards inorganic mercury. It was, however, discovered that there is a larger matrix effect exhibited on hair samples when the standard addition, or spike, is an organomercurial instead of the conventionally used inorganic mercuric chloride standard addition.

For over ten years after its development $[29,30,35,21]$, the cold-vapor atomic absorption determination of mercury was a method exhibiting a substantial matrix effect. In 1981 Wigfield et. al. [34] showed that the measurement of peak area, rather than peak height, essentially eliminated this matrix effect on human hair samples. Not all biological matrices, however, are matrix free and some biological samples have been reported showing which matrices still give a persistent matrix effect and which do not [31] In this chapter results are presented for environmental samples inciuding grass, leaves, and soil, 
where hair is analyzed as a control for the matrix effect. Hair has then shown in the past to exhibit no significant matrix effect towards inorganic mercuric chloride 134 !.

Until now, matrix effect evaluations have been performed by makin $x_{z}$ standard additions of $\mathrm{HgCl}_{2}$ and evaluating the percent recovery. In matrix studies, the type of standard addition is now being put into question. Does it matter whether the standard addition is an inorganic salt of mercury or an organo-mercury salt, and could the matrix effect exhibited on one be greater than on the other? Work is presented with hair to evaluate the difference between the matrix effect exhibited on standard additions of mercuric chloride and phenylmercuric acetate.

\section{EXPERIMENTAL SECTION}

The cold-vapor atomic absorption reagents, preparation solutions, and apparatus used are summarized in Table 2.1. of Chapter 2. Environmental samples were collected from the Carletcn University grounds and the adjacent Rideau River.

Determination and Percent Recovery. In addition to reporting the matrix effect as

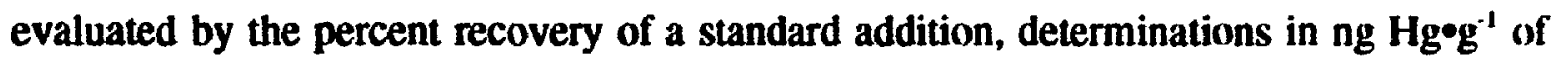
sample, are reported for the samples investigated. With a net analysis volume of $30.0 \mathrm{~mL}$, a $1.00 \mathrm{~mL}$ standard addition of $150 \mathrm{ng}^{\bullet} \mathrm{mL}^{-1}$ gave a $5.0 \mathrm{ng} \cdot \mathrm{mL}^{-1}$ mercury spike for hair, grass, leaves, $50.0 \mathrm{ng}^{\circ} \mathrm{mL}^{-1}$ imparted a $1.66 \mathrm{ng}^{\circ} \mathrm{mL}^{-1}$ spike of inorganic mercuric chloride. Both River water samples and hair samples were additionally analyzed for their matrix effects towards phenylmercuric acetate. The organomercurial internal standard additions were 
the same size as the inorganic intrnal standard additions. Calculated determinations for mercury are based on the sensitivity the internal standards, and do not take into account the presence of sample matrices.

Sample Preparation. For hair, grass, leaves, and soil, the digestion solution contained 8.0

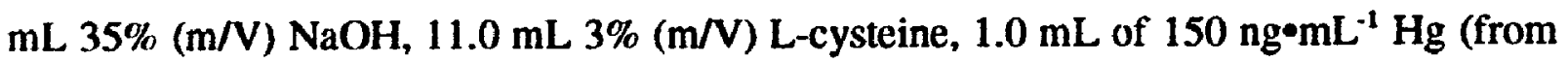
$\mathrm{HgCl}_{2}$, and $\mathrm{C}_{6} \mathrm{H}_{5} \mathrm{HgOOCCH}_{3}$ for hair samples only) or $1.0 \mathrm{~mL}$ of deionized water, $8.0 \mathrm{~mL}$ of $1 \% \mathrm{NaCl}$, and approximate sample masses of $0.2,0.20 .7$ and $1.0 \mathrm{~g}$ for hair, grass, leaves, and soil respectively. River water digestion solutions contained $10.0 \mathrm{~mL}$ of $35 \%$ $\mathrm{NaOH}, 1.0 \mathrm{~mL}$ of $3 \%$ L-cysteine, $1.0 \mathrm{~mL}$ of $50 \mathrm{ng}^{\circ \mathrm{mL}^{-1}} \mathrm{Hg}$ (from $\mathrm{HgCl}_{2}$ and $\mathrm{C}_{6} \mathrm{H}_{5} \mathrm{HgOOCCH}{ }_{3}$ ) or $1.0 \mathrm{~mL}$ of deionized water, $1.0 \mathrm{~mL}$ of $8 \% \mathrm{NaCl}$, and $15.0 \mathrm{~mL}$ of river water. These solutions were digested at $80-90^{\circ} \mathrm{C}$ for $1 \mathrm{~h}$. After cooling to room temperature, they were made up to $30.0 \mathrm{~mL}$ with distilled deionized water. The grass and leaf digests were homogenized with a Brinkmann high speed homogenizer. Precalibrated $20 \times 200 \mathrm{~mL}$ test-tubes were used. All samples except soil were vortexed immediately before analysis. For soil samples, only the supernatant was analyzed.

\section{RESULTS}

Table 11.1 outlines the calculations for making determinations and measurements for the degree of the matrix effect. Table 11.2 lists a typical set of results for hair, grass, leaf, and soil analyses. Standard additions for evaluation of the matrix effect were performed with mercuric chloride only. Table 11.3 summarizes results of river water samples. The four separate determinations, four separate digestion solutions from one 
river sample, each have their own reagent blank, sample, and sample plus standard addition. Table 11.4 list the results of organic and inorganic mercury determination and recovery experiments from hair samples.

Table 11.1 Calculations for making determinations and measurements for the degree of matrix effect

\begin{tabular}{|c|c|c|}
\hline Parameter & Variable & Units \\
\hline Volume of standard addition & A & $\mathrm{mL}$ \\
\hline Concentration of standard addition & B & $\mathrm{ng} / \mathrm{mL}$ \\
\hline River water sample size & C & $\mathrm{mL}$ \\
\hline Net analysis volume & D & $\mathrm{mL}$ \\
\hline Control mass (without standard addition) & $\mathrm{E}$ & $\mathrm{g}$ \\
\hline Sample mass (no standard addition) & $\mathbf{F}$ & g \\
\hline Reagent blank signal & $\mathbf{G}$ & $2 \mu \mathrm{Vs}$ \\
\hline Standard signal & $\mathbf{H}$ & $2 \mu \mathrm{Vs}$ \\
\hline Sample signal & I & $2 \mu \mathrm{Vs}$ \\
\hline Sample and standard addition signal & J & $2 \mu \mathrm{Vs}$ \\
\hline \multirow[t]{2}{*}{$\begin{array}{l}\text { Transposed sample mass signal } \\
\text { normalized to the control mass }\end{array}$} & \multicolumn{2}{|l|}{$\mathrm{O}=\mathrm{I} \times \mathrm{E} / \mathrm{I}$} \\
\hline & \multicolumn{2}{|l|}{ Hair, Grass, Leaves, Soil } \\
\hline Determination & $Q=A \times B \times(O-G) /(J-O) / E$ & $\mathrm{ng} / \mathrm{g}$ \\
\hline \multirow[t]{2}{*}{ Percent Recovery } & $T=100((J-G) /(O+H-2 G)$ & \\
\hline & River Water & \\
\hline Determination & $\mathrm{S}=\mathrm{AxB} \times \mathrm{Cx}(\mathrm{I}-\mathrm{G}) /(\mathrm{J}-\mathrm{I}) / \mathrm{D}^{2}$ & $\mathrm{ng} / \mathrm{mL}$ \\
\hline Percent Recovery & $\Gamma=100(J-G) /(1+H-2 G)$ & \\
\hline
\end{tabular}

Table 11.2 Typical environmental sample analyses results $\left(\tilde{x}_{s}, \pm\right.$ S.D. $)$

\begin{tabular}{lrr}
\hline Sample & $\begin{array}{r}\text { Recovery } \\
(\%)\end{array}$ & $\begin{array}{r}\text { Determination } \\
(\mathrm{ng} / \mathrm{g})\end{array}$ \\
& & \\
Hair & $107 \pm 4$ & $180 \pm 13$ \\
Grass & $95 \pm 4$ & $77 \pm 8$ \\
Leaves & $95 \pm 4$ & $136 \pm 9$ \\
Soil & $95 \pm 4$ & $18 \pm 3$ \\
\hline
\end{tabular}


Table 11.3 Rideau River mercury determinations and matrix evaluations $\left(\bar{x}_{5}, \pm\right.$ S.D. $)$

\begin{tabular}{|c|c|c|c|c|}
\hline \multirow{2}{*}{$\begin{array}{l}\text { Specimen } \\
\text { Number }\end{array}$} & \multicolumn{2}{|c|}{ Determination/(ng・g $\left.{ }^{-1}\right)$} & \multicolumn{2}{|c|}{ Recovery/(\%) } \\
\hline & Inorganic & Organic & Inorganic & Organic \\
\hline 1 & $-24 \pm 28$ & $-19 \pm 38$ & $102.7 \pm 9.4$ & $102.0 \pm 8.9$ \\
\hline 2 & $-9 \pm 19$ & $-8 \pm 31$ & $100.5 \pm 9.6$ & $93.7 \pm 7.0$ \\
\hline 3 & $-26 \pm 24$ & $-12 \pm 37$ & $103.1 \pm 7.7$ & $98.2 \pm 8.6$ \\
\hline 4 & $-8 \pm 31$ & $-7 \pm 46$ & $98.4 \pm 10$ & $89.2 \pm 6.3$ \\
\hline
\end{tabular}

Table 11.4 Typical hair analysis results $\left(\bar{x}_{5}, \pm\right.$ S.D. $)$ for a comparison of the matrix effect using phenylmercuric acetate and mercuric chloride internal standard additions

\begin{tabular}{|c|c|c|c|c|}
\hline \multirow{2}{*}{$\begin{array}{l}\text { Specimen } \\
\text { Number }\end{array}$} & \multicolumn{2}{|c|}{ Determination/(ng・g $\left.{ }^{-3}\right)$} & \multicolumn{2}{|c|}{ Recovery/(\%) } \\
\hline & Inorganic & Organic & Inorganic & Organic \\
\hline 1 & $52 \pm 5$ & $96 \pm 10$ & $98 \pm 5$ & $73 \pm 2$ \\
\hline 2 & $16 \pm 9$ & $24 \pm 5$ & $94 \pm 4$ & $86 \pm 3$ \\
\hline 3 & $163 \pm 25$ & $284 \pm 41$ & $98 \pm 5$ & $82 \pm 2$ \\
\hline 4 & $95 \pm 7$ & $82 \pm 16$ & $95 \pm 3$ & $93 \pm 3$ \\
\hline 5 & $66 \pm 10$ & $86 \pm 32$ & $116 \pm 14$ & $119 \pm 15$ \\
\hline
\end{tabular}

\section{DISCUSSION}

Essentially no matrix effect was observed during the analysis of grass, leaves, and soil, where the mean recovery of mercuric chloride was always greater than 95\% (Table 11.2). This contrasts with the analysis of other samples, like milk, brain, and liver, which gave more substantial matrix effects, $92.7 \pm 3.8 \%, 86.6 \pm 2.0 \%$, and $85.1 \pm 2.1 \%$ respectively [31]. The data of Table 11.2 suggests the bio-accumulation of mercury early in the food chain starting with grass and leaves bearing higher concentrations than the soil they were found in.

A curious phenomenon, the residual matrix effect, is also worth noting (Table 11.3). 
This is the effect of adding a sample containing essentially no analyte, mercury, to the reagent blank. Such addition causes two effects: (1) the signal is due entirely to mercury in the reagent blank, and (2) this signal decreases due to the addition of sample matrices. Thus a reading from a sample plus a standard addition can be less than the reading of the standard alone. Literal interpretation of these figures suggests the ludicrous situation of a negative determination. This phenomenon has clear implications about the limit of detection that this or any other method has when analyzing real samples.

The results of Table 11.4 strongly suggest that matrix studies should be performed using both inorganic and organic mercury standards when a single digestion technique is being followed. Although sample 5 recovery results were not very reproducible, samples 1-4 show consistently the lower recovery of phenyl mercuric acetate compared to mercuric chloride.

The consequences of a large matrix effect (35\% for sample \#1) being exhibited by hair towards an organomercurial (phenylmercuric acetate) are serious when the method of standard additions is not followed using some form of organic mercury. One claim, suggesting the elimination of the matrix effect by using peak-area integration instead of peak heights [34], might, unknowingly, have had a significant matrix effect towards organomercurials. 


\section{REFERENCES}

1. T.T. Woodson, Rev. Sci. Instrum., 10, 308 (1939)

2. G. Lindstedt, Analyst, 9, 264 (1970)

3. F.A.J. Armstrong and J.F. Uthe, Atomic Absorption Newsletter, 10, 5, 101 (1971)

4. G. Lindstedt and I. Skare, Analyst, 96, 223 (1971)

5. I. Skare, Analyst, 97,148 (1972)

6. U. Ebbestad, N. Gundersen and T. Torgrimsen, Atomic Absorption Newsletter, 14,6 (1975)

7. A. Campe, N. Velghe and A. Claeys, Atomic Absorption Newsletter, 17, 5, 100 (1978)

8. N. Velghe, A. Campe, and A. Claeys, Atomic Absorption Newsletter, 17, 6, 139 (1978)

9. D.C. Sharma and P.S. Davis, Clin. Chem., 25, 5, 769 (1979)

10. D.H. Cox, J. Anal. Toxicol., 13, 367 (1989)

11. N. Chun-Han, F. Swee-Cheng, P. Wai-On, J. Anal. Toxicol., 12, 132 (1988)

12. S.H. Omang and P.E. Paus, Anal. Chim. Acta, 56, 393 (1971)

13. A. A. El-Awady, R.B. Miller and M.J. Carter, Anal. Chem., 48, 1, 110 (1976)

14. M. Jaffar, M. Ashraf and M. Tariq, Atomic Spectroscopy, 7, 4, 96 (1986)

15. M. Goto, E. Munaf, and D. Ishii, Fresenius Z. Anal. Chem., 332, 745 (1988)

16. L. Cherian, V.K. Gupta, Fresenius J. Anal. Chem., 336, 400 (1990)

17. A. Kuldvere, Analyst, 115, 559 (1990)

18. K. Tanabe, K. Chiba, H. Haraguchi and K. Fuwa, Anal. Chem., 53, 1450 (1981)

19. L. Jiaxi, Y. Xiaotao, D. Yichen and G. Tiezheng, J. Anal. At. Spectrom., 3, 537 (1988) 
20. E. Temmerman, R. Dumarey and R. Dams, Analytical Letters 18 (A2), 203 (1985)

21. D.C. Wigfield, J.E. Willette, J.E. Mackeen, S.L. Perkins, and J.-P. Farant, J. Anal. Toxicol. 6, 276 (1982)

22. M. Goto, E. Munaf and D. Ishii, Fresenius Z. Anal. Chem., 332, 745 (1988)

23. J.-P. Farant, D. Brissette, L. Moncion, L. Bigras and A. Chartrand, J. Anal. Toxicol., 5, 47 (1981)

24. D.C. Wigfield and R.S. Daniels, J. Anal. Toxicol., 12, 94 (1988)

25. B.V. L'vov, Atomic Absorption Spectrochemical Analysis, Adam Hilger Ltd., London, 1970

26. R.E. Sturgeon, Ph.D. Thesis, "Studies in Electrothermal Atomization in Graphite Furnace Atomic Absorption Spectrometry," Carleton University, Ottawa, Ontario, Canada, 1977, pp. 141-146.

27. J.E. Hawley and J.D. Ingle, Anal. Chem., 47, 4, 719 (1975)

28. $\quad$ L. Magos and A. Cernik, Brit. J. Ind. Med., 26, 144 (1969)

$29 . \quad$ L. Magos, Analyst, 96, 847 (1971)

30. M.R. Greenwood, P. Dahir, T.W. Clarkson, J.-P. Farant, A. Chartrand and A. Khayat, J. Anal. Toxicol., 1, 265 (1977)

31. D.C. Wigfield and S.A. Eatock, J. Anal. Toxicol., 11, 137 (1987)

32. R.S. Daniels and D.C. Wigfield, Sci. Total Environ., 89, 319 (1989)

33. D.C. Wigfield and R.S. Daniels, J. Anal. Toxicol., 13, 191 (1989)

34. D.C. Wigfield, S.M. Croteau and S.L. Perkins, J. Anal. Toxicol., 5, 52 (1981)

35. W.R. Hatch and W.L. Ott, Anal, Chem., 40, 2085 (1968)

36. G. Westöö, Acta. Chem. Scand., 20, 2131 (1966)

37. S.C. Height and M.T. Corcoran, J. Assoc. Off. Anal. Chem., 70, 24 (1987)

38. N. Bloom and W.F. Fitzgerald, Anal. Chim. Acta., 208, 151 (1988)

39. J. Gui-bin, N. Zhe-Ming, W. Shun-rong, and H. Heng-bin, Z. Anal. Chem.,334, 27 (1989) 
40. J. Gui-bin, N. Zhe-ming, W. Shun-rong and H. Heng-bin, J. Anal. At. Spec., 4, 315 (1989)

41. Y. Umezaki and K. Iwamoto, Japan Analyst, 20, 173 (1971)

42. J. Toffaletti and J. Savory, Anal. Chem., 47, 13, 2091 (1975)

43. D.C. Wigfield and S.L. Perkins, J. Anal. Toxicol., 6, 279 (1982)

44. D.C. Wigfield, and S.L. Perkins, Anal. Chim. Acta, 167, 419, (1985)

45. H. Pinstock and F. Umland, Z. Anal. Chem., 240, 320 (1985)

46. R. Ahmed, K. May and M. Stoeppler, Analytische Chemie, 6, 510 (1987)

47. D.R. Christmann and J.D. Ingle, Anal. Chim. Acta, 86, 285 (1976)

48. F. Umland and E. Schumecher, Z. Anal. Chem., 269, 5, 367 (1974)

49. G. Marshall and D. Midgley, Anal. Chem., 53, 1760 (1981)

50. D.L. Rabenstein and M.T. Fairhurst, J. Am. Chem. Soc., 97,8, 2086 (1975)

51. R. Ahmed and M. Stoeppler, Analyst, 111, 1371 (1986)

52. R. Ahmed, K. May and M. Stoeppler, Z. Anal. Chem., 326, 6, 510 (1987)

53. R.S. Daniels and D.C. Wigfield, Sci. Total Environ., 89, 331 (1989)

54. J.E. Cantle, Proc. Analyt. Div. Chem. Soc., 276 (1976)

55. B.V. L'vov, V.G. Nikolaev, E.A. Norman, L.K. Polzik and M. Mojica, Spectrochim. Acta, 41B, 1043 (1986)

56. H.H. Willard, L.L. Merrit, J.A. Dean and F.A. Settle, Instrumental Methods of Analysis, Wadsworth Ltd., Belmont, CA, 1981

57. $\quad$ B.V. L'vov, Spectrochim. Acta, 33b, 154, (1978)

58. A. Walsh, Spectrochimica Acta, 7, 108 (1955)

59. R. Dumarey, E. Temmerman, R. Dams and J. Hoste, Analytica Chimica Acta, 170,337 (1985)

60. Handbook of Chemistry and Physics, 56th Edition, R.C. Weast, Ed., Chemical Rubber Co., Cleveland, Ohio, 1976 p. D-182 
61. R. Dumarey, R. Dams and J. Hoste, Anal. Chem., 57, 2638 (1985)

62. A. Walsh, Spectrochimica Acta, 7, 108 (1955)

63. L. de Galan, Analytica Chimica Acta, 34, 2 (1966)

64. W. Slavin, Anal. Proc., 21, 59 (1984)

65. R.E. Sturgeon, and S.S. Berman, Anal. Chem., 55, 190 (1983)

66. W. Slavin, and G.R. Carnrick, Spectrochimica Acta, 39B, 2/3, 271 (1984)

67. W. Fretch, and D. Baxter, Spectrochimica Acta, 45B (1990)

68. L. de Galen, Spectrochimica Acta, 24B, 629 (1969)

69. B.V. L'vov, Talanta, 23, 109 (1976)

70. R.S. Daniels, D.C. Wigfield, Sci. Tot. Environ., 89, 331 (1989)

71. B.V. L'vov, Spectrochimica Acta, 45B, 7, 633 (1990)

72. B.V. L'vov, Spectrochimica Acta, 33B, 153, (1978)

73. R.E. Sturgeon, C.L. Chakrabarti, I.S. Maines, and P.C. Bertels, Anal. Chem., $47,8,1240$ (1975)

74. R.E. Sturgeon, C.L. Chakrabarti, and P.C. Bertels, Anal. Chem., 47, 8, 125() (1975)

75. N.S. Poluektov and R.A. Vitkun, Zh. Anal. Khim., 18 (1963) 33.

76. K.-H. Friese, M. Roschig, G. Wuenscher, and H. Matschiner, Fresenius J. Anal. Chem., 337, 860 (1990)

77. Public communication with J.P. Weber (Centre de Toxicologie du Quebec, University de Laval, St-Foy, PQ., G1V 4G2), at the $36^{\text {th }}$ Canadian Spectroscopy Conference, CSC 1990, St. Catharines

78. M.C. Ginter and J. T. Vanderslice, Journal of Molecular Spectroscopy, 33, 505 (1970)

79. W. H. Holak, Anal. Chem., 41, 1712 (1969)

80. V.F. Hodge, S.L. Seidel and E.D. Goldberg, Anal. Chem., 51, 1256 (1979)

81. P.N. Vijan, Atomic Spectroscopy., 1, 143 (1980) 
82. D.S. Lee, Anal. Chem., 54, 1182 (1982)

83. J. Alary, J. Vandaele and C. Escrieut, Talanta, 33, 748 (1986)

84. R.E. Sturgeon, S.N. Willie, G.I. Sproule and S.S. Berman, J. Anal. At. Spectrom., 2, 719 (1987)

85. R.S. Daniels, D.C. Wigfield, Sci. Total Environ., 89, 331 (1989)

86. S. Landi, F. Fagoli, C. Locatelli and R. Vecchietti, Analyst, 115, 173 (1990) 


\section{APPENDIX I Glossary of Terms used in this work}

\begin{tabular}{|c|c|c|}
\hline Term & Meaning & Chapter of tirst appetarance \\
\hline $\mathbf{m}$ & mass & 2 \\
\hline $\mathbf{V}$ & volt & 2 \\
\hline$v$ & volume(tubing, absorbance cell, plug) & 2 \\
\hline $\mathbf{L}$ & liter & \\
\hline$\varepsilon$ & atomic extinction coefficient & 4 \\
\hline$\sigma$ & absorbance cell cross-sectional area & 4 \\
\hline$f$ & volume flow rate & 4 \\
\hline$\tau$ & atom residence time & 4 \\
\hline $\mathbf{C}$ & concentration $\left(\right.$ moles $\left.{ }^{-1}{ }^{-1}\right)$ & 4 \\
\hline$\ell$ & length of absorbance cell & 4 \\
\hline $\mathbf{I}_{\mathrm{A}}$ & acquisition increment & 4 \\
\hline $\mathbf{N}_{\mathrm{C}}$ & number of times atoms "counted" & 4 \\
\hline At & relative instantaneous absorbance & 4 \\
\hline A. & absolute instantaneous absorbance & 4 \\
\hline $\mathbf{k}$ & atomic absorption coefficient & 5 \\
\hline$A_{N(r, 0)}, A_{N}$ & fully normalized integrated absorbance & 6 \\
\hline$A_{N(\tau)}$ & integrated absorbance normalized for $\tau$ & 6 \\
\hline$A_{N(0)}$ & instantaneous absorbance, normalized for $\sigma$ & 6 \\
\hline$A, A_{0}$ & instantaneous absorbance & 6 \\
\hline $\mathbf{m}_{\mathrm{o}}$ & characteristic mass & 6 \\
\hline $\mathbf{m}_{\mathrm{oN}(\boldsymbol{\sigma})}$ & instantaneous, or peak-height, characteristic mass & 6 \\
\hline $\mathbf{m}_{\mathrm{ON}(\mathrm{r} \sigma)}$ & integrated, or peak-area, characteristic mass & 6 \\
\hline d & diameter & 7 \\
\hline $\mathbf{s}$ & surface area & 7 \\
\hline $\mathbf{g}$ & geometry factor & 8 \\
\hline$\rho$ & atom sticking probability & 8 \\
\hline $\mathbf{r}$ & tube radius & 8 \\
\hline $\boldsymbol{x}$ & vapor plug length & 8 \\
\hline $\boldsymbol{\mu}$ & viscosity & 8 \\
\hline$\dot{\lambda}$ & $\begin{array}{l}\text { mean free path of } \\
\mathrm{Hg}_{(\omega)}^{\circ} \text { in } \mathrm{N}_{2(\boldsymbol{s})}\end{array}$ & 8 \\
\hline $\mathbf{Z}$ & $\begin{array}{l}\text { collision frequency, } \\
\mathbf{H g}^{\circ}{ }_{(\text {(t) }} \text { with } \mathrm{N}_{2(\boldsymbol{k})}\end{array}$ & 8 \\
\hline$\lambda^{\prime}$ & ambient $\lambda$ & 8 \\
\hline $\mathbf{Z}^{\prime}$ & ambient $\mathbf{Z}$ & 8 \\
\hline$f^{\prime}$ & ambient $f$ & 8 \\
\hline
\end{tabular}


APPENDIX II Calibration curve for mass of mercury in $10 \mu \mathrm{L}$ of mercury saturated air versus temperature

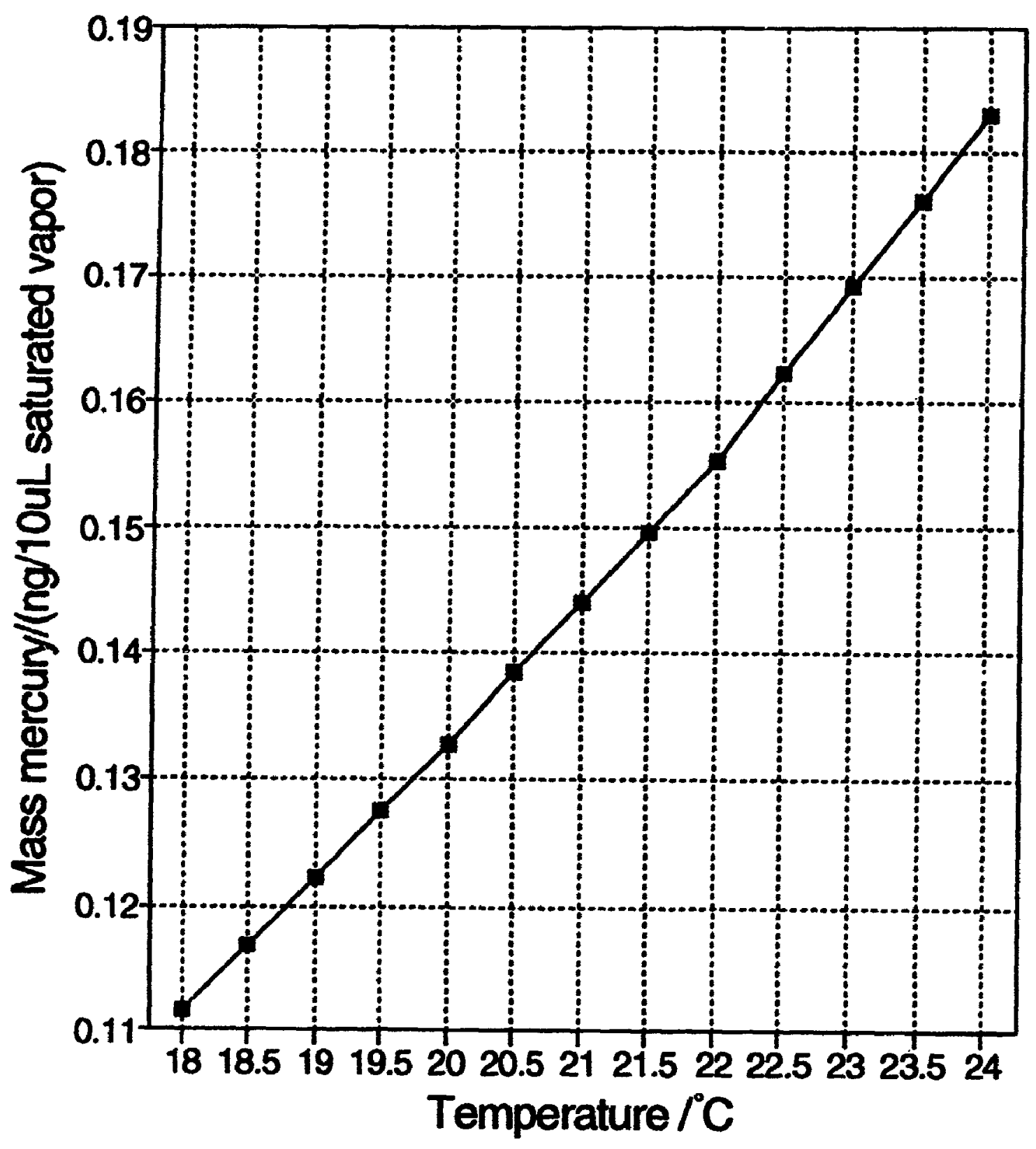


APPENDIX III Diffusional atom residence time in the graphite furnace

If $\mathrm{N}$ is the number of analyte atoms in the furnace at any time, $N_{0}$ is the total number. and $\mathrm{k}$ is the rate constant for loss determined solely by diffusion duc to a concentration gradient, then the number $\mathbf{N}$ at any time $\mathrm{t}$ is given by the following:

$$
\begin{aligned}
\frac{d N}{d t} & =-k N \\
\int_{N_{0}}^{N} \frac{1}{N} d N & =-\int_{0}^{t} k d t \\
\ln \frac{N}{N_{0}} & =-k t \\
N & =N_{0} e^{-k t}
\end{aligned}
$$

It still remains to be shown that the reciprocal of the rate constant $k$ is the mean atom residence time $\tau$. To calculate the mean life-time of an atom in the analysis volume, divide the sum of each individual life-time by $\mathrm{N}_{\mathrm{o}}$. This would be the same as taking the area under a plot of $\mathbf{N}$ versus time and dividing by $\mathbf{N}_{\mathbf{0}}$.

$$
\begin{aligned}
\tau=\frac{\text { area }}{N_{0}} & =\frac{1}{N_{0}} \int_{0}^{\infty} N d t \\
& =\frac{1}{N_{0}} \int_{0}^{-} N_{0} e^{-k} d t \\
& =\frac{1}{k}
\end{aligned}
$$

Clearly, the average atom residence time in the optical analysis volume, $\tau$, is the reciprocal of the rate cons' $n$ nt for diffusional loss. This rate constant can be obtained by taking the slope of a $\ln$ (absorbance) versus time plot for an absorbance transient, from the peak maximum until some time $t$ that gives good linearity. 
APPENDIX IV Solving for the geometry term, g: the fraction of atoms, within the distance $\lambda$ from the tube wall, that strike the wall

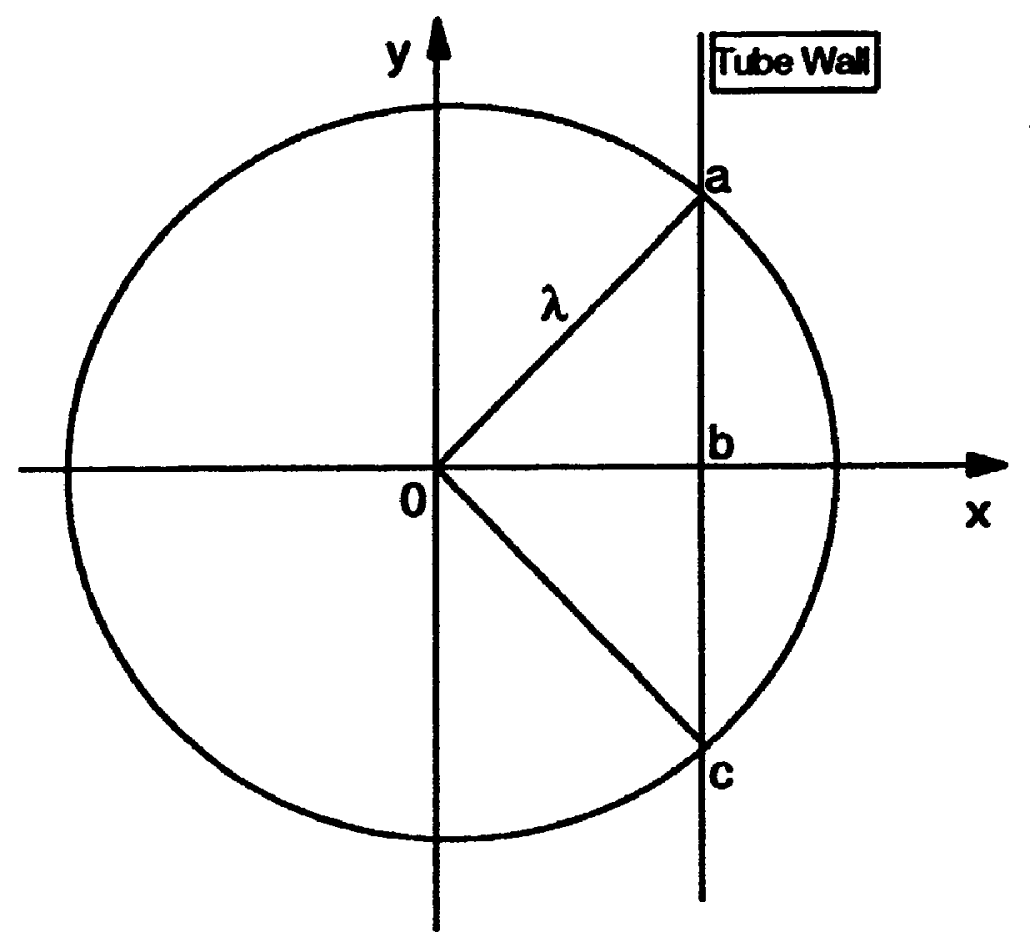

In the above figure, consider $a$ wall at some distance $b, 0 \leq b \leq \lambda$, from an atom at the origin. ${ }^{\dagger}$ On this micro-scale, where $\lambda$ is the mean free distance travelled by a mercury atom before collision with a nitrogen molecule, the tube wall will be considered to be flat and not curved.

The geometry term. g. represents the probability that an atom, at some distance less than or equal to $\lambda$ from a wall, will strike the wall before hitting a nitrogen molecule.

\footnotetext{
'It is more convenient to consider an atom at the origin and the wall at different distances from the origin, than the reverse case.
} 
APPENDIX IV continued

$g$ is the ratio of the average sector-area of a sphere swept out hy revolving the curve $y=\left(\lambda^{2}-x^{2}\right)^{1 / 2}, b \leq x \leq \lambda$, for $0 \leq b \leq \lambda$, about the $x$-axis to the total sphere surlace area $4 \pi \lambda^{2}$.

The general area of a surface, a sector-area of a sphere, swept out by revolving the curve $y=f(x), a \leq x \leq b$, about the $x$-axis is ${ }^{4}$

$$
\int_{0}^{b} 2 \pi y \sqrt{1+\left(y^{\prime}\right)^{2}} d x
$$

therefore, the sector-area of a sphere swept out by revolving the curve $y=\left(\lambda^{2}-x^{2}\right)^{1 / 2}, h \leq x \leq \lambda$, about the $x$-axis, where $\lambda$ is the sphere radius, is

$$
\begin{aligned}
& \int_{b}^{\lambda} 2 \pi \sqrt{\lambda^{2}-x^{2}} \sqrt{1+\frac{x^{2}}{\lambda^{2}-x^{2}}} d x \\
= & \int_{b}^{\lambda} 2 \pi \sqrt{\lambda^{2}-x^{2}} \sqrt{\frac{\lambda^{2}}{\lambda^{2}-x^{2}}} d x \\
= & \int_{b}^{\lambda} 2 \pi \lambda d x \\
= & 2 \pi \lambda(\lambda-b),
\end{aligned}
$$

and the general sector-area $A_{8}$ swept out by revolving the curve $y=\left(\lambda^{2}-x^{2}\right)^{1 / 2}$ about the $x$-axis is

$2 \pi \lambda(\lambda-x), 0 \leq x \leq \lambda$

₹ G. Thomas and I. Finney, Calculus and Analytical Geometry, Addison-Wesley Co., U.S.A., 1988, p. 336 


\section{APPENDIX IV continued}

The average $\dot{A}_{s}$ of the general sector-area $A_{s}$ swept out by revolving the curve $y=\left(\lambda^{2}-x^{2}\right)^{1 / 2}$ about the $x$-axis, for $0 \leq x \leq \lambda$, is

$$
\begin{aligned}
\bar{A}_{s} & =\frac{1}{\lambda} \int_{0}^{\lambda} A_{s} d x \\
& =\frac{1}{\lambda} \int_{0}^{\lambda} 2 \pi \lambda(\lambda-x) d x \\
& =2 \pi\left[\int_{0}^{\lambda} \lambda d x-\int_{0}^{\lambda} x d x\right] \\
& =2 \pi\left[\lambda^{2}-\frac{\lambda^{2}}{2}\right] \\
& =\pi \lambda^{2} .
\end{aligned}
$$

Therefore, $g$, the ratio of $\bar{A}_{s}$ to the total sphere surface area $4 \pi \lambda^{2}$, is

$$
\begin{aligned}
g & =\frac{\bar{A}_{s}}{4 \pi \lambda^{2}} \\
& =\frac{1}{4} .
\end{aligned}
$$



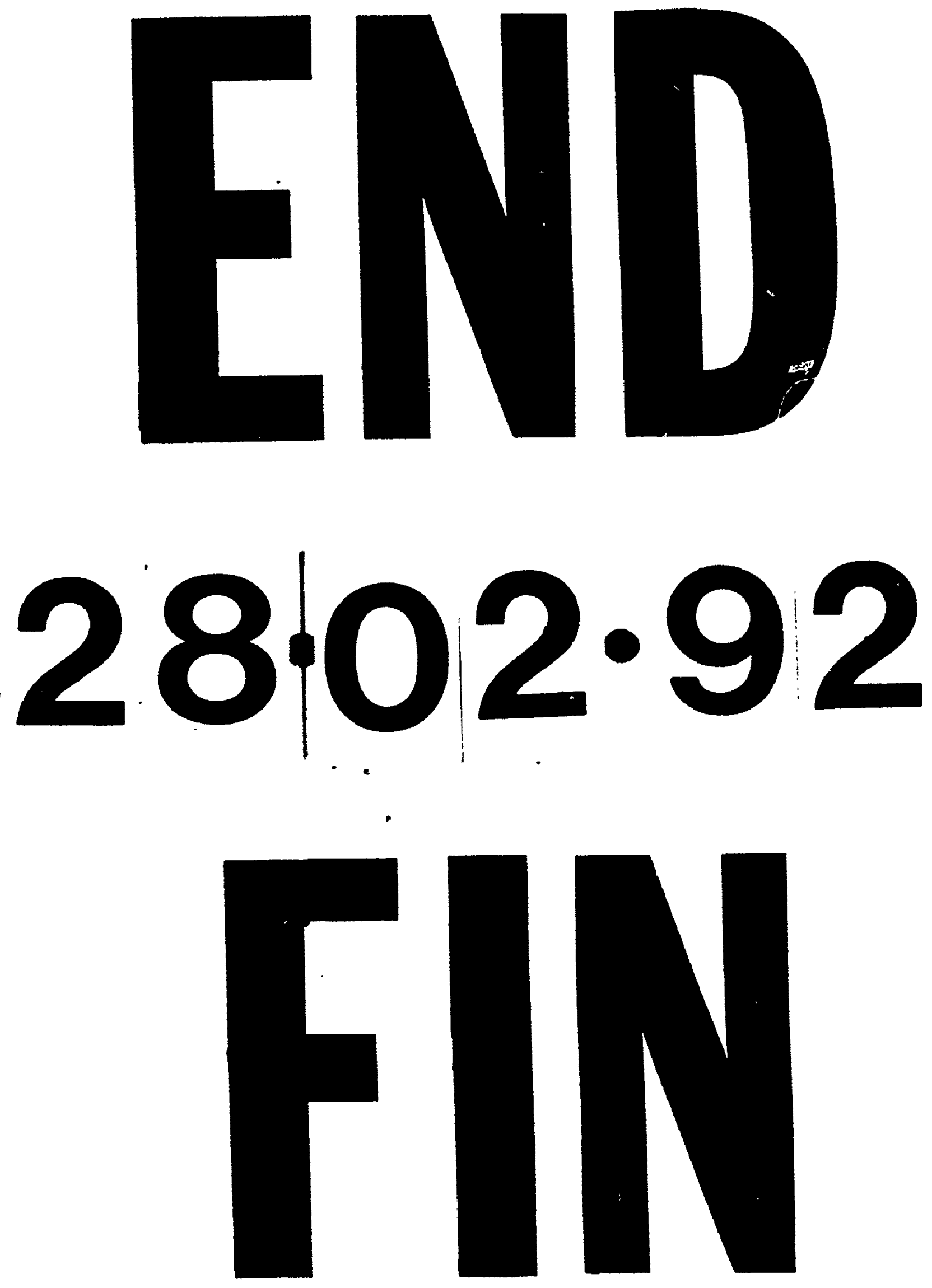